UNIVERSIDADE DE SÃO PAULO

ESCOLA DE ENFERMAGEM

JANAINA SOARES

ATITUDES E CONHECIMENTOS DE ENFERMEIROS

FRENTE AO ÁLCOOL, ALCOOLISMO E ALCOOLISTA:

ESTUDO COMPARATIVO ENTRE DOIS GRUPOS

SÃO PAULO

2010 


\title{
ATITUDES E CONHECIMENTOS DE ENFERMEIROS FRENTE AO ÁLCOOL, ALCOOLISMO E ALCOOLISTA: ESTUDO COMPARATIVO ENTRE DOIS GRUPOS
}

\author{
Dissertação inserida na linha de \\ pesquisa - Uso e abuso de drogas e \\ álcool apresentado ao Departamento \\ de enfermagem materno-infantil e \\ psiquiátrica da Escola de Enfermagem \\ da Universidade de São Paulo, para a \\ obtenção do título de Mestre em \\ Cuidado em Saúde. \\ Orientador: Prof. Dr. Divane de Vargas
}

\section{SÃO PAULO}


AUTORIZO A REPRODUÇÃO E DIVULGAÇÃO TOTAL OU PARCIAL DESTE TRABALHO, POR QUALQUER MEIO CONVENCIONAL OU ELETRÔNICO, PARA FINS DE ESTUDO E PESQUISA, DESDE QUE CITADA A FONTE.

Assinatura:

Data:

Soares, Janaina

Atitudes e conhecimentos de enfermeiros frente ao álcool, alcoolismo e alcoolista: Estudo comparativo entre dois grupos. São Paulo, 2010.

106 p. : il. ; $30 \mathrm{~cm}$

Dissertação de Mestrado apresentada à Escola de Enfermagem da Universidade de São Paulo - EEUSP - Área de concentração: Cuidado em Saúde.

Orientador: Prof. Dr. Divane de Vargas

1. Atitudes. 2. Conhecimentos 3. Enfermeiros 4. Alcoolismo 


\section{FOLHA DE APROVAÇÃO}

Nome: JANAINA SOARES

Título: ATITUDES E CONHECIMENTOS DE ENFERMEIROS FRENTE AO ÁLCOOL, ALCOOLISMO E ALCOOLISTA: ESTUDO COMPARATIVO ENTRE DOIS GRUPOS

Dissertação apresentada à Escola de Enfermagem da Universidade de São Paulo para a obtenção de título de Mestre.

Área de concentração: Cuidado em Saúde

Aprovada em:

\section{Banca Examinadora}

Prof. Dr. Divane de Vargas

Escola de Enfermagem da Universidade de São Paulo.

Julgamento:

Assinatura:

Profa. Dr ${ }^{a}$ Prof ${ }^{a}$ Margarita Antonia Villar Luís

Escola de Enfermagem de Ribeirão Preto da Universidade de São Paulo.

Julgamento:

Assinatura:

Profa. Dr ${ }^{\mathrm{a}}$ Prof $^{\mathrm{a}}$ Márcia Aparecida Ferreira de Oliveira

Escola de Enfermagem da Universidade de São Paulo.

Julgamento:

Assinatura: 


\section{Dedico este trabalho}

A minha família pelo apoio e consideração em todos os momentos dessa trajetória a permitirem que alcançasse mais um objetivo em minha vida. 


\section{Agradecimentos}

Ao Prof. Dr. Divane de Vargas meu orientador por ter mais que tudo acreditado em meu potencial e ter me feito sentirme segura e nos momentos mais difíceis estar ao meu lado, além de me sentir privilegiada por ser sua primeira filha, meu muito obrigada.

A Profa. Dra. Márcia Aparecida Ferreira de Oliveira por me apresentar a Escola de Enfermagem da USP, assim como ao Grupo de Pesquisas em Álcool e Outras Drogas e estar ao meu lado desde o início deste trabalho até na qualificação, sempre contribuindo com todo seu cuidado até o final, meus sinceros agradecimentos.

Aos meus colegas do GEAD pelas significativas contribuições desde a preocupação com o andamento do meu trabalho até a troca, apoio e acolfimento durante essa trajetória.

Ao corpo docente da Saúde Mental da EEUSP pelas contribuições de ensino no PAE e durante a Monitoria, muito obrigada.

Aos Funcionários do Departamento de Enfermagem Materno-infantil e psiquiátrica pelas contribuições diretas e indiretamente neste trabalho, pelo acolhimento e amizade, meus sinceros agradecimentos.

Ao IME pelas contribuições no cálculo dos dados deste estudo, muito obrigada.

$\mathcal{A}$ todos meus amigos, meu muito obrigada! 
Soares, J. Atitudes e conhecimentos de enfermeiros frente ao álcool, alcoolismo e alcoolista: Estudo comparativo entre dois grupos. 2010. 106 f. Dissertação (Mestrado) - Escola de Enfermagem, Universidade de São Paulo, São Paulo, 2010.

\section{RESUMO}

Introdução: O consumo mundial do álcool e de outras substâncias psicoativas vem crescendo significativamente nas últimas décadas, fenômeno que tem contribuído para o aumento da carga de doenças em todo o mundo. No Brasil, os levantamentos realizados sobre o uso de álcool e drogas vem apontando elevadas taxas de dependentes dessas substâncias, fato que tem contribuído para ampliar o contato dos profissionais da saúde, dentre eles, os enfermeiros, com situações que envolvem o uso e o abuso de substâncias psicoativas, independente do local onde atuem. O fato justifica a importância da realização de estudos para investigar as atitudes e os conhecimentos desses profissionais frente ao álcool, o alcoolismo e ao alcoolista. Objetivo: verificar e comparar as atitudes e os conhecimentos de dois grupos de enfermeiros frente ao álcool, ao alcoolismo e ao alcoolista. Método: Tratou-se de um estudo exploratório de abordagem quase-experimental, realizado com uma amostra de 280 enfermeiros, destes, 140 foram submetidos a um curso de capacitação na área de álcool e outras drogas e constituíram o Grupo experimental. $\mathrm{Na}$ coleta de dados, foram aplicados um questionário sociodemográfico, um questionário de conhecimento e a Escala de Atitudes frente ao álcool, alcoolismo e alcoolista - EAFAAA. Para verificar e comparar as atitudes e os conhecimentos entre os dois grupos, procederam-se análises estatísticas descritivas e para analisar a associação entre as variáveis do estudo e as atitudes e conhecimentos, procedeu-se uma análise por Regressão logística. Todas as analises foram feitas por meio do pacote SPSS versão 17.0. Resultados: A amostra final contou com 185 participantes, 101 enfermeiros do grupo controle e 84 do grupo experimental. Os participantes de ambos os grupos tenderam a apresentar atitudes mais positivas, observando-se uma discreta predominância de atitudes positivas no GE. Com relação aos conhecimentos, não foram observadas diferenças significativas entre os dois grupos. Os maiores preditores para atitudes positivas encontrados neste estudo foram "possuir preparo para atuar com dependentes químicos" ( $z=2,895)$, "ter recebido maior carga-horária durante a graduação sobre a temática álcool e outras drogas" $(z=2,202)$ e "possuir pós-graduação $(z=1,806)$. Conclusão: O nível de conhecimento influencia diretamente nas atitudes de enfermeiros frente ao álcool, alcoolismo e ao alcoolista, a relação entre as atitudes e conhecimentos é proporcional, ou seja, quanto maior o conhecimento maior a tendência de apresentar atitudes mais positivas. Enfermeiros que receberam maior carga horária de conteúdos relacionados ao tema durante a formação profissional, apresentaram atitudes mais positivas e melhor conhecimento frente ao tema do estudo do que aqueles que não receberam nenhuma formação ou a receberam-na em menor carga horária. 
Soares, J. Attitudes and knowledge of nurses towards alcohol, alcoholism and alcoholics: A comparative study between two groups. 2010. 106 f. Dissertação (Mestrado) - Escola de Enfermagem, Universidade de São Paulo, São Paulo, 2010.

\begin{abstract}
Introduction: Global consumption of alcohol and other psychoactive substances has significantly increased in recent decades. This phenomenon has contributed to increase the disease burden around the world. In Brazil, surveys on alcohol and drugs use have appointed high rates of dependence on these substances, a fact that has contributed to increase health professionals' contact, including nurses, with situations that involve psychoactive substance use and abuse, independently of their place of work. This fact justifies the importance of research on these professionals' attitudes and knowledge regarding alcohol, alcoholism and alcoholics. Aim: to verify and compare attitudes and knowledge regarding alcohol, alcoholism and alcoholics in two groups of nurses. Method: An exploratory study with a quasi-experimental approach was carried out in a sample of 280 nurses, 140 of whom were submitted to a training course in alcohol and other drugs, who constituted the Trial group (TG). For data collection, a socio-demographic questionnaire was applied, as well as a knowledge questionnaire and the Scale of Attitudes towards alcohol, alcoholism and alcoholics - EAFAAA. To verify and compare attitudes and knowledge between both groups, descriptive statistical analyses were carried out. To check for associations between the study variables and the attitudes and knowledge, logistic regression analysis was applied, using SPSS version 17.0. Results: The final sample included 185 participants, 101 nurses in the control group and 84 in the trial group. Participants in both groups tended to present more positive attitudes, showing a slight predominance of positive attitudes in the TG. Regarding knowledge, no significant differences were observed between the two groups. The main predictors of positive attitudes found in this study were "being prepared to work with chemical addicts" ( $z=2.895)$, "having received more hours on alcohol and other drugs in the undergraduate program" ( $z=2.202)$ and "having a graduate degree $(z=1.806)$. Conclusion: The knowledge level directly influences the nurses' attitudes towards alcohol, alcoholism and alcoholics, the relation between attitudes and knowledge is proportional, i.e. the greater the knowledge, the stronger the trend to present more positive attitudes. Nurses who received more hours of contents on the theme during their professional education displayed more positive attitudes and better knowledge on alcohol, alcoholism and alcoholics than those who did not receive any or less hours of education.
\end{abstract}




\section{LISTA DE TABELAS}

Tabela 1 - Distribuição das variáveis incluídas no estudo $(n=185)$.....

Tabela 2 - Distribuição dos acertos nas questões de conhecimento para os dois grupos ....60

Tabela 3 - Distribuição dos acertos segundo a Questão 1 referente ao uso nocivo de álcool do questionário de conhecimento.

Tabela 4 - Distribuição dos acertos segundo a Questão 2 referente a "Sindrome de abstinência do álcool, Alucinose alcoólica e Delirium Tremens ” do questionário de conhecimento.

Tabela 5 - Distribuição dos acertos segundo a Questão 3 referente "intoxicação patológica, aguda e crônica” do questionário de conhecimento.

Tabela 6 - Distribuição dos acertos segundo a Questão 4 referente a "Tolerância, Intoxicação, Dependência e Uso nocivo ou prejudicial" do questionário de conhecimento.

Tabela 7 - Distribuição dos acertos segundo a Questão 5 de verdadeiro ou falso do questionário de conhecimento.

Tabela 8 - Distribuição dos escores de atitude e pontuação de conhecimento para o grupo controle

Tabela 9 - Distribuição dos escores de atitude e pontuação de conhecimento para o grupo experimental

Tabela 10 - Distribuição dos escores de atitude e pontuação de conhecimento segundo a variável "Sexo" para os dois grupos

Tabela 11 - Distribuição dos escores de atitude e pontuação de conhecimento segundo a variável "Escola de Formação" para os dois grupos

Tabela 12 - Distribuição dos escores de atitude e pontuação de conhecimento segundo a variável "Possui Experiência Profissional com Alcoolistas" para os dois grupos

Tabela 13 - Distribuição dos escores de atitude e pontuação de conhecimento segundo a variável "Possui Pós Graduação" para os dois grupos

Tabela 14 - Distribuição dos escores de atitude e pontuação de conhecimento segundo a variável "Possui Preparo para Lidar com Dependentes" para os dois grupos.....

Tabela 15 - Distribuição dos escores de atitude e pontuação de conhecimento segundo a variável "Idade" para os dois grupos

Tabela 16 - Regressão logística, análise de relação entre as atitudes frente o álcool, alcoolismo e alcoolista com as variáveis significantes no estudo. 


\section{LISTA DE ILUSTRAÇÕES}

Quadro 1 - Fatores e itens da Escala de Atitudes Frente ao Álcool, ao Alcoolismo e ao Alcoolista - EAFAAA......

Gráfico 1 - Distribuição das publicações $(n=38)$ sobre as atitudes de enfermeiros frente ao álcool, alcoolismo e alcoolista entre 1950 a 2009.

Gráfico 2 - Distribuição da variável "Carga horária do curso para atuar com dependentes químicos" nos dois grupos. .59 


\section{SUMÁRIO}

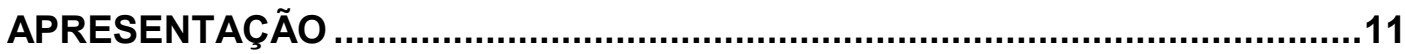

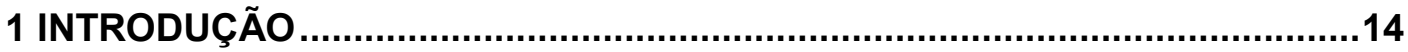

1.1 A problemática do álcool e do alcoolismo ................................................14

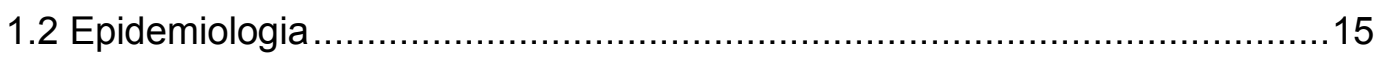

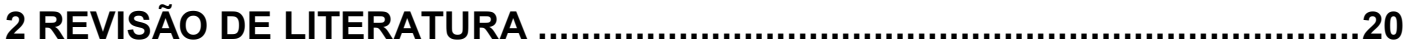

2.1 Considerações conceituais sobre atitudes..............................................20

2.2 Atitudes de enfermeiros frente ao álcool, alcoolismo e alcoolista ...............21

2.2 Estratégias de formação em álcool e outras drogas e suas repercussões nas atitudes e conhecimentos de enfermeiros ..........................................31

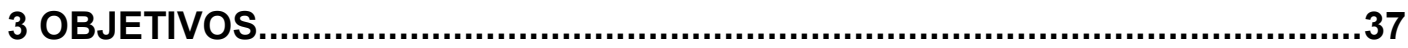

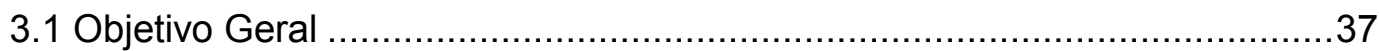

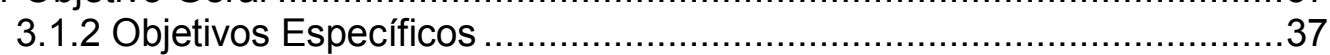

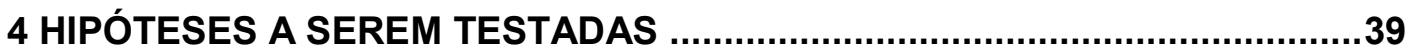

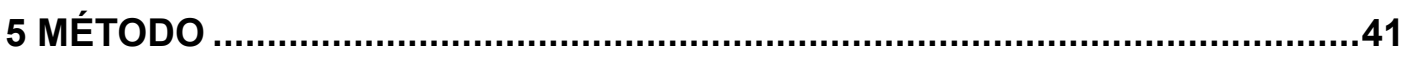

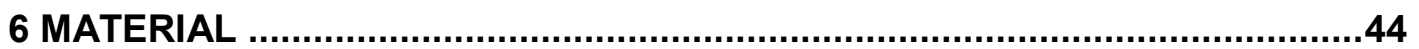

6.1 O curso SUPERA (Sistema para detecção do uso abusivo e dependência de substâncias psicoativas: Encaminhamento, intervenção breve, reinserção social e acompanhamento) ..........................................48

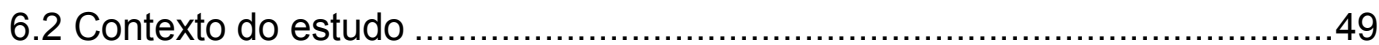

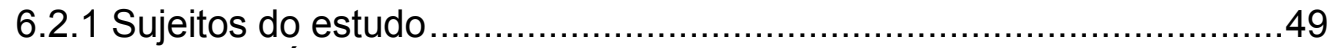

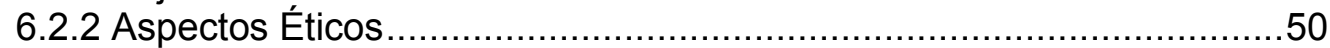

6.2.3 Coleta dos dados ...................................................................... 51

6.3 Procedimentos para análise dos dados .........................................52

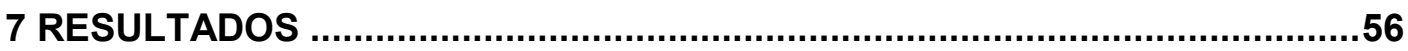

7.1 Caracterização geral da população estudada ..........................................56

7.2 Conhecimento frente ao álcool e ao alcoolismo..........................................60

7.3 Atitudes frente ao álcool, alcoolismo e alcoolista ......................................66

7.4 Relação entre variáveis sociodemográficas, conhecimento e atitudes.........68

7.5 Associação entre as variáveis sociodemográficas e as atitudes de

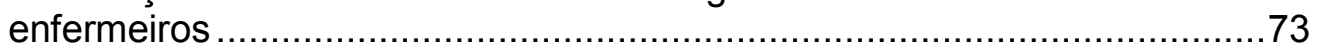

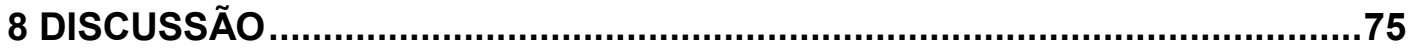

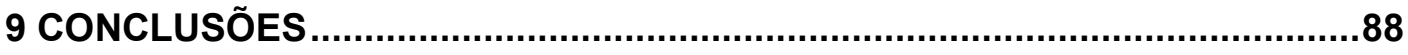

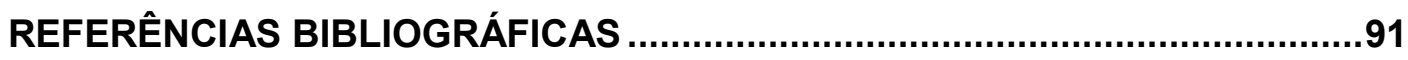

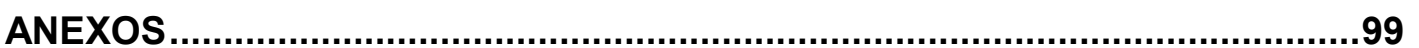


Apresentação 


\section{APRESENTAÇÃO}

Meu interesse sobre o tema álcool e outras drogas ocorreu durante o final da graduação, no estágio no CAPS-AD, onde percebi uma certa discriminação ao usuário de substâncias psicoativas, quando este aparecia alcoolizado ao serviço de tratamento, tanto pelos colegas em tratamento como pelos profissionais do CAPS-AD. Além disso em sala de aula, muitas vezes, os colegas graduandos relatavam a rejeição dos pacientes alcoolistas. Diante disso, senti vontade de conhecer como era para os profissionais enfermeiros cuidar de pacientes alcoolistas.

Para encontrar respostas a esta inquietude, fui cursar o mestrado na área de álcool e outras drogas, realizando um estágio na cidade de São Paulo, para conhecer os Centros de Atenção Psicossociais em álcool e outras drogas - CAPS AD da cidade e participar do Grupo de Estudos em álcool e outras drogas da Escola de Enfermagem da Universidade de São Paulo - GEAD EEUSP para fazer contato.

Após isso, fui aprovada na seleção do curso de Mestrado e, ao ingressar na pós-graduação, apresentei um projeto de cunho qualitativo com o intuito de investigar a visão do profissional enfermeiro no cuidado ao dependente de drogas no CAPS $A D$, porém em razão do orientador trabalhar com a linha de pesquisa quantitativa sobre o tema atitudes de enfermeiros frente ao álcool, ao alcoolismo e ao alcoolista, fui orientada a estudar de forma sistematizada as atitudes de enfermeiros frente a pacientes alcoolistas para a construção do projeto de mestrado nessa temática.

Mas ao realizar o levantamento dos estudos, verifiquei que já havia outros a respeito das atitudes de enfermeiros e que, entre esses profissionais, predominavam atitudes negativas frente ao álcool, alcoolismo e alcoolista. Os pesquisadores concluiram que a capacitação desses profissionais poderia favorecer a mudança de atitudes. 
Pensando na perspectiva da influência da capacitação nas atitudes dos enfermeiros frente ao álcool, alcoolismo e alcoolista, preocupei-me em realizar a pesquisa de mestrado em função da importância da temática atitudes frente ao álcool, alcoolismo e alcoolista, pois existem poucos estudos relacionados à capacitação em atenção a usuários de álcool e outras drogas de enfermeiros. 


\section{Introdução}




\section{INTRODUÇÃO}

\subsection{A PROBLEMÁTICA DO ÁLCOOL E DO ALCOOLISMO}

Desde os tempos remotos, bebidas alcoólicas vêm sendo usadas em diversas culturas, cada uma com um significado ou credo diferente, o que confirma sua importância para o homem (Vargas, 2005). Assim, entre os pesquisadores, é consenso que, do mesmo modo que outras substâncias psicoativas, o uso do álcool é tão antigo quanto a existência das civilizações e mesmo que os textos históricos façam referência a seu uso habitual, encontramos citações de uso problemático entre os egípcios, cerca de cinco mil anos antes de Cristo, por exemplo, verificamos, nas inscrições em seus templos, cenas que demonstram embriaguez, Hipócrates (460 a.C) já teria feito descrições da loucura provocada pelo álcool e dos problemas de seu uso pelos epilépticos no Gênesis; na Bíblia é descrito o episódio em que Noé, alegre pela salvação dos seres vivos do dilúvio, embebeda-se com vinho (Silveira, Moreira, 2006).

Com o aumento da disponibilidade, após o advento da destilação, o consumo do álcool passou a ser mais frequente e abusivo, em contraste com a situação anterior, em que o uso era predominantemente associado a rituais religiosos ou festivos. Portanto, o aumento dos problemas em razão desse beber excessivo, levou a ser considerado como categoria nosológica, sendo, o termo alcoolismo usado pela primeira vez, em 1849, pelo médico sueco Magnus Huss, ao se referir apenas às consequências somáticas e efeitos nocivos que a ingestão crônica proporcionava. Apesar do alcoolismo ser considerado uma doença, o "beber excessivamente" continuou a ser percebido como um comportamento pecador e transgressor, conceito esse que foi incorporado às regras morais das diversas culturas na época (Vargas, 2005). 
Janaina Soares

No século $X X$, nos Estados Unidos da América (EUA), o termo alcoolismo, como doença foi utilizado pelo cientista Jellinek, para indicar que o consumo de álcool pode levar a vários danos, além dos físicos, incluindo os psicológicos ou sociais, mas sua imprecisão levou a Organização Mundial de Saúde (OMS), em 1979, a estreitar sua amplitude, para Síndrome de dependência do álcool, caracterizada como um conjunto de fenômenos comportamentais, cognitivos e fisiológicos que podem se desenvolver, após o uso repetido de bebidas alcoólicas, para possibilitar um melhor diagnóstico, antes de qualquer abordagem (Brasil, 2006). Atualmente, o alcoolismo é compreendido, como um padrão de uso crônico e continuado de álcool ou ingestão periódica que pode ser caracterizado pelo descontrole sobre a ingestão (Brasil, 2006).

Para Vargas e Luís (2008a), apesar de sua ampla aceitação social, o consumo de álcool em excesso é visto como um dos problemas médicosociais mais graves da atualidade, por gerar altos custos para a sociedade, como pode ser constatado pelos relatos científicos de prejuízos físicos, psicológicos, elevado número de acidentes de trânsito, invalidez, absenteísmo e outros distúrbios sociais que lhe estão atribuídos (Noto et al., 2002; Meloni, Laranjeira, 2004). Entretanto é primordial compreender que o uso de drogas, como o álcool não deve ser examinado isoladamente, já que todas as tentativas de explicações genéricas, baseadas em premissas fisiológicas e psicológicas tenderam a ser rotuladas como estigmatizantes (Velho, 1999).

\subsection{EPIDEMIOLOGIA}

De acordo com o Relatório Sobre a Saúde no Mundo, das 20 doenças na faixa etária de 15 a 44 anos que acarretam anos vividos com alguma incapacidade, os transtornos relacionados ao abuso de álcool assumem o segundo lugar com 5,5\% (Brasil, 2008). 
Em uma análise do consumo de bebidas alcoólicas em quantidades potencialmente prejudiciais, o Departamento de Saúde e de Serviços Humanos dos Estados Unidos da América, em pesquisa nacional sobre o uso de drogas realizadas pela Substance Abuse and Mental Health Services Adminstration (SAMHSA) (Nida, 2009), indicou que, em 2008, 51,6\% dos norte-americanos acima de 12 anos tinham usado álcool, pelo menos, uma vez nos últimos 30 dias, antes de serem pesquisados; $23,3 \%$ tinham bebido cinco ou mais doses em um período de 2 horas e 23,3\%, beberam pesadamente.

No Brasil, o I Levantamento Domiciliar sobre o uso de drogas psicotrópicas que envolveu as 107 maiores cidades do País no ano de 2001(Carlini et al., 2001), indicou que o uso de álcool na vida atingiu 68,7\%, e $11,2 \%$ da população preencheu critérios para dependência dessa substância. Em 2005, o II Levantamento Domiciliar envolvendo as 108 maiores cidades do País (Galduróz et al., 2006), apontou que 74,6\% dos entrevistados já fizeram uso de bebida alcoólica e que $12,3 \%$ da população entre 12 e 65 anos preencheram critérios para dependência de álcool. Um comparativo entre esses dados permite evidenciar um aumento significativo da problemática no País.

Segundo a Organização Internacional do Trabalho (OIT), entre 10\% a $12 \%$ da população economicamente produtiva, acima dos 14 anos, apresentam problemas de uso abusivo ou dependência do álcool, ainda segundo esse levantamento, o trabalhador que faz uso de drogas ou é dependente, tem 3,6 vezes mais chances de causar acidentes de trabalho, 2,5 vezes mais chances de faltar sem justificativa 8 ou mais dias de trabalho, utiliza três vezes mais dos benefícios médicos, tem sua capacidade produtiva reduzida a $67 \%$, é punido disciplinarmente sete vezes mais, e é cinco vezes mais "queixoso" que os trabalhadores não usuários (Brasil, 2008).

No que se refere à questão econômica, dados especulativos estimulam que o Brasil gaste, anualmente, $7,3 \%$ do Produto Interno Bruto (PIB) com consequências de problemas relacionados ao álcool, desde o 
tratamento das condições médicas até a perda da produtividade decorrente de seu uso (Gallassi, 2008).

No que se refere à análise de exames toxicológicos realizados no Instituto Médico Legal de São Paulo, durante 1994, apontou que 52\% das vítimas de homicídio, $64 \%$ das vítimas de afogamentos fatais e 51\% das vítimas fatais de acidentes de trânsito apresentaram álcool na corrente sanguínea em níveis mais elevados do que o permitido por lei, na época da pesquisa (quando a taxa mínima de álcool no sangue prevista pelo Código Brasileiro era de 0,6 gramas por litro) (Gazal-Carvalho et al., 2002).

Os dados são preocupantes, tendo em vista que, o uso e abuso de álcool é um dos fatores que contribuem para riscos e agravos à saúde da população, e está associado a mais de 60 condições listadas no Código Internacional de Doenças (CID). Além de estar relacionado a mortes e internações por lesões intencionais e não intencionais; decorrentes da violência doméstica e contra terceiros, acidentes de trânsito, afogamentos, queimaduras, suicídios e homicídios, dentre outros (Brasil, 2004, 2006).

Considerando a associação entre o uso de álcool e problemas de saúde, é possível presumir que cada vez mais os profissionais de saúde estão sujeitos a ter contato com pessoas com problemas relacionados ao álcool (Vargas, Labate, 2005). O que é consistente com resultados de pesquisas que apontam que, atualmente, alcoolistas ocupam números significativos de leitos nas enfermarias das clinicas médica e cirúrgica para tratamento de doenças físicas (Noto et al., 2002), bem como estão presentes em serviços de atenção primária à saúde (Aalto et al., 1999; Magnabosco, 2007; Vargas, Araújo, 2009), o que tem levado os profissionais de saúde, dentre eles, o enfermeiro a prestar assistência a pacientes que abusam do álcool com frequência, aumentando a cada dia o contato desse profissional com essa clientela (Lucca et al., 2006).

De acordo com Spricigo e Alencastre (2004), o enfermeiro é o profissional que mantém o maior contato com os usuários dos serviços de saúde e tem grande potencial para reconhecer os problemas relacionados ao uso de drogas e desenvolver ações assistenciais, pois é um profissional 
que pode desenvolver atividades de prevenção e atuar nos fatores de risco para o uso/abuso de drogas, além de promover a integração da família e dos demais segmentos sociais. Pode, ainda, atuar na saúde fortalecendo os fatores protetores, com vistas à melhoria da autoestima e desenvolvendo estratégias para a manutenção da saúde (Lopes, Pessanha, 2008).

Apesar do enfermeiro ser considerado um profissional de reconhecida importância na atuação frente aos problemas relacionados ao uso do álcool e alcoolismo, levando em conta que estudos (Vargas, 2005; Lucca et al., 2006) vêm evidenciando um aumento significativo dessa clientela nos Serviços de Saúde. Esses profissionais demonstram uma visão moralista estereotipada desses pacientes (Howard, Chung, 2000; Chung et al., 2003), o que tem sido atribuído à falta de preparo e habilidades na atenção ao tratamento de usuários de álcool e outras drogas, sugerindo que essas atitudes negativas do enfermeiro frente ao alcoolista podem estar diretamente relacionadas à falta de preparo/conhecimento da temática (Lock, 2002; Vargas, 2010a).

Assim, uma vez que o aumento do conhecimento e das habilidades podem influenciar nessa mudança de atitudes e, consequentemente, favorecer a melhora do desempenho do profissional na atuação ao cuidado em álcool e outras drogas (Vargas, Labate, 2006; Vargas, 2010a), torna-se importante a realização de estudos para melhor conhecer a questão. 
Revisão da Literatura 


\section{REVISÃO DE LITERATURA}

\subsection{CONSIDERAÇÕES CONCEITUAIS SOBRE ATITUDES}

Concepções clássicas de atitude surgiram nos livros de Psicologia na década de 1970 (Fishbein, Ajzen, 1975; Whedall, 1976; Rodrigues, 1978). Krech e Crutchfield (1969) ao conceituarem atitude, afirmam que as ações sociais do indivíduo refletem suas atitudes, que são sistemas duradouros de avaliações positivas e negativas, sentimentos emocionais e tendências de ação, favoráveis e desfavoráveis, com relação a objetos sociais.

Portanto, à medida que o indivíduo se desenvolve, suas cognições, sentimentos e tendências de ação diante de vários objetos de seu universo tornam-se organizados em sistemas duradouros denominados atitudes.

É preciso ressaltar que existem duas categorias a serem visualizadas nas definições de atitudes: definições multidimensionais e unidimensionais. Nas concepções multidimensionais, as definições de atitudes integram três componentes, conforme propõe Triadis (1971): o cognitivo, o afetivo e o comportamental.

O componente cognitivo, aspecto intelectual das atitudes, também é denominado de componente perceptual, componente informativo ou componente estereotípico, consiste no que seu portador vê, sabe ou raciocina sobre o objeto da atitude (Harrison, 1975). O componente afetivo é denominado de componente emocional ou sentimentos, relaciona-se a sentimentos de inclusão ou aversão da pessoa em relação a um objeto de atitude. Neste caso, não se refere ao que a pessoa pensa sobre o objeto, mas o que sente sobre ele. É considerado o componente mais característico da atitude. $O$ julgamento de gostar $x$ não gostar, aprovar $x$ desaprovar; atração $x$ repulsa, é muito influenciado pelos valores de uma pessoa e suas concepções de como deve ou não reagir (Whedall, 1976). 
O componente comportamental ou comportamento conativo que se refere à ação, a prontidão para reagir frente ao estímulo atitudinal revelam uma tendência do indivíduo em um movimento ou em uma ação na direção do objeto de atitude. Esse comportamento pode ser verbal e não verbal (Whedall, 1976).

Dentre os contestadores da concepção multidimensional, assumindo a posição unidimensional das atitudes, destacam-se Fishbein e Ajzen (1975). Para esses pesquisadores, o componente afetivo definido como sentimento pró ou contra determinado objeto, é o único característico das atitudes, cujas crenças e comportamentos associados a uma atitude, não são partes integrantes da mesma. São elementos pelos quais se pode medir a atitude (Fishbein, Ajzen, 1975).

Cook e Selltiz (1964) referem que, de acordo com literatura, as crenças e os comportamentos de pessoas ou grupos seriam os indicadores pelos quais as atitudes poderiam ser mensuradas. Entretanto, para a maioria dos estudiosos do assunto, uma atitude é uma predisposição para responder a um objeto e não uma conduta afetiva em relação ao mesmo. A atitude mantém-se de forma persistente, o que não significa que seja imutável. Desta forma, ainda que passível de modificação, a alteração das atitudes requer uma forte pressão (Vargas, 2005).

\subsection{ATITUDES DE ENFERMEIROS FRENTE AO ÁLCOOL, ALCOOLISMO E ALCOOLISTA}

Conforme Vargas (2005), revisão da literatura internacional demonstra que estudos sobre as atitudes de enfermeiros frente ao álcool, alcoolismo e alcoolista têm sido realizados sobretudo em países de língua inglesa.

Nos países norte-americanos, em especial, os Estados Unidos da América e alguns da Europa, os estudos de (Blane, Hill, 1964; Jonson, 1965; Heinemann, Rhodes 1967; Waring, 1975; Wallston, Wallston, De Velli, 1976; Cornish, Miller, 1976; Rosembaum, 1977; Gross, Lismam, 1979; Biener, 
Janaina Soares

1983; Reisman, Shrader, 1984; Potaminos et al., 1985; Bartek, Lindeman, Newton, 1988) vêm em sua maioria, objetivando identificar atitudes de enfermeiros nos diversos cenários de atuação desse profissional, dentre eles, hospitais gerais (Wallston, Wallston, De Velli, 1976; Biener, 1983, Potaminos et al., 1985; Bartek, Lindeman, Newton, 1988), atenção primária (Lock et al.,2002), clínicas especializadas (Heinemann, Rhodes, 1967; Gross, Lismam, 1979), ambulatórios, departamentos de emergências (Chung et al., 2003) dentre outros, cujos dados, geralmente, são coletados pela aplicação de escalas, questionários e estudos de caso que permitem examinar como são mostradas as atitudes desses profissionais.

Na década de 1960, nos Estados Unidos da América, foram surgindo os primeiros estudos sobre as atitudes de enfermeiros frente à problemática do álcool. As evidências desses estudos foram que os enfermeiros acreditavam que o tratamento do alcoolista era desesperançoso (Blane, Hill, 1964), que os enfermeiros que tinham contato direto com usuários de álcool tinham sentimentos ambivalentes ou negativos sobre o cuidar dessa clientela (Jonson, 1965), e os enfermeiros de maior nível educacional e menor faixa etária apresentavam atitudes mais positivas frente ao álcool e ao alcoolismo (Heinemann, Rhodes, 1967).

$\mathrm{Na}$ década de 1970, surgem estudos que se ocuparam de avaliar o impacto de treinamentos sobre as atitudes de enfermeiros (Waring, 1975). Esses estudos evidenciaram, que o estereótipo atribuído ao alcoolismo e ao alcoolista influencia diretamente nas atitudes dos profissionais enfermeiros (Wallston, Wallston, De Velli, 1976; Cornish, Miller, 1976) que os enfermeiros eram moralistas e pouco otimistas com relação ao tratamento para esses pacientes (Rosembaum, 1977) e que os enfermeiros de unidades de internação eram mais humanistas e apresentavam concepções menos condenatórias frente a pacientes alcoolistas do que aqueles de unidades de emergência (Gross, Lismam, 1979).

$\mathrm{Na}$ década de 1980, as pesquisas mostraram que os enfermeiros consideravam o paciente alcoolista como mais responsável por seus problemas de saúde do que os pacientes relatados como não alcoolistas 
(Biener, 1983). Os estudos de Reisman e Shrader (1984) surgem relacionados ao conhecimento do profissional enfermeiro frente aos problemas relacionados ao alcoolismo que evidenciam que os profissionais enfermeiros relatavam não ter conhecimento suficiente para detectar o alcoolismo entre os pacientes, além desses profissionais citarem sentir uma frustração sobre as recaídas de pacientes alcoolistas (Bartek, Lindeman, Newton, 1988). No entanto, observou-se que enfermeiros de clínicas médicas e cirúrgicas apresentaram maior aceitação do conceito de doença médica/orgânica do que as enfermeiras alocadas em unidades psiquiátricas (Potaminos et al., 1985).

A literatura traz relatos de pesquisas relacionadas às atitudes de enfermeiros frente ao álcool, alcoolismo e alcoolista. Na década de 1990, observa-se um avanço nessas pesquisas que começam a despertar o interesse dos investigadores ao redor de todo o mundo, inclusive, de pesquisadores brasileiros. Estudo realizado (Vargas, Soares, 2010) evidenciou que houve um aumento 15,8\%, no período de 2000 a 2009 relacionado ao número de publicações na década de 1990 referente às atitudes de enfermeiros frente ao álcool, alcoolismo e alcoolista, segundo evidencia os dados do gráfico 1.

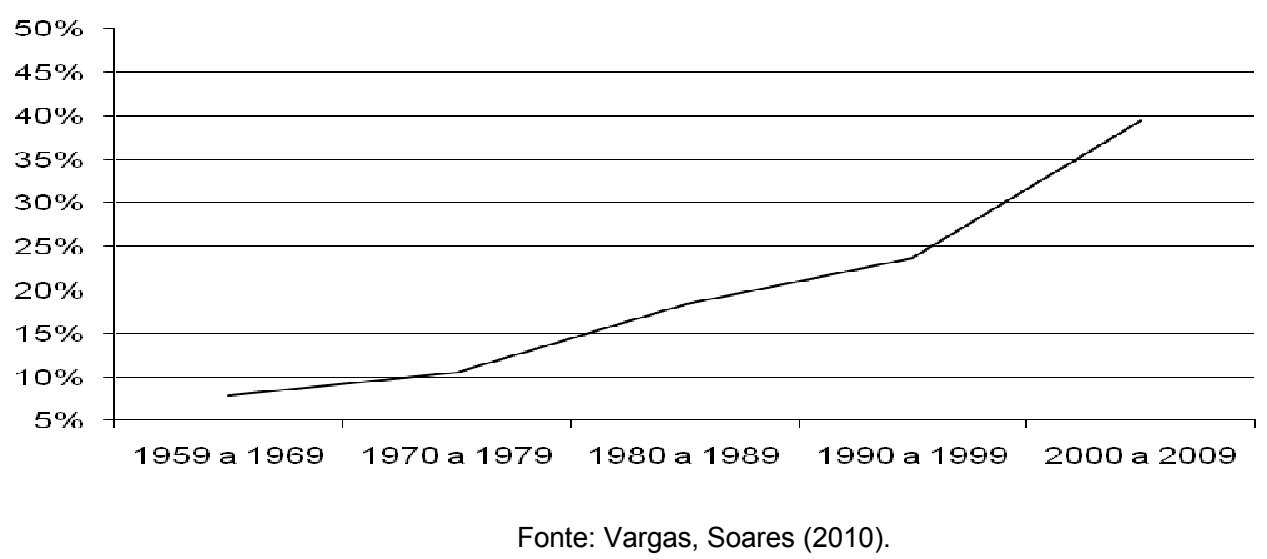

Gráfico 1 - Distribuição das publicações $(n=38)$ sobre as atitudes de enfermeiros frente ao álcool, alcoolismo e alcoolista entre 1950 a 2009. 
Conforme o levantamento de todas as produções encontradas entre 1990 a 2009, o Brasil foi responsável por 34,2\% dessa produção. De acordo com a análise das pesquisas (Allen, 1993), pela primeira vez, os fatores apontados pelos enfermeiros, como causas importantes do controle do uso de álcool pelos usuários foram o aumento do conhecimento e a mudança de atitudes positivas nos profissionais (Hegemaster et al., 1993; Gerace, Hughes, Spunt, 1995) para trabalhar com pacientes não alcoolistas (Grief, Elliott, 1994) e a discriminização do usuário de álcool (Krueger, 1995).

No Brasil, os estudos sobre atitudes iniciaram-se no final da década de 1990 (Pillon, 1998). Ao avaliar três instrumentos para a mensuração de atitudes de enfermeiros frente ao alcoolismo, "The Marcus Alcoholism Questionnaire" (1980) e "The Tolor-Tamerin Attitudes Toward Alcohol Alcoholism Scale”, (1975), “ The Seaman Mannello Nurses's Attitudes Toward Alcohol and Alcoholism Scale", (1978), com uma composição de tais instrumentos, efetuando uma Análise Fatorial, chegou a um instrumento único vertido para a língua portuguesa que media vários fatores das atitudes dos profissionais da saúde frente ao álcool (Vargas, Luís, 2008b).

Nos anos 2000, o interesse pelo tema atitudes frente ao álcool, alcoolismo e alcoolista manteve-se entre os pesquisadores de todo o mundo, inclusive, no Brasil. Howard, Chung (2000) no levantamento utilizado a respeito de pesquisas indicaram que as atitudes de enfermeiros frente 0 abuso de álcool indicou que os enfermeiros percebiam os pacientes usuários de álcool mais negativamente que os outros pacientes, que os enfermeiros que são pouco tolerantes ao beber social e ao uso de drogas, têm atitudes moralmente mais condenatórias ao dependente químico que outros profissionais de saúde.

Lock et al. (2002) mostram que os enfermeiros de cuidados primários de saúde têm muitas oportunidades para se envolver em uma intervenção de álcool, a maioria recebe pouca ou nenhuma preparação para esse trabalho. Isto tem deixado os enfermeiros em situação de desvantagem, visto que o consumo de álcool é uma área confusa e delicada para os profissionais de saúde e pacientes. 
Deehan et al. (2002) realizaram um estudo para verificar a subutilização do pessoal de enfermagem na identificação e manejo dos problemas relacionados ao álcool e alcoolismo, encontraram que, apesar dos enfermeiros manterem contato direto com essa população e de seu grande potencial para identificar e orientar os usuários sobre o consumo e abuso de álcool, constituindo um instrumento importante na atenção à saúde dessa população, não eram utilizados para essa função.

Chung et al. (2003) em seu estudo verificaram as atitudes de enfermeiros de um departamento de emergência em Hong Kong frente a pacientes alcoolistas utilizando um questionário sobre a percepção desses sujeitos a respeito de pacientes alcoolistas (AAPPQ), revelaram que os enfermeiros tendem a ter atitudes negativas frente a esses pacientes.

Willaing e Ladelund (2005) no estudo realizado para identificar a associação entre o autorrelato de enfermeiros de hospital geral, relacionado à prática clínica do cuidado a pacientes usuários de álcool, e a autoavaliação desse enfermeiro quanto às suas qualificações para o aconselhamento frente ao cuidado de pacientes com consumo abusivo de álcool. Observaram que a autoavaliação das qualificações dos enfermeiros estudados influencia de modo significativo no cuidado clínico desses pacientes. O relato de autoeficácia do profissional mostrou-se diretamente relacionado às atitudes positivas frente ao paciente.

Bendtsen et al. (2007) avaliaram as mudanças nas atitudes frente à prevenção relacionada ao álcool entre enfermeiros e as atitudes depois da implementação de um programa computadorizado para o rastreamento e intervenção dos problemas relacionados ao álcool. Encontraram que mais de $60 \%$ dos enfermeiros esperavam que os pacientes reagissem negativamente quando questionados sobre seus hábitos alcoólicos. Após um ano de rastreio, apenas $10 \%$ relataram a experiência das reações negativas dos pacientes. Mais de $50 \%$ dos enfermeiros acharam fácil ou muito fácil abordar o paciente sobre os problemas relacionados ao álcool e mais de $75 \%$ concordaram que esse rastreamento não afetou sua carga de trabalho. 
Newton (2007) avaliando a recidiva do uso do álcool, após o transplante de fígado de pacientes alcoolistas, mostrou que as contribuições da enfermagem para aconselhar a abstinência para receptores adultos de transplante de fígado são desconhecidas, conclui que enfermeiros especialistas nessa área não têm conhecimento suficiente do abuso de álcool e dependência química.

Na América Latina, só no início desta década, surgiram as primeiras publicações de estudos específicos sobre as atitudes de enfermeiros frente ao tema álcool (Vargas, 2005). Navarrete e Luis (2004) estudaram as atitudes de 71 enfermeiras de um complexo hospitalar em La Paz na Bolívia, utilizando a "Seaman Mannello Nurses's Attitudes Toward Alcohol and Alcoholism Scale". Os dados mostraram que os enfermeiros do estudo concebem o alcoolismo como uma doença, e o alcoolista precisando receber atendimento hospitalar. Embora a maioria dos enfermeiros não tenha apresentado preferência para trabalhar com alcoolistas, acreditava que eles têm sérias dificuldades emocionais e que mesmo não obedecendo às ordens da enfermagem devem ser atendidos. Essa população de enfermeiros não foi favorável ao beber moderado, pois considera-o prejudicial à saúde.

Ao fazer um apanhado geral sobre os estudos internacionais, pode-se evidenciar que os pacientes alcoolistas são percebidos como pacientes mais responsáveis pela sua doença do que outros não alcoolistas. $\mathrm{Na}$ atenção primária à saúde, os profissionais enfermeiros também demonstram despreparo e falta de habilidade frente ao tratamento do alcoolista, considerando que, quando esses profissionais são treinados ou capacitados, sentem-se mais dispostos e aptos a cuidar desse paciente, além de diminuir suas atitudes negativas frente ao tratamento. De forma marcante na década de 1970, surgem estudos com propostas de avaliar o impacto dos treinamentos em álcool e outras drogas no preparo do enfermeiro. Em 1980, encontram-se os primeiros indícios de que os enfermeiros consideravam os fatores emocionais e psicológicos, como influenciadores no desenvolvimento do alcoolismo. 
A partir dos anos 2000, houve um importante aumento dos estudos sobre treinamentos e capacitações. Além disso, o final da década de 1990 e início dos anos 2000, como já relatado, foi marcado pelo início de estudos sobre as atitudes de enfermeiros frente ao álcool, alcoolismo e alcoolista no Brasil.

Pillon (2003) utilizou o instrumento de seu primeiro estudo (Pillon, 1998) verificou as atitudes de uma população de 340 sujeitos composta por 90 docentes, 220 enfermeiros assistenciais e 60 estudantes de enfermagem, buscando conhecer as atitudes desses sujeitos quanto ao pensar, ao sentir e comportar-se frente a pacientes alcoolistas. Os resultados do estudo mostram que os enfermeiros eram favoráveis ao tratamento para o alcoolismo, sendo este percebido como doente, mas apresentaram atitudes negativas frente à satisfação em trabalhar com esta clientela. No mesmo ano Vargas et al. (2003), verificando as atitudes de enfermeiros de hospital geral quanto à disposição para o tratamento ou punição de pacientes alcoolistas, evidenciam que os enfermeiros consideravam o alcoolismo uma doença; acreditavam que esses pacientes deveriam receber tratamento médico e consulta psiquiátrica, concluíram que os enfermeiros acreditavam que os alcoolistas tratavam-se de pessoas fisicamente doentes, devendo submeterse a tratamento médico.

Posteriormente, Vargas, (2005) realizou um estudo com 196 enfermeiros, de um hospital geral de uma cidade do interior do Estado de São Paulo e utilizou a "Seaman Mannello Nurses's Attitudes Toward Alcohol and Alcoholism Scale". Os resultados apontaram que esses profissionais eram favoráveis à terapia para o alcoolismo, pois concebiam o alcoolista, como uma pessoa doente, sendo o tratamento médico necessário. Revelaram que se sentiam embaraçados ao trabalharem com pessoas com problemas de bebida.

No que se refere às características pessoais do alcoolista, os enfermeiros concebem-no como infeliz, solitário, sensitivo que duvida de seu próprio valor e com várias dificuldades emocionais. Para esses enfermeiros, o perigo está no álcool e não na pessoa que ingere, pois seu consumo, em 
Janaina Soares

qualquer quantidade, é nocivo e moralmente errado. Em um outro estudo Vargas e Labate (2006), objetivando mensurar as atitudes de enfermeiros no mesmo hospital geral referente ao álcool e ao beber, evidenciam que os enfermeiros consideram as bebidas alcoólicas prejudiciais, que o beber não é inofensivo, sendo errado e que as bebidas alcoólicas têm a capacidade de tornar as pessoas "débeis e loucas". O estudo revelou que os enfermeiros tinham dificuldade para aceitar o beber como um direito da pessoa.

Lucca et al. (2006) realizaram um estudo em uma cidade do interior de São Paulo, para verificar as concepções de enfermeiros de hospital geral frente ao álcool, alcoolista e alcoolismo, assim, $50 \%$ dos sujeitos pesquisados expressaram indiferença ao trabalhar com alcoolistas e $60 \%$ desses profissionais acreditavam que essas pessoas bebiam para fugir dos problemas, $12 \%$ que esses pacientes estavam satisfeitos com a vida que levavam. O estudo aponta ainda que, embora a maioria dos sujeitos tenha revelado alguma experiência no atendimento a pacientes alcoolistas, poucos relataram contato frequente, demonstrando um contrassenso uma vez que atualmente grande número de leitos hospitalares é ocupado por pacientes alcoolistas, (Noto et al., 2002). Lucca e Vargas (2006) associaram esses resultados à falta de preparo dos profissionais para reconhecer a doença do alcoolismo e sua relação com as patologias clínicas.

$\mathrm{Na}$ pesquisa realizada com estudantes e docentes da enfermagem em uma Universidade Pública de São Paulo, sobre as atitudes de enfermeiros relacionadas ao alcoolismo, foi verificado que os enfermeiros percebiam os alcoolistas como doentes e o tratamento por terapia precisa ser oferecido, 92,5\% da amostra total apresentaram atitudes positivas em relação à disponibilidade de tratamento e sentiam-se recompensados no trabalho com alcoolistas, referente às habilidades para manejar com êxito os problemas do alcoolista, mas prevaleceram atitudes neutras, além disso, esses enfermeiros percebiam-se pouco aptos para ajudar (Pillon, Laranjeira, 2005).

Vargas (2010a) verificou as atitudes de 171 enfermeiros de um hospital universitário do Estado de São Paulo, frente às habilidades de 
Janaina Soares

identificação para ajudar o paciente alcoolista por meio de uma escala de atitudes. Observa-se que os enfermeiros são capazes de ajudarem esses pacientes a alcançarem a recuperação, demonstrando atitudes positivas. No entanto, identificou o conflito nas atitudes frente à vontade e ao querer do alcoolista, revelando a influência do modelo moral de explicação para o alcoolismo.

De modo geral, os estudos sobre as atitudes de enfermeiros frente ao álcool, alcoolismo e alcoolista, realizados, particularmente, no Estado de São Paulo permitem evidenciar que os enfermeiros percebem o alcoolista como um doente e que precisa ser tratado e o uso nocivo de álcool pode levar a sérios problemas de saúde, porém sentem dificuldade para intervir sobre esse paciente, preferindo não trabalhar com os mesmos, mostrou um predomínio de atitudes negativas frente à questão (Pillon, 1998; Pillon, 2003; Vargas, 2005; Pillon, Laranjeira, 2005 e Vargas, 2010a).

Em relação ao preparo e ao conhecimento dos enfermeiros sobre o álcool, alcoolismo e alcoolista, Pillon et al. (2006) evidenciaram que a minoria da população de enfermeiros estudados recebeu informação sobre o tema durante a graduação, e $90 \%$ dos pós-graduados receberam informações sobre o tema, mas estas mostraram-se limitadas, pois os enfermeiros, apesar de identificarem os problemas advindos do uso abusivo do álcool, apresentavam dificuldades para percebê-lo na prática para realização de intervenções breves, focando o problema. Vargas e Labate (2005), avaliaram questões que envolvem a satisfação de enfermeiros de um hospital geral do interior de São Paulo para trabalhar com pacientes alcoolistas, identificaram apoiados em uma amostra de 171 enfermeiros, que $46,5 \%$ destes não se sentem preparados para trabalhar com essa clientela, pois apenas dois desse contingente afirmaram que trabalham melhor com tais pacientes do que com os outros, pois como não têm conhecimento satisfatório sobre o tema, sentem-se despreparados para atuar frente ao caso.

Sendo assim, a maioria dos autores (Lock et al., 2002; Deehan et al., 2002; Vargas et al., 2003; Vargas, 2005; Lucca et al., 2006; Pillon et al., 
2006; Newton, 2007) vem associando o pouco preparo dos enfermeiros para o enfrentamento da problemática. Conforme evidencia a literatura (Vargas, Labate, 2006; Vargas, Luís, 2008a), apesar do aumento na demanda por atividades relacionadas ao uso de substâncias psicoativas, não tem havido uma preocupação das instituições formadoras e de saúde para preparar tais profissionais para o manejo dessas situações, o que repercute em atitudes negativas frente a esses indivíduos.

O levantamento realizado a respeito de estudos experimentais relacionados às atitudes de enfermeiros frente ao álcool, alcoolismo e alcoolista da literatura nacional e internacional permite evidenciar a existência de estudos que se ocuparam em diagnosticar as atitudes de enfermeiros (Gross, Lismam,1979; Hisatomi et al., 1998; Happell, Taylor, 2001). Poucos trabalhos ocuparam-se em realizar estudos experimentais com os enfermeiros do tipo estudos comparativos, e os poucos estudos dessa natureza que foram encontrados, buscaram comparar as atitudes de enfermeiros que trabalharam ou que tiveram contato com pacientes alcoolistas e os que não tiveram tal experiência.

Gross e Lismam (1979) comparam as atitudes entre dois grupos de enfermeiros. O primeiro grupo, era de trabalhadores alocados em uma unidade de tratamento do alcoolismo que mantinham contato com pacientes abstêmios; o segundo, era constituído por enfermeiros de uma unidade de urgência que trabalhavam com pacientes intoxicados diariamente. Observaram que os enfermeiros da unidade de internação eram mais favoráveis às abordagens humanistas e terapêuticas de tratamento do que os da unidade de emergência.

No estudo realizado com objetivo de comparar as atitudes e conhecimentos entre enfermeiros de unidades gerais de internação e as de unidades especializadas em alcoolismo, Hisatomi et al. (1998) Evidenciam que os enfermeiros de unidades gerais mostraram-se mais tolerantes a beber, mas tinham atitudes mais moralistas frente ao alcoolismo, além de possuírem menos conhecimento sobre os problemas relacionados ao álcool e alcoolismo. 
Happell e Taylor (2001) procuraram determinar a existência de diferença entre as atitudes de enfermeiros que utilizam os serviços de interconsulta em psiquiatria para atendimento de alcoolistas e os que não usam. Aplicaram um questionário em 200 enfermeiros, os resultados não evidenciaram diferenças estatísticas nas atitudes dos dois grupos.

Embora exista um número reduzido de estudos que se ocupou de comparar grupos de enfermeiros em relação às atitudes frente ao álcool, alcoolismo e alcoolista, publicados na literatura, seus resultados sugerem que os profissionais enfermeiros que mantêm maior contato com pacientes alcoolistas ou intoxicados tendem a ter atitudes mais negativas frente ao alcoolista, e os enfermeiros que são de instituições especializadas no tratamento tendem a ter atitudes mais positivas.

\subsection{ESTRATÉGIAS DE FORMAÇÃO EM ÁLCOOL E OUTRAS DROGAS E SUAS REPERCUSSÕES NAS ATITUDES E CONHECIMENTOS DE ENFERMEIROS}

Na literatura, há indícios (Rosebaun, 1977; Hegemaster et al., 1993; Gerace, Hughes, Spunt, 1995; Bendtsen, Akerlind,1999; Ford, Bammer, Becker, 2009) a respeito das atitudes de enfermeiros frente ao alcoolismo e o alcoolista e o aumento do conhecimento sobre o tema pode associar-se à mudança de atitude. Em um deles, Rosebaun (1977) estudou enfermeiros de saúde pública que haviam participado de um programa de treinamento em álcool e alcoolismo. Encontra que, ao término do curso, a maioria dos enfermeiros estava otimista com relação ao tratamento do alcoolismo, julgando que este precisa ser motivado, para que obtenha sucesso. No entanto, a maioria dos sujeitos continuou apresentando visões moralistas sobre o alcoolismo.

No mesmo período, Hagemaster et al. (1993) avaliaram os resultados de um workshop oferecido para conscientização de enfermeiros de saúde pública sobre os problemas de saúde, decorrentes do uso de substâncias. Para isso, aplicaram escalas de mensuração de atitudes e conhecimentos, 
Janaina Soares

antes e 3 meses após o treinamento houve um significativo aumento de conhecimento relacionado às substâncias encontradas no pós-treinamento em comparação com o pré.

Após o treinamento, observou-se diminuição das atitudes permissivas em relação ao uso de drogas, concomitante a um aumento da confiança desses enfermeiros em relação à eficácia do tratamento. Ainda nos anos de 1990, Gerace et al. (1995) avaliaram a eficácia de um programa de 3 anos, elaborado para melhorar as atitudes de enfermeiros frente a usuários de substâncias psicoativas e aumentar suas habilidades clínicas. Convidaram um grupo de enfermeiros de um hospital universitário a participar voluntariamente de treinamento. Antes do treinamento e no final do terceiro ano, os enfermeiros completaram uma escala, avaliando seu conhecimento em relação ao álcool e às drogas, bem como suas atitudes frente a pessoas com problemas de abuso de substâncias. A escala de atitudes mostrou significativas mudanças na comparação entre o pré e o pós-treinamento, os enfermeiros pós-treinados apresentavam atitudes mais positivas frente ao paciente e estavam mais otimistas em relação ao tratamento.

Bendtsen e Akerlind (1999) avaliaram um grupo de enfermeiros de quatro centros de atenção primária à saúde na Suécia, que receberam treinamento e acompanhamento de especialistas na detecção e tratamento de problemas relacionados ao álcool durante 1 e 2 meses. Os resultados do estudo mostram que houve significativa mudança nas atitudes dos mesmos, havendo o predomínio de atitudes mais positivas, após o acompanhamento.

Ford, Bammer e Becker (2009) analisaram o impacto da educação continuada sobre o tema álcool e outras drogas no local de trabalho sobre as atitudes de enfermeiros australianos frente aos pacientes que usam drogas ilícitas, encontraram que a educação continuada sobre o tema álcool e outras drogas melhorou a atitude dos enfermeiros.

Dos poucos estudos publicados sobre a avaliação do impacto de cursos em álcool e alcoolismo sobre as atitudes e o conhecimento aos profissionais de saúde no Brasil, destaca-se o de Silva (2005), realizado em 2000, que avaliou o impacto de um curso de 8 horas sobre as atitudes e 
conhecimento de um grupo de profissionais da saúde composto por 172 sujeitos de níveis superior e médio, aplicando um instrumento de Atitudes e um de Conhecimento em três momentos distintos: antes do curso, imediatamente após o curso e uma medida de follow-up de 2 anos após o curso.

Os resultados apontam que os profissionais de nível médio representaram o grupo que mais concordou com a etiologia moral da dependência, sendo também o que apresentava maior preconceito sobre a pessoa dependente; acreditando que o paciente pode controlar seu uso. $O$ autor aponta um paradoxo nesse achado, uma vez que constatou que esses profissionais sentiam-se bem preparados para atender aos pacientes, não eram pessimistas com relação ao prognóstico. Para ele, é provável que essa situação tenha sido verificada, pois os técnicos encontram-se na linha de frente da equipe, o que explica ser um dos grupos que mais atende (metade deles atendia mais que quatro pacientes semanalmente). Contudo, o atendimento pode ser apenas uma assistência paliativa e não um tratamento, já que a maioria dos profissionais não recebeu algum treinamento.

No que se refere aos grupos de profissionais de nível superior, o autor encontrou atitudes moralistas e preconceituosas em todos eles, embora em diferentes níveis e com melhoras após o curso. Com relação ao conhecimento, todos os grupos avançaram em seu conhecimento de forma similar, comparando-se a primeira avaliação com a segunda ou a segunda com a última.

O estudo de Silva (2005) conclui que o curso oferecido foi eficaz, sendo seu impacto substancial nas duas medidas de desfecho: as Atitudes e os Conhecimentos. A melhora das Atitudes foi significativa entre a primeira avaliação (antes do curso), e a segunda (imediatamente após o curso), bem como o nível de Conhecimento que também melhorou significativamente. A medida de follow-up (2 anos após ser ministrado o curso) mostrou melhora em relação a segunda avaliação (imediatamente, após o curso), o que 
Janaina Soares

segundo 0 autor sugere que estes profissionais tenham buscado informações sobre a questão, após o término do mesmo.

Ainda segundo o autor, estudos sobre educação vêm sendo feitos na tentativa de treinar os profissionais, preparando-os para atuarem com eficácia nos pontos falhos da educação formal. Estes dividem-se em duas frentes a serem pesquisadas cuidadosamente: o ensino formal nas escolas de graduação, revendo as competências a serem obtidas pelos alunos; e a capacitação dos profissionais já formados, propondo modelos de ensino complementar para deficiências na educação formal.

No que se refere à questão do conhecimento dos profissionais frente ao alcoolismo, constata-se que a quantidade de conhecimentos recebidos pelos mesmos influencia positivamente nas atitudes e percepções destes frente ao alcoolista (Rosebaun, 1977; Hagemaster et al., 1993; Gerace et al., 1995; Bendtsen, Akerlind,1999; Silva, 2005).

Em relação à associação entre a aquisição de conhecimento e a mudança de atitudes é unânime ainda entre os pesquisadores sobre o tema (Rosebaun, 1977; Hegemaster et al., 1993; Gerace, Hughes, Spunt, 1995; Bendtsen, Akerlind,1999; Silva, 2005; Ford, Bammer, Becker, 2009), assim, há necessidade de aprimorar os conhecimentos desses profissionais, para que haja uma mudança de atitude, desde a formação até a educação continuada ou a capacitação.

Essa necessidade é, inclusive, reconhecida pelo Ministério da Saúde que, por meio da Política Nacional de Atenção Integral ao usuário de álcool e outras drogas (Brasil, 2004), preconiza a promoção e o oferecimento de programas de formação específica aos trabalhadores de saúde que atuam na rede de atenção aos usuários de álcool no Sistema Único de Saúde.

No âmbito educacional, a mesma política aponta que deve ser desenvolvido um trabalho intersetorial voltado à revisão e reformulação dos parâmetros curriculares vigentes, garantindo a inclusão consistente de álcool e drogas nas grades curriculares escolares. 
Da mesma forma, devem ser operadas mudanças relativas à formação de profissionais das diversas áreas de saúde, com a inclusão das disciplinas especificamente voltadas para esta área ou com a remodelação das já existentes, garantindo carga-horária teórico-prática suficiente, apesar do consenso entre os pesquisadores e das recomendações do MS para melhorar estratégias de formação e capacitação dos profissionais de saúde para atendimento de pacientes com problemas relacionados ao álcool e outras drogas.

No Brasil, as escolas não estão considerando estas orientações e poucas são as oportunidades de capacitação e treinamento oferecidas a esses profissionais, o que parecem justificar a escassez na literatura nacional de estudos, envolvendo a avaliação ou mesmo descrição de experiências com esse fim.

Portanto, considerando a necessidade de se identificar e avaliar novos métodos que favoreçam a aquisição de conhecimentos e a mudança de atitudes dos enfermeiros frente às questões relacionadas ao álcool e outras drogas e considerando, que nos últimos anos, tem sido oferecido o curso Sistema para detecção do Uso abusivo e dependência de substâncias Psicoativas: Encaminhamento, intervenção breve, Reinserção social e Acompanhamento (SUPERA), gratuitamente aos profissionais da saúde de todo o País, por meio de um convênio firmado entre a Secretaria Nacional de Políticas sobre Drogas (SENAD) e a Universidade Federal de São Paulo (UNIFESP), considerou-se esta uma importante estratégia a ser investigada. 


\section{Objetivos}




\section{OBJETIVOS}

\subsection{OBJETIVO GERAL}

Comparar as atitudes e os conhecimentos entre um grupo de enfermeiros capacitados em álcool e outras drogas por um curso específico e um grupo de enfermeiros que não recebeu tal capacitação, frente ao álcool, alcoolismo e alcoolista.

\subsubsection{Objetivos Específicos}

- Verificar a influência das variáveis sociodemográficas nas atitudes e conhecimentos dos enfermeiros.

- Verificar a influência do conhecimento nas atitudes da população do estudo.

- Comparar as atitudes entre enfermeiros capacitados e enfermeiros não capacitados. 


\section{Hipóteses a serem testadas}




\section{HIPÓTESES A SEREM TESTADAS}

1. Os enfermeiros que foram capacitados por meio do curso SUPERA deverão apresentar atitudes mais positivas e melhor conhecimento frente ao álcool, alcoolismo e alcoolista do que os enfermeiros que não foram capacitados.

2. Os enfermeiros que receberam maior carga horária de conteúdos relacionados ao tema durante a formação profissional, deverão apresentar atitudes mais positivas e melhor conhecimento frente ao álcool, alcoolismo e alcoolista do que aqueles que não receberam nenhuma formação ou a receberam em menor carga horária. 
Método 


\section{MÉTODO}

Trata-se de um estudo exploratório de abordagem quaseexperimental, cuja investigação é fundamentada na mensuração das atitudes e conhecimentos de um grupo de enfermeiros que participou de um curso de capacitação em álcool e outras drogas frente ao álcool, alcoolismo e alcoolista comparado a um grupo de enfermeiros que não realizou tal capacitação.

A pesquisa quase-experimental assemelha-se muito aos experimentos, porque os estudos quase-experimentais também envolvem a manipulação de uma variável independente. No entanto, não possuem características típicas dos experimentos verdadeiros, como a randomização ou a de grupo controle. Há vários delineamentos quase-experimentais, mas os dois mais comumentes usados pelos pesquisadores em enfermagem são o delineamento grupo de controle não equivalente e o delineamento temposérie (Polit 2004).

O delineamento da série de tempo é caracterizado por não possuir um grupo de controle nem distribuição aleatória. Para tanto, neste caso, a única espécie de comparação possível de ser feita é o contraste antes e depois (pré e pós-teste). Assim, podemos comparar o da variável, por exemplo, durante o período de 3 meses, antes de aplicar um determinado teste e no período de 3 meses, após a aplicação do teste (Polit, 2004).

O delineamento de grupo controle não equivalente é caracterizado pelo envolvimento de um tratamento experimental de dois ou mais grupos de sujeitos, que deveriam ser submetidos a um pré-teste comparativo de como os grupos comportam a respectiva variável independente e um pós-teste. Este delineamento de pesquisa quase-experimental é idêntico ao delineamento experimental antes depois, a não ser pelo fato dos sujeitos não serem designados aos grupos de forma randomizada. 
O delineamento quase-experimental é substancialmente mais fraco, porque sem a distribuição aleatória não mais podemos crer que os grupos experimental e de comparação sejam iguais, no início do estudo. Trata-se de um projeto de valor, porque a coleta de dados, no pré-teste, permite que determinemos se os grupos apresentariam inicialmente alguma semelhança, em termos de variável. No caso dos grupos de comparação (controle) e experimental responderem da mesma maneira, em média, ao questionário pré-teste, poderíamos ter uma relativa confiança que qualquer diferença no pós-teste seria resultado do tratamento experimental.

Nos casos em que não sejam coletados dados, no pré-teste, como neste estudo, em que não se aplicou a escala no grupo de enfermeiros que realizou a capacitação por meio do curso SUPERA $3^{a}$ Edição, antes do início do curso. Recomendamos o uso do delineamento quase-experimental do grupo de controle não equivalente só pós-teste (Campbell, Staley, 1979), razão pela qual se adotou esta metodologia no presente estudo.

O delineamento do grupo de controle não equivalente só pós-teste é caracterizado pela escolha aleatória (Campbell, Stanley, 1979) de um grupo de comparação (grupo controle) e um grupo experimental não equivalente ao grupo controle que será submetido à aplicação de um mesmo instrumento, respectivo a uma variável independente, sendo assim, trata-se de um estudo que testa uma hipótese, eliminando múltiplas variáveis com o intuito de levantar questões pertinentes que permitam estudos futuros mais profundos e favoreçam reflexões para uma futura fundamentação teórica sobre o tema. (Gonçalves, Nunes, 2005). 
Material 


\section{MATERIAL}

Utilizou-se, como instrumento de mensuração das atitudes a "Escala de Atitudes Frente ao Álcool, ao Alcoolismo e ao Alcoolista" (EAFAAA) (Anexo 1), composta de 80 itens, divididos em entre cinco fatores que abordam o tema alcoolista sob ângulos diferentes. São eles:

Fator 1: Alcoolista, com 33 afirmações sobre o tema.

Fator 2: Etiologia, com 17 afirmações.

Fator 3: Alcoolismo, com 13 afirmações.

Fator 4: Repercussões decorrentes do uso/abuso do álcool, com 6 afirmações.

Fator 5: Bebida alcoólica, com 11 afirmações.

Fator I: Alcoolista: este fator envolve as opiniões, sentimentos, percepções do enfermeiro, frente ao indivíduo alcoolista, destacando sobretudo suas características físicas e psíquicas, bem como os comportamentos e as atitudes atribuídos a esse paciente.

Fator II: Etiologia: é composto por um conjunto de itens que refletem as opiniões, sentimentos e atitudes dos enfermeiros, frente à etiologia do alcoolismo. O fator, portanto, envolve situações, acontecimentos e características pessoais determinantes do beber abusivo.

Fator III: Alcoolismo: este fator envolve as percepções e sentimentos dos enfermeiros frente ao alcoolismo, estabelecendo critérios de classificação para defini-lo, como problema ou não de saúde.

Fator IV: Repercussões decorrentes do uso/abuso do álcool: o fator em questão diz respeito às opiniões, sentimentos e predisposições do enfermeiro sobre os custos psíquicos e sociais acarretados pelo uso/abuso do álcool, envolvendo o indivíduo, a família e outras esferas de relacionamento social (trabalho, amizades e, etc.). Descreve as 
consequências do uso; influências do tipo de personalidade no adoecer, bem como as questões morais que cercam o álcool e o beber.

Fator V: A Bebida Alcoólica: este fator envolve as opiniões, sentimentos e condutas dos enfermeiros frente à bebida alcoólica; consequências trazidas pelo uso das bebidas ao indivíduo; o limite entre o beber normal e o patológico; efeitos da bebida sobre o comportamento da pessoa.

A EAFAAA é uma escala do tipo likert, com alternativas de um (discordo totalmente) a cinco (concordo totalmente). O enfoque Likert consiste em verificar o nível de concordância do sujeito, com uma série de afirmações que expressam algo de favorável ou desfavorável em relação a um objeto psicológico. Essas afirmações são respondidas em uma escala de pontos, que podem variar de três a dez, sendo mais utilizadas as escalas de cinco a sete pontos. No caso da EAFAAA, cada um dos 80 itens que compõe o instrumento entregue aos enfermeiros, pode ser respondido por meio de uma escala de cinco pontos (Vargas, 2005).

1. Discordo totalmente

2. Discordo em parte

3. Estou em dúvida

4. Concordo em parte

5. Concordo totalmente

O instrumento foi criado por Vargas (2005), com uma amostra original de 148 enfermeiros atuantes nos três níveis de assistência à saúde de Ribeirão Preto - São Paulo (Brasil), e outros oito municípios da região de Ribeirão Preto/SP e Barretos/SP, dentre os quais, aproximadamente, $40 \%$ eram enfermeiros hospitalares 23\%, enfermeiros da Saúde Pública e 14\%, enfermeiros da docência.

A escala EAFAAA é específica para medir as atitudes dos profissionais relacionadas às questões de álcool, de forma segura; além disso, a EAFAAA permite avaliar atitudes de dois atributos que não são 
contemplados em nenhum instrumento anterior dos que se tem conhecimento; as atitudes frente ao relacionamento interpessoal com o paciente alcoolista e às atitudes diante das repercussões do alcoolismo no contexto pessoal e social. Ainda no que se refere às vantagens do instrumento utilizado, pode-se dizer que facilita sua aplicação no Brasil, pelo fato de ter sido construída em Língua Portuguesa (Vargas, Luís, 2008b).

A seguir, os dados do quadro mostram os itens de cada um dos cinco fatores que compõem o instrumento.

Quadro 1 - Fatores e itens da Escala de Atitudes Frente ao Álcool, ao Alcoolismo e ao Alcoolista - EAFAAA

\begin{tabular}{|c|c|c|c|c|c|c|}
\hline \multicolumn{7}{|c|}{ Fator I - O Alcoolista } \\
\hline 1 & O alcoolista é uma pessoa que não tem limite. & 1 & 2 & 3 & 4 & 5 \\
\hline 6 & Alcoolistas não têm bom senso. & 1 & 2 & 3 & 4 & 5 \\
\hline 16 & O alcoolista é um irresponsável. & 1 & 2 & 3 & 4 & 5 \\
\hline 26 & Os Alcoolistas são pacientes violentos. & 1 & 2 & 3 & 4 & 5 \\
\hline 31 & O alcoolista bebe sem a preocupação do que vai acontecer depois. & 1 & 2 & 3 & 4 & 5 \\
\hline 36 & Penso que pessoas que desenvolvem o alcoolismo são fracas. & 1 & 2 & 3 & 4 & 5 \\
\hline 41 & O alcoolista não quer se cuidar. & 1 & 2 & 3 & 4 & 5 \\
\hline 46 & Não se deve confiar em pessoas alcoolistas. & 1 & 2 & 3 & 4 & 5 \\
\hline 50 & O alcoolista é um imoral. & 1 & 2 & 3 & 4 & 5 \\
\hline 58 & Penso que o alcoolista é culpado por seus problemas de saúde. & 1 & 2 & 3 & 4 & 5 \\
\hline 63 & O alcoolismo é um vício irreparável. & 1 & 2 & 3 & 4 & 5 \\
\hline 65 & $\begin{array}{l}\text { O paciente alcoolista acaba sempre voltando ao serviço com o mesmo } \\
\text { problema. }\end{array}$ & 1 & 2 & 3 & 4 & 5 \\
\hline 67 & Considero paciente alcoolista o mais difícil de lidar. & 1 & 2 & 3 & 4 & 5 \\
\hline 69 & O alcoolista é um paciente que nunca dá retorno do cuidado. & 1 & 2 & 3 & 4 & 5 \\
\hline 71 & O alcoolista é uma pessoa de difícil contato. & 1 & 2 & 3 & 4 & 5 \\
\hline 73 & Eu tenho medo de abordar o problema do alcoolismo com o paciente. & 1 & 2 & 3 & 4 & 5 \\
\hline 75 & Eu tenho medo da agressividade do alcoolista. & 1 & 2 & 3 & 4 & 5 \\
\hline 76 & Sinto-me frustrado quando trabalho com alcoolistas. & 1 & 2 & 3 & 4 & 5 \\
\hline 77 & Quando o paciente não quer colaborar, o melhor é desistir de ajudar. & 1 & 2 & 3 & 4 & 5 \\
\hline 78 & Quando trabalho com o alcoolista, não sei como conduzir a situação. & 1 & 2 & 3 & 4 & 5 \\
\hline 79 & Para atender o alcoolista, é preciso contê-lo. & 1 & 2 & 3 & 4 & 5 \\
\hline 80 & Penso que alcoolistas dão muito trabalho para a enfermagem. & 1 & 2 & 3 & 4 & 5 \\
\hline 81 & Devo cuidar do alcoolista, mesmo que ele não queira. & 1 & 2 & 3 & 4 & 5 \\
\hline 84 & Sinto raiva ao trabalhar com alcoolistas. & 1 & 2 & 3 & 4 & 5 \\
\hline 85 & O paciente alcoolista não aceita o que eu falo. & 1 & 2 & 3 & 4 & 5 \\
\hline 86 & Percebo o alcoolista como um caso perdido. & 1 & 2 & 3 & 4 & 5 \\
\hline 87 & Alcoolistas são pacientes que não colaboram com o tratamento. & 1 & 2 & 3 & 4 & 5 \\
\hline 88 & Alcoolistas são pessoas difíceis de tratar. & 1 & 2 & 3 & 4 & 5 \\
\hline 89 & $\begin{array}{l}\text { Pacientes alcoolistas só são encontrados para atendimento em unidades } \\
\text { básicas de periferia. }\end{array}$ & 1 & 2 & 3 & 4 & 5 \\
\hline 90 & O alcoolista não leva o tratamento a sério. & 1 & 2 & 3 & 4 & 5 \\
\hline 91 & $\begin{array}{l}\text { Eu prefiro trabalhar com pacientes alcoolistas a trabalhar com outros } \\
\text { pacientes. }\end{array}$ & 1 & 2 & 3 & 4 & 5 \\
\hline 94 & O alcoolismo é a perda da identidade e da moral. & 1 & 2 & 3 & 4 & 5 \\
\hline 95 & Os alcoolistas têm uma situação de vida precária. & 1 & 2 & 3 & 4 & 5 \\
\hline
\end{tabular}




\section{Fator II - Etiologia}

\begin{tabular}{|c|c|c|c|c|c|c|}
\hline 07 & Penso que fatores hereditários influenciam no abuso do álcool. & 1 & 2 & 3 & 4 & 5 \\
\hline 12 & $\begin{array}{l}\text { Alcoolistas são pessoas que buscam na bebida soluções para problemas } \\
\text { afetivos. }\end{array}$ & 1 & 2 & 3 & 4 & 5 \\
\hline 17 & Penso que passar por um desajuste familiar leva ao alcoolismo. & 1 & 2 & 3 & 4 & 5 \\
\hline 22 & O álcool é usado como fuga. & 1 & 2 & 3 & 4 & 5 \\
\hline 27 & Pessoas tímidas ou inibidas têm maior chance de desenvolver o alcoolismo. & 1 & 2 & 3 & 4 & 5 \\
\hline 37 & O alcoolista tem algo no passado que o conduz a beber. & 1 & 2 & 3 & 4 & 5 \\
\hline 42 & A falta de autocontrole leva ao alcoolismo & 1 & 2 & 3 & 4 & 5 \\
\hline 47 & Problemas sociais e econômicos desencadeiam o beber excessivo & 1 & 2 & 3 & 4 & 5 \\
\hline 51 & Penso que a depressão leva ao alcoolismo. & 1 & 2 & 3 & 4 & 5 \\
\hline 55 & O alcoolismo está relacionado ao nível de instrução do indivíduo. & 1 & 2 & 3 & 4 & 5 \\
\hline 59 & O que falta no alcoolista é força de vontade. & 1 & 2 & 3 & 4 & 5 \\
\hline 64 & Pessoas sem emprego fixo desenvolvem o alcoolismo. & 1 & 2 & 3 & 4 & 5 \\
\hline 66 & Filhos de alcoolistas têm tendência a serem alcoolistas. & 1 & 2 & 3 & 4 & 5 \\
\hline 68 & Pessoas mal resolvidas se tornam alcoolistas. & 1 & 2 & 3 & 4 & 5 \\
\hline 70 & Pessoas insatisfeitas abusam do álcool. & 1 & 2 & 3 & 4 & 5 \\
\hline 72 & Penso que pessoas que consomem álcool estão fugindo de algum problema. & 1 & 2 & 3 & 4 & 5 \\
\hline 74 & Penso que alcoolistas têm problemas financeiros. & 1 & 2 & 3 & 4 & 5 \\
\hline \multicolumn{7}{|c|}{ Fator III - Alcoolismo } \\
\hline 03 & O alcoolista é um doente. & 1 & 2 & 3 & 4 & 5 \\
\hline 08 & Percebo que o alcoolista tem baixa autoestima. & 1 & 2 & 3 & 4 & 5 \\
\hline 13 & Os alcoolistas são pessoas psicologicamente abaladas. & 1 & 2 & 3 & 4 & 5 \\
\hline 18 & $\begin{array}{l}\text { O alcoolista é um indivíduo que não consegue controlar sua ingestão } \\
\text { alcoólica }\end{array}$ & 1 & 2 & 3 & 4 & 5 \\
\hline 23 & O alcoolismo é uma doença. & 1 & 2 & 3 & 4 & 5 \\
\hline 28 & A equipe precisa de treinamento para trabalhar com o alcoolista. & 1 & 2 & 3 & 4 & 5 \\
\hline 33 & Não adianta ser agressivo com o paciente alcoolista. & 1 & 2 & 3 & 4 & 5 \\
\hline 38 & Ë preciso tomar cuidado ao trabalhar com o paciente alcoolista. & 1 & 2 & 3 & 4 & 5 \\
\hline 43 & O alcoolista deve ser encaminhado ao psiquiatra. & 1 & 2 & 3 & 4 & 5 \\
\hline 48 & As pessoas bebem para se sentirem mais alegres e mais soltas. & 1 & 2 & 3 & 4 & 5 \\
\hline 52 & O álcool é usado como uma válvula de escape. & 1 & 2 & 3 & 4 & 5 \\
\hline 56 & O alcoolista bebe para fugir da realidade. & 1 & 2 & 3 & 4 & 5 \\
\hline 60 & O alcoolista é um doente & 1 & 2 & 3 & 4 & 5 \\
\hline
\end{tabular}

Fator IV - Repercussões decorrentes do uso/abuso do álcool

\begin{tabular}{|c|c|c|c|c|c|c|}
\hline 09 & Percebo o alcoolista como alguém marginalizado. & 1 & 2 & 3 & 4 & 5 \\
\hline 19 & Penso que o álcool prejudica as funções mentais. & 1 & 2 & 3 & 4 & 5 \\
\hline 24 & O alcoolismo causa dependência física e psíquica. & 1 & 2 & 3 & 4 & 5 \\
\hline 29 & A maioria dos alcoolistas acaba só. & 1 & 2 & 3 & 4 & 5 \\
\hline 34 & O álcool leva à loucura e à morte. & 1 & 2 & 3 & 4 & 5 \\
\hline 39 & A bebida alcoólica altera o estado emocional. & 1 & 2 & 3 & 4 & 5 \\
\hline
\end{tabular}

\section{Fator $\mathbf{V}$ - A bebida alcoólica}

\begin{tabular}{|l|l|l|l|l|l|l|}
\hline $\mathbf{5}$ & Penso que as pessoas têm o direito de beber se elas quiserem. & $\mathbf{1}$ & $\mathbf{2}$ & $\mathbf{3}$ & $\mathbf{4}$ & $\mathbf{5}$ \\
\hline $\mathbf{1 0}$ & A bebida alcoólica é agradável e traz bem-estar. & $\mathbf{1}$ & $\mathbf{2}$ & $\mathbf{3}$ & $\mathbf{4}$ & $\mathbf{5}$ \\
\hline $\mathbf{1 5}$ & O uso de bebida alcoólica é algo normal. & $\mathbf{1}$ & $\mathbf{2}$ & $\mathbf{3}$ & $\mathbf{4}$ & $\mathbf{5}$ \\
\hline $\mathbf{2 0}$ & Penso que beber uma dose de uísque é considerado beber social. & $\mathbf{1}$ & $\mathbf{2}$ & $\mathbf{3}$ & $\mathbf{4}$ & $\mathbf{5}$ \\
\hline $\mathbf{2 5}$ & A bebida em qualquer quantidade vai deixar o indivíduo dependente. & $\mathbf{1}$ & $\mathbf{2}$ & $\mathbf{3}$ & $\mathbf{4}$ & $\mathbf{5}$ \\
\hline $\mathbf{3 0}$ & Beber com moderação não é prejudicial. & $\mathbf{1}$ & $\mathbf{2}$ & $\mathbf{3}$ & $\mathbf{4}$ & $\mathbf{5}$ \\
\hline $\mathbf{3 5}$ & Eu sou contra o uso do álcool em qualquer momento. & $\mathbf{1}$ & $\mathbf{2}$ & $\mathbf{3}$ & $\mathbf{4}$ & $\mathbf{5}$ \\
\hline $\mathbf{4 0}$ & O álcool em quantidades reduzidas é benéfico. & $\mathbf{1}$ & $\mathbf{2}$ & $\mathbf{3}$ & $\mathbf{4}$ & $\mathbf{5}$ \\
\hline $\mathbf{4 5}$ & O álcool relaxa as tensões do dia a dia & $\mathbf{1}$ & $\mathbf{2}$ & $\mathbf{3}$ & $\mathbf{4}$ & $\mathbf{5}$ \\
\hline $\mathbf{4 9}$ & Eu sou a favor do beber moderado. & $\mathbf{1}$ & $\mathbf{2}$ & $\mathbf{3}$ & $\mathbf{4}$ & $\mathbf{5}$ \\
\hline $\mathbf{5 3}$ & Doses pequenas de álcool são capazes de causar dependência. & $\mathbf{1}$ & $\mathbf{2}$ & $\mathbf{3}$ & $\mathbf{4}$ & $\mathbf{5}$ \\
\hline
\end{tabular}


Janaina Soares

Para verificação dos conhecimentos, utilizou-se a escala de conhecimentos proposta por Silva (2005) e adaptada para uso entre enfermeiros, contém quatro questões de múltipla escolha e oito para assinalar verdadeiro ou falso. A escala aborda o conhecimento sobre os seguintes tópicos: (i) diagnóstico de Uso Nocivo, Dependência e tolerância ; (ii) quantidade de uso de baixo risco; (iii) complicações comumente associadas ao uso do álcool (intoxicação aguda; síndrome de abstinência; alucinose alcoólica;(iv) estágios motivacionais do usuários de substâncias psicoativas (v) Intervenção Breve. $\mathrm{Na}$ adaptação da escala de conhecimentos para a aplicação em enfermeiros, retirou-se o ítem (iii) as deficiências cognitivas e síndrome de Wernick-Korsakoff); e o item (iv) tratamento farmacológico da dependência e das complicações; foi substituído por estágios motivacionais dos usuários de substâncias psicoativas (ANEXO 2), visto que estes itens tratam de assuntos voltados ao âmbito clínico, considerou-se mais relevante para estudar entre os profissionais enfermeiros assuntos relacionados às ações e práticas de cuidado a pacientes usuários de álcool, como a entrevista motivacional.

Com os instrumentos de coleta, foi aplicado também um questionário com informações sociodemográficas do sujeito (ANEXO 3), e para o grupo experimental acrescentou-se ao questionário sociodemográfico, questões que se referiam à avaliação e sugestões relativas ao curso realizado (ANEXO 4).

6.1 O CURSO SUPERA (SISTEMA PARA DETECÇÃO DO USO ABUSIVO E DEPENDÊNCIA DE SUBSTÂNCIAS PSICOATIVAS: ENCAMINHAMENTO, INTERVENÇÃO BREVE, REINSERÇÃO SOCIAL E ACOMPANHAMENTO)

O curso SUPERA $3^{\circ}$ Edição foi implantado para capacitar profissionais de saúde de todo o Brasil, trata-se de um curso de ensino a distância, oferecido gratuitamente. Elaborado por profissionais de todo país com grande experiência nas áreas de política sobre drogas, prevenção do 
Janaina Soares

uso abusivo ou tratamento da dependência de álcool ou outras drogas, com o objetivo atualizar os profissionais de saúde com conhecimentos básicos para o atendimento aos usuários de substâncias psicoativas com vistas a melhorar o atendimento a esses pacientes, o referido curso tem duração de 4 meses com uma carga horária de 120 horas (Supera, 2009).

\subsection{CONTEXTO DO ESTUDO}

\subsubsection{Sujeitos do estudo}

A amostra total foi constituída por 280 enfermeiros que foram alocados em dois grupos, 140 sujeitos para o grupo de comparação (grupo controle - GC) e 140 sujeitos para o grupo experimental (GE). Dos 140 enfermeiros do GC, 101 (72,1\%) enfermeiros responderam à pesquisa e no GE, $84(60 \%)$ dos 184 enfermeiros convidados a participara devolveram o instrumento respondido. Dos 185 participantes que devolveram o instrumento respondido, três participantes do GC foram excluídos da amostra, pelo fato de terem respondido menos de $50 \%$ dos instrumentos de coleta, dessa forma, a amostra final do estudo constituiu-se de 182 participantes.

\section{Grupo de comparação}

O GC constituiu-se de enfermeiros que trabalhavam no momento da coleta de dados nas unidades de assistência de uma instituição hospitalar universitária de grande porte, localizada na cidade de São Paulo. A escolha desse local deveu-se ao fato de ser um hospital de ensino de excelência, utilizado pelos cursos de atenção à saúde da Universidade de São Paulo e que, dentre suas atividades de pesquisa, privilegia as pesquisas relacionadas aos problemas de saúde mais comuns da população brasileira, além de ser uma instituição que conta em seu quadro com um número 
significativo de enfermeiros, com características semelhantes em relação ao atendimento dos horários de trabalho, folgas, supervisão, remuneração e benefícios recebidos.

No estudo, foram incluídos os seguintes locais: Unidade de Clínica Médica, Unidade de Clínica Cirúrgica, Unidade de Centro-Cirúrgico, ProntoSocorro Adulto, Unidade de Endoscopia, Unidade de Hemodiálise, Unidade de Terapia Intensiva Adulto, Hospital-Dia, Unidade Básica de Atenção à Saúde, Comissão de Controle de Infecção Hospitalar, Serviço de Iconologia, Departamento de Enfermagem, Serviço de Apoio Educacional, Centro de Material e Esterilização, Ambulatório, Unidade de Pediatria, Maternidade e Unidade de Terapia Intensiva Pediátrica.

\section{Grupo Experimental}

O GE constituiu-se da população de enfermeiros residentes no Estado de São Paulo, que realizaram o curso SUPERA $3^{a}$ Edição, em 2009, $(n=184)$. Adotou-se como critério de inclusão na amostra ter a conclusão do curso SUPERA $3^{a}$ Edição, residir no Estado de São Paulo e aceitar participar do estudo. Os sujeitos que não aceitaram participar do estudo, foram excluídos da amostra.

\subsubsection{Aspectos Éticos}

Os cuidados éticos da pesquisa são representados pela aprovação do projeto pelo Comitê de Ética em Pesquisa com Seres Humanos do Hospital Universitário da Universidade de São Paulo, Resolução 196/96, sob o protocolo № 946/09 e a assinatura do Termo de consentimento Livre Esclarecido por todos os participantes do estudo. 


\subsubsection{Coleta dos dados}

\section{Grupo de comparação}

Primeiramente, foi solicitado o parecer favorável à pesquisa para a Divisão de Enfermagem do Hospital Universitário da Universidade de São Paulo, após a aprovação, foram realizadas reuniões com as diretoras de serviço e enfermeiras-chefes de cada seção, no sentido de prestar esclarecimentos sobre a coleta de dados e os objetivos do estudo. Em seguida, foi solicitado às diretoras de serviço e enfermeiras-chefes, que informassem a existência de estudo aos enfermeiros alocados em suas unidades de responsabilidade.

A coleta de dados foi realizada em três turnos (manhã, tarde, noite, nos meses de janeiro e fevereiro de 2010). Aos enfermeiros que foram encontrados trabalhando nos respectivos períodos, dispostos a participar do estudo, foram distribuídos um envelope com o instrumento de coleta de dados, uma folha de instruções (ANEXO 5) e esclarecimentos e uma outra para registro dos dados profissionais dos mesmos sempre no final de cada turno visando interferir o mínimo possível no andamento da rotina de trabalho do profissional.

Com vistas a garantir a não identificação dos sujeitos, estes assinaram o Termo de Consentimento Livre e Esclarecido (ANEXO 7) que foi devolvido no primeiro contato com o enfermeiro, após este concordar em participar do estudo.

A devolução dos instrumentos preenchidos ocorreu de 24 a 48 horas, após sua entrega, tendo sido feita ao autor da pesquisa, também dentro dos envelopes, e conforme combinado estes não continham qualquer identificação. Distribuiu-se entre os participantes 140 questionários, dos quais $101(72,1 \%)$ foram devolvidos no período compreendido entre 19 de janeiro de 2010 a 10 de fevereiro de 2010, portanto, dos 140 (100\%) sujeitos que se dispuseram a participar do estudo, 39 (28\%) não devolveram o instrumento, mesmo após várias solicitações do autor. Alegaram falta de 
tempo, perda do instrumento e esquecimento. Diante disso, foram excluídos da pesquisa.

\section{Grupo Experimental}

Para iniciar a coleta de dados do GE, foi solicitado o parecer favorável à pesquisa para a Coordenação do Curso SUPERA $3^{a}$ Edição e da SENAD e, após a aprovação, foi realizado o contato com os mesmos via endereço eletrônico e via telefone no sentido de convidá-los a participar do estudo. Nesse momento, deu-se ciência aos sujeitos sobre os propósitos do estudo, garantia de sigilo, direito de recusar a participar, bem como da voluntariedade da participação.

Uma vez que o sujeito aceitou participar do estudo foram enviados os instrumentos de coleta dos dados via correio-eletrônico. Com os instrumentos de coleta, foram enviadas as instruções (ANEXO 6) de preenchimento do instrumento para a devolução dos instrumentos ao endereço eletrônico da autora.

No momento da coleta de dados, período compreendido pelos meses de fevereiro e março de 2010, foram distribuídos 140 questionários por correio eletrônico entre os enfermeiros que concluíram o curso, dos quais 84 $(60 \%)$ foram devolvidos.

\subsection{Procedimentos para análise dos dados}

Os dados foram agrupados em banco de dados Statistical Package for the Social Sciences, versão 17.0 (SPSS), onde foram realizados todos os testes estatísticos. A análise foi dividida em duas etapas, uma análise descritiva das informações sociodemográficas da população estudada e a segunda, foi à análise dos dados obtidos com a aplicação da escala de conhecimento e da EAFAAA.

Buscando a relação entre as atitudes e os conhecimentos, além de comparar os resultados obtidos entre os dois grupos (GC e GE), foram 
Janaina Soares

realizadas estatísticas descritivas básicas e utilizados testes paramétricos e não paramétricos para comparação entre os grupos dos resultados, segundo as variáveis socioeconômicas, demográficas e de nível de conhecimentos e atitudes.

Conforme orienta Vargas (2005), para a avaliação da escala, foram atribuídos 1 e 2 pontos às categorias de respostas desfavoráveis à questão proposta; 4 e 5 pontos, às categorias favoráveis e 3 aos níveis intermediários da resposta. Assim, a média de escore elevada foi considerada indicativa de atitudes positivas, e a média de escore baixa relacionada às atitudes negativas. Para analisar os conhecimentos, foram obtidas as notas, totalizando-se as respostas corretas, as respostas em branco ou não sei que tiveram pontuação zerada. Considerando que a maioria dos itens da EAFAAA têm sentido negativo, isto é, caso a pessoa demonstre atitude concordante com este item, ela terá uma atitude negativa com relação ao alcoolista, inverteu-se a pontuação dada a esse tipo de questão que passou a ser considerada com valores inversos $(1=5),(2=4)$, $(3=3), \quad(4=2), \quad(5=1)$. De maneira que concordar com um item negativo recebeu pontuações mínimas e discordar de tais itens, pontuação máxima.

Para análise dos dados obtidos pelos participantes na EAFAAA, os escores dos fatores foram calculados, de acordo com as respostas dos participantes em cada um dos itens que podia variar de 1 a 5 . E o escore geral - atitude perante o alcoolista, de forma geral podia varia de 5 a 25 . Dessa forma, o cálculo de pontuação dos escores dos fatores foi realizado da seguinte maneira: os valores assinalados por indivíduo, ou seja, um indivíduo que tenha tido uma pontuação total 81 pontos no Fator 1, obteve uma média de 2,45 nesse fator, uma vez que o mesmo é composto de 33 itens. Já o escore geral, foi representado pela soma dos escores dos fatores.

O questionário de conhecimento foi composto por 12 questões e cada questão respondida corretamente obteve valor um e a cada questão deixada em branco ou respondida de forma incorreta, valor zero. A pontuação do conhecimento foi obtida somando-se as notas de cada questão, podendo ir de 0 a 12. 
Para verificar a relação entre as atitudes e os conhecimentos dos participantes, foi feita uma regressão logística como uma forma de encontrar variáveis que pudessem diferenciar os indivíduos quanto às suas atitudes. Nesse tipo de modelo a variável resposta é binária, dividiu-se Atitude Geral em duas categorias: Atitude Negativa, valores menores ou iguais a 15 da variável Atitude Geral, e Atitude Positiva, valores maiores ou iguais a 16 da variável Atitude Geral. Esse ponto de corte foi estabelecido, de acordo com o seguinte raciocínio, uma vez que são cinco fatores na EAFAAA a soma dos escores de um indivíduo que tenha se posicionado de forma neutra (3- Estou em dúvida) em todos os itens seria 15, ou seja, ao multiplicar-se a pontuação média (3) pelo número de Fatores (5) obteve-se um escore total igual a $15(3 \times 5=15)$. Dessa forma, escores que obtiveram 1 ponto acima dessa média foram indicativos de atitudes positivas e 1 ponto abaixo, como atitudes negativas.

Estabelecido esse ponto de corte, realizou-se uma análise univariada, no intuito de verificar a influência das variáveis do estudo nas atitudes dos enfermeiros frente ao álcool, alcoolismo e alcoolista. Nesse sentido, incluíram-se no modelo de análise as variáveis sociodemográficas (Sexo, Idade, Estado Civil, Experiência com Alcoolistas, Carga-horária, Possui Pós (se cursou pós graduação), Preparo (se possui preparo para lidar com dependentes), Tempo de Profissão, Tipo de Pós (especialização, mestrado ou doutorado) e Grupo), com o intuito de identificar a associação entre cada uma das variáveis. As variáveis que demonstraram associação significativa na regressão logística univariada foram incluídas no modelo múltiplo, o nível de significância adotado foi de $5 \%(p<0,05)$, e as estatísticas com $p$ menor do que ou igual a 0,05 foram consideradas significantes. Nesta análise demonstraram significância estatística as variáveis: Carga-horária, Ter cursado pós-graduação e ter recebido preparo para atuar com dependentes químicos. As variáveis que demonstraram associação estatística na regressão univariada, foram introduzidas no modelo múltillpo de Regressão mantendo significância estatística (Tabela 16). 
Resultados 


\section{RESULTADOS}

\subsection{CARACTERIZAÇÃO GERAL DA POPULAÇÃO ESTUDADA}

Um total de 185 (66\%) sujeitos, dentre os 280 enfermeiros selecionados, aceitou participar do estudo, e dos 140 questionários entregues para o GC, apenas 101(72,1\%) foram devolvidos. Desses participantes, três eram diretores de seção; 15 enfermeiros-chefe; 82 enfermeiros. No GE dos 118 indivíduos que se dispuseram a participar da pesquisa, 34 não devolveram o instrumento mesmo após várias solicitações do autor, sendo assim, a amostra constituiu-se de 84 (60\%) enfermeiros, divididos da seguinte maneira, de acordo com seu local de trabalho: 70 enfermeiros estavam alocados no momento da coleta dos dados em Unidades Básicas de Saúde (UBS); seis Centros de Atenção Psicossocial Álcool e outras Drogas (CAPS AD); seis Serviços Hospitalares e duas Prefeituras. 
Tabela 1 - Distribuição das variáveis incluídas no estudo ( $N=185)$

\begin{tabular}{|c|c|c|c|c|}
\hline \multirow[t]{2}{*}{ Variáveis } & \multicolumn{2}{|c|}{ Controle } & \multicolumn{2}{|c|}{ Experimental } \\
\hline & $(n=101)$ & $\%$ & $(n=84)$ & $\%$ \\
\hline \multicolumn{5}{|l|}{ Idade } \\
\hline 20 a 26 anos & 7 & 6,9 & 26 & 30,9 \\
\hline 27 a 31 anos & 29 & 28,7 & 16 & 19 \\
\hline 32 a 39 anos & 14 & 13,9 & 23 & 27,4 \\
\hline 40 a 45 anos & 23 & 22,8 & 11 & 13 \\
\hline$>45$ anos & 28 & 27,7 & 7 & 8,3 \\
\hline Omissos & 0 & 0 & 1 & 1,2 \\
\hline \multicolumn{5}{|l|}{ Sexo } \\
\hline Feminino & 91 & 90,1 & 73 & 86,9 \\
\hline Masculino & 10 & 9,9 & 11 & 13,1 \\
\hline \multicolumn{5}{|l|}{ Estado civil } \\
\hline Casado & 53 & 52,5 & 39 & 46,4 \\
\hline Solteiro & 40 & 39,6 & 37 & 44 \\
\hline Viúvo & 1 & 1 & 0 & 0 \\
\hline Separado & 3 & 3 & 4 & 4,8 \\
\hline Outros & 4 & 4 & 4 & 4,8 \\
\hline \multicolumn{5}{|l|}{ Tempo de Profissão } \\
\hline Até 4 anos & 18 & 17,8 & 38 & 45,2 \\
\hline 5 a 8 anos & 23 & 22,8 & 16 & 19 \\
\hline 9 a 17 anos & 19 & 18,8 & 18 & 21,4 \\
\hline Acima de 17 anos & 41 & 40,6 & 10 & 11,9 \\
\hline Omissos & 0 & 0 & 2 & 2,4 \\
\hline \multicolumn{5}{|l|}{ Experiência Profissional } \\
\hline $\operatorname{Sim}$ & 46 & 46,9 & 44 & 53 \\
\hline Não & 52 & 53,1 & 39 & 47 \\
\hline Omissos & 3 & 3 & 1 & 1,2 \\
\hline \multicolumn{5}{|l|}{ Instituição de Formação } \\
\hline Pública & 40 & 39,6 & 28 & 33,7 \\
\hline Privada & 61 & 60,4 & 55 & 66,3 \\
\hline \multicolumn{5}{|l|}{ Pós-Graduação } \\
\hline $\operatorname{Sim}$ & 88 & 88 & 63 & 75 \\
\hline Não & 12 & 12 & 21 & 25 \\
\hline \multicolumn{5}{|l|}{ Tipo de Pós } \\
\hline Especialização & 66 & 71,7 & 54 & 87,1 \\
\hline Mestrado & 19 & 20,7 & 7 & 11,3 \\
\hline Doutorado & 7 & 7,6 & 1 & 1,6 \\
\hline Omissos & 9 & 8,9 & 22 & 26,2 \\
\hline \multicolumn{5}{|l|}{ Preparo } \\
\hline $\operatorname{Sim}$ & 39 & 39 & 39 & 47 \\
\hline Não & 61 & 61 & 45 & 53 \\
\hline \multicolumn{5}{|l|}{ Carga-horária } \\
\hline 5 horas & 8 & 22,9 & 4 & 10,5 \\
\hline 10 horas & 4 & 11,4 & 5 & 13,2 \\
\hline 15 horas & 4 & 11,4 & 1 & 2,6 \\
\hline 20 horas & 4 & 11,4 & 3 & 7,9 \\
\hline 30 horas & 4 & 11,4 & 6 & 15,8 \\
\hline Outras & 11 & 31,4 & 19 & 50 \\
\hline Omissos & 66 & 65,3 & 46 & 54,8 \\
\hline \multicolumn{5}{|l|}{ Experiência Clínica } \\
\hline Antes da graduação & 0 & 0 & 9 & 16,4 \\
\hline Durante a graduação & 20 & 32,3 & 24 & 43,6 \\
\hline Após a graduação & 42 & 67,7 & 21 & 38,2 \\
\hline Durante e após a graduação & 0 & 0 & 1 & 1,8 \\
\hline Omissos & 39 & 38,6 & 29 & 34,5 \\
\hline
\end{tabular}


Os dados da Tabela 1 mostram o número de sujeitos, segundo as alternativas de respostas, e as porcentagens totais, considerando as repostas dos avaliados, excluindo os que não responderam e a porcentagem válida que considera apenas os indivíduos que responderam a todas as questões.

Com relação à variável sexo, os dois grupos apresentam grande maioria dos profissionais do sexo feminino. No GC, representam $90,1 \%$ da amostra e no GE, $86,9 \%$.

Com relação à faixa etária, esses profissionais têm idade entre 20 e 63 anos, e estão divididos em cinco faixas etárias. A maioria do GC $(65,4 \%)$ concentra-se nas faixas etárias correspondentes às idades entre 27 e 45 anos, e a maioria do GE (62,9\%) concentra-se nas faixas etárias correspondentes às idades entre 20 e 39 anos. Esses profissionais têm tempo de profissão de 0 a 30 anos, divididos em quatro faixas. A maioria dos profissionais do GC $(59,4 \%)$ distribui-se pelas faixas correspondentes até 17 anos de profissão, enquanto a maioria do GE $(64,2 \%)$ distribui-se pelas faixas correspondentes até 8 anos de profissão.

De acordo com a experiência profissional com alcoolistas, os grupos GC e GE são bastante próximos quanto à distribuição. No primeiro, 46,9\% possuem esse tipo de experiência; no segundo, 53\%. Os profissionais do GC, $60,4 \%$ formaram-se em instituições privadas; os do GE, $66,3 \%$.

Em relação à pós-graduação dos indivíduos do GC, 88\% fizeram pósgraduação e $75 \%$ do GE.

Referente ao tipo de pós-graduação cursado, os profissionais do GC, $71,7 \%$ fizeram especialização, 20,7\% mestrado e 7,6\% doutorado, contra $87,1 \%, 11,3 \%$ e $1,6 \%$, respectivamente, do GE.

Quanto ao preparo para atuar com dependentes químicos, dentre os indivíduos do GC, 39\% relataram possuir preparo para atuar com dependentes químicos e $47 \%$ do GE também possuem esse preparo.

Quanto à carga-horária, observou-se que a maioria dos sujeitos informou ter tido outras cargas-horária de preparo para atuar com 
dependentes químicos diferentes daquelas sugeridas no instrumento de coleta, o que pode ser indicativo de que ou os participantes tiveram menos horas do que o mínimo em que poderiam colocar ou mais, o que não se pode confirmar em razão da própria característica do estudo. Chama a atenção ainda o alto índice de participantes que não respondem a essa questão, perfazendo $65,3 \%$ do GC e $54,8 \%$ do GE, o que pode ser indicativo de que não tenham respondido pelo fato de não terem recebido tal preparo durante a formação, conforme ilustram os dados do Gráfico 2 abaixo:

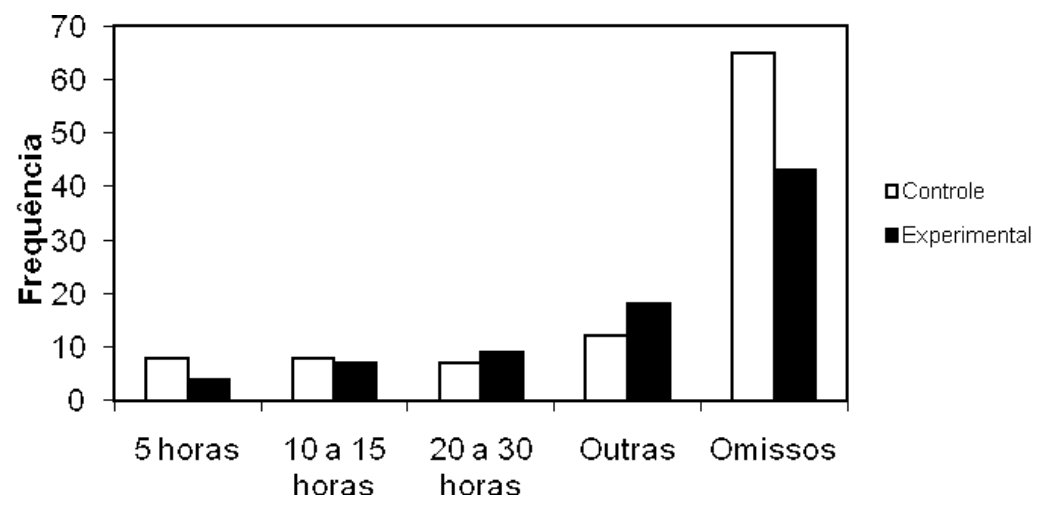

Gráfico 2 - Distribuição da variável "Carga horária do curso para atuar com dependentes químicos" nos dois grupos

De acordo com os profissionais do GC, 32,3\% adquiriram experiência prática durante a graduação e 67,7\%, após a graduação. Do GE, 43,6\% e $38,2 \%$, respectivamente, ainda houve profissionais desse grupo que afirmaram ter tal experiência durante e após a graduação, porém mais de $30 \%$ dos sujeitos da pesquisa de ambos os grupos não responderam tal questão. 


\subsection{CONHECIMENTO FRENTE AO ÁLCOOL E AO ALCOOLISMO}

Ao se analisar as respostas dadas ao questionário de conhecimento, observou-se que a maioria dos participantes pontuou entre 5 e 8 pontos, quando foram analisados os dados de acordo com cada grupo (GC e GE) observou-se que no GC $61 \%$ sujeitos pontuaram entre 5 e 7 pontos no questionário de conhecimentos, com uma média de 6 pontos. Já no GE, $61,7 \%$ dos participantes alocados nesse grupo pontuaram entre 5 e 7 pontos, perfazendo uma média de 6 pontos.

Tabela 2 - Distribuição dos acertos nas questões de conhecimento para os dois grupos

\begin{tabular}{|c|c|c|c|c|c|c|}
\hline \multicolumn{7}{|c|}{ Conhecimento } \\
\hline \multirow{3}{*}{$\begin{array}{c}\text { Nota } \\
\mathbf{0}\end{array}$} & \multicolumn{4}{|c|}{ Grupo } & \multirow{2}{*}{\multicolumn{2}{|c|}{ Total }} \\
\hline & \multicolumn{2}{|c|}{ Controle } & \multicolumn{2}{|c|}{ Experimental } & & \\
\hline & 0 & $0,0 \%$ & 3 & $3,7 \%$ & 3 & $1,7 \%$ \\
\hline 1 & 0 & $0,0 \%$ & 0 & $0,0 \%$ & 0 & $0,0 \%$ \\
\hline 2 & 4 & $4,0 \%$ & 3 & $3,7 \%$ & 7 & $3,9 \%$ \\
\hline 3 & 6 & $6,0 \%$ & 5 & $6,2 \%$ & 11 & $6,1 \%$ \\
\hline 4 & 14 & $14,0 \%$ & 9 & $11,1 \%$ & 23 & $12,7 \%$ \\
\hline 5 & 19 & $19,0 \%$ & 15 & $18,5 \%$ & 34 & $18,8 \%$ \\
\hline 6 & 21 & $21,0 \%$ & 21 & $25,9 \%$ & 42 & $23,2 \%$ \\
\hline 7 & 21 & $21,0 \%$ & 14 & $17,3 \%$ & 35 & $19,3 \%$ \\
\hline 8 & 13 & $13,0 \%$ & 5 & $6,2 \%$ & 18 & $9,9 \%$ \\
\hline 9 & 2 & $2,0 \%$ & 6 & $7,4 \%$ & 8 & $4,4 \%$ \\
\hline 10 & 0 & $0,0 \%$ & 0 & $0,0 \%$ & 0 & $0,0 \%$ \\
\hline 11 & 0 & $0,0 \%$ & 0 & $0,0 \%$ & 0 & $0,0 \%$ \\
\hline 12 & 0 & $0,0 \%$ & 0 & $0,0 \%$ & 0 & $0,0 \%$ \\
\hline Total & 100 & $100,0 \%$ & 81 & $100,0 \%$ & 181 & $100,0 \%$ \\
\hline
\end{tabular}

Para melhor visualizar os acertos dos dois grupos no questionário de conhecimentos, optou-se por analisar suas respostas, de acordo com cada questão, apresentando as estatísticas descritivas em tabelas conforme segue:

Analisando as respostas dadas à questão 1 referente ao uso nocivo de álcool do questionário, verificou-se que o GE teve mais acertos do que o GC. 
Tabela 3 - Distribuição dos acertos segundo a Questão 1 referente ao uso nocivo de álcool do questionário de conhecimento.

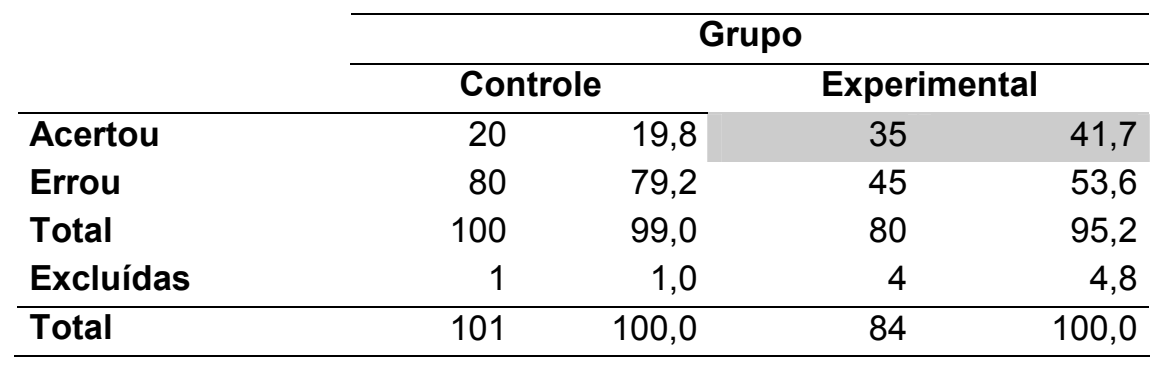

Quando foram verificados os conhecimentos dos dois grupos para diferenciar o diagnóstico referente ao padrão de uso de álcool; nos dois grupos, observou-se que $79,2 \%$ do GC e $53,6 \%$ do GE não conseguem diferenciar quadros de dependência e uso nocivo.

De acordo com a OMS (1998), dependência pode ser caracterizada como o uso de repetidas doses de álcool ou outra droga para evitar sensações ruins diferente de uso nocivo que equivale a um padrão de uso qualquer que leva a causar algum dano à saúde do individuo físico ou mental.

Conforme com os dados da Tabela 4, notou-se que a maioria dos participantes de ambos os grupos não consegue diferenciar tais quadros descritos abaixo.

Tabela 4 - Distribuição dos acertos segundo a Questão 2 referente a "Sindrome de abstinência do álcool, Alucinose alcoólica e Delirium Tremens " do questionário de conhecimento.

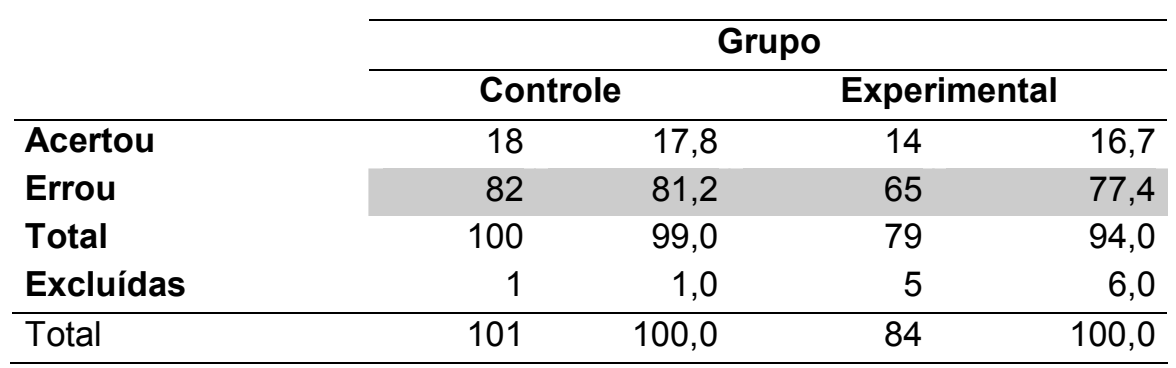

A Síndrome de abstinência do álcool refere-se a um grupo de sintomas de configuração e gravidade variáveis que ocorrem, após a cessação ou redução do uso de uma substância psicoativa que vinha sendo 
usada repetidamente e, geralmente, após um longo período e/ou em altas doses que podem ser acompanhadas por sinais de alterações fisiológicas e progredir para uma alucinose alcoólica. Esta consiste em alucinações persistentes ou recorrentes, em geral, visuais ou auditivas, que ocorrem com clareza de consciência, mas, que o indivíduo afetado pode ou não reconhecer como irreais e podem ser acompanhadas ou não do delirium tremens que consiste em um estado psicótico agudo que se verifica em indivíduos dependentes de álcool, durante a fase de abstinência. É caracterizado por confusão, desorientação, ideação paranoide, delírios, ilusões, alucinações (tipicamente visuais ou táteis, menos comumente auditivas, olfatórias ou vestibulares), inquietação, distraibilidade, tremores (algumas vezes grosseiros), sudorese, taquicardia e hipertensão. Usualmente, é precedida por sinais de síndrome de abstinência simples. $O$ início do delirium tremens ocorre, usualmente, 48 hs ou mais após a suspensão ou a redução do consumo de álcool, mas pode apresentar-se até 1 semana, após esse período. O delirium tremens deve ser distinguido da alucinose alcoólica, que nem sempre é um fenômeno da abstinência, OMS (1998).

Conforme ilustram os dados da tabela 5, observou-se que a maioria dos participantes em ambos os grupos acertou a questão que se referia aos tipos de intoxicação alcoólica, porém mais de $50 \%$ dos sujeitos do grupo de comparação não souberam diferenciar tal conhecimento.

Tabela 5 - Distribuição dos acertos segundo a Questão 3 referente "intoxicação patológica, aguda e crônica” do questionário de conhecimento.

\begin{tabular}{|c|c|c|c|c|}
\hline \multirow[b]{3}{*}{ Acertou } & \multicolumn{4}{|c|}{ Grupo } \\
\hline & \multicolumn{2}{|c|}{ Controle } & \multicolumn{2}{|c|}{ Experimental } \\
\hline & 47 & 46,5 & 53 & 63,1 \\
\hline Errou & 53 & 52,5 & 27 & 32,1 \\
\hline Total & 100 & 99,0 & 80 & 95,2 \\
\hline Excluídas & 1 & 1,0 & 4 & 4,8 \\
\hline Total & 101 & 100,0 & 84 & 100,0 \\
\hline
\end{tabular}


Conforme o CID-10, a intoxicação aguda ou embriaguez refere-se à ingestão de álcool, resulta na mudança de padrões das funções e das respostas fisiológicas e psicológicas,com comprometimento da consciência e do controle do comportamento. Quando essa ingestão passa a ficar mais prolongada o individuo passa a ter efeitos deletérios crônicos com o surgimento de hepatite ou outras doenças crônicas (intoxicação crônica). Já a intoxicação patológica consiste em uma síndrome caracterizada por excitação extrema, com componentes agressivos e violentos e, frequentemente, ideias de perseguição, após o consumo de uma quantidade desproporcionalmente pequena de álcool. Dura várias horas e termina com o adormecer do paciente e, normalmente, há uma amnésia completa do episódio (OMS, 1998).

No que se refere aos dados da Tabela 6 , os resultados sobre o conhecimento da questão 4 relacionada a diferenciar "Tolerância, Intoxicação, Dependência e Uso nocivo ou prejudicial", foi observado que $64,3 \%$ do grupo experimental acertaram tal questão e $67,3 \%$ do grupo de comparação não souberam diferenciar tais conceitos.

Segundo o CID-10, a tolerância é um estado, no qual o indivíduo necessita aumentar a quantidade da dose de álcool para sentir os efeitos da droga, ou seja, para o individuo se intoxicar, ele precisa ingerir uma dose cada vez maior; entretanto, o uso prejudicial ou abusivo é caracterizado pelas consequências além de fisiológicas e psicológicas (uso nocivo) e também sociais (OMS, 1998).

Tabela 6 - Distribuição dos acertos segundo a Questão 4 referente a "Tolerância, Intoxicação, Dependência e Uso nocivo ou prejudicial" do questionário de conhecimento.

\begin{tabular}{|c|c|c|c|c|}
\hline \multirow[b]{3}{*}{ Acertou } & \multicolumn{4}{|c|}{ Grupo } \\
\hline & \multicolumn{2}{|c|}{ Controle } & \multicolumn{2}{|c|}{ Experimental } \\
\hline & 32 & 31,7 & 54 & 64,3 \\
\hline Errou & 68 & 67,3 & 26 & 31,0 \\
\hline Total & 100 & 99,0 & 80 & 95,2 \\
\hline Excluídas & 1 & 1,0 & 4 & 4,8 \\
\hline Total & 101 & 100,0 & 84 & 100,0 \\
\hline
\end{tabular}


Nos dados da tabela 7, é observado que o GC teve mais acertos, porém quando vemos as questões $\mathrm{A}$ e $\mathrm{F}$ o mesmo teve alto índice de erros em relação ao GE que se mostra levemente equilibrado quanto à porcentagem de acertos e erros. 
Janaina Soares

Tabela 7 - Distribuição dos acertos segundo a Questão 5 de verdadeiro ou falso do questionário de conhecimento.

\begin{tabular}{|c|c|c|c|c|c|c|c|c|}
\hline \multirow{4}{*}{ Questões } & \multicolumn{8}{|c|}{ Grupo } \\
\hline & \multicolumn{4}{|c|}{ Controle $(n=101)$} & \multicolumn{4}{|c|}{ Experimental $(n=84)$} \\
\hline & \multicolumn{2}{|c|}{ Acertou } & \multicolumn{2}{|c|}{ Errou } & \multicolumn{2}{|c|}{ Acertou } & \multicolumn{2}{|c|}{ Errou } \\
\hline & $\mathrm{N}$ & $\%$ & $\mathrm{~N}$ & $\%$ & $\mathrm{~N}$ & $\%$ & $\mathrm{~N}$ & $\%$ \\
\hline $\begin{array}{l}\text { A -Um homem adulto pode beber até no } \\
\text { máximo } 2 \text { doses de uísque (total de } 100 \\
\text { ml) por dia. }\end{array}$ & 14 & 14,3 & 84 & 85,7 & 22 & 31 & 49 & 69 \\
\hline $\begin{array}{l}\text { B- A mulher pode beber menos do que } \\
\text { o homem, porque possui } \\
\text { proporcionalmente, maior quantidade } \\
\text { de gordura corporal, o que aumenta a } \\
\text { biodisponibilidade do álcool. }\end{array}$ & 43 & 42,6 & 57 & 56,4 & 33 & 39,3 & 38 & 45,2 \\
\hline $\begin{array}{l}\text { C- A Intervenção Breve (IB) é um tipo } \\
\text { de tratamento não farmacológico que é } \\
\text { eficaz para dependências leves e } \\
\text { usuários nocivos. }\end{array}$ & 64 & 63,4 & 35 & 34,7 & 53 & 63,1 & 18 & 21,4 \\
\hline $\begin{array}{l}\text { D- A IB pode ser aplicada em } \\
\text { consultas de } 10 \text { a } 15 \text { minutos por } \\
\text { médicos, enfermeiros, psicólogos, e } \\
\text { outros profissionais treinados. }\end{array}$ & 67 & 66,3 & 32 & 31,7 & 57 & 67,9 & 14 & 16,7 \\
\hline $\begin{array}{l}\text { E- A meta do beber seguro } \\
\text { (socialmente) deve ser evitada para } \\
\text { pacientes que fazem uso nocivo de } \\
\text { bebidas alcoólicas. }\end{array}$ & 94 & 93,1 & 6 & 5,9 & 53 & 63,1 & 18 & 21,4 \\
\hline $\begin{array}{l}\text { F- Para pacientes não motivados ao } \\
\text { tratamento, o médico deve respeitar a } \\
\text { sua opinião e aguardar até que ele se } \\
\text { sinta motivado para iniciar o } \\
\text { tratamento. }\end{array}$ & 31 & 30,7 & 69 & 68,3 & 30 & 35,7 & 41 & 48,8 \\
\hline $\begin{array}{l}\text { G- Pacientes em pré-contemplação } \\
\text { consideram a hipótese de parar de } \\
\text { beber, mas não conseguem mudar de } \\
\text { comportamento em relação a bebida. }\end{array}$ & 83 & 82,2 & 17 & 16,8 & 37 & 44,0 & 34 & 40,5 \\
\hline $\begin{array}{l}\text { H-Uma vez identificada a dependência } \\
\text { do álcool deve-se fazer as primeiras } \\
\text { orientações e encaminhar o paciente } \\
\text { ao especialista. }\end{array}$ & 99 & 98,0 & 1 & 1,0 & 33 & 39,3 & 38 & 45,2 \\
\hline
\end{tabular}




\subsection{ATITUDES FRENTE AO ÁLCOOL, ALCOOLISMO E ALCOOLISTA}

Considerando os 80 itens de atitude, o escore médio dos indivíduos do GC foi de 14,2 ( $s=1,57$ ), e o escore médio dos indivíduos do GE foi de $14,4(s=1,57)$. Portanto, ambos os grupos revelam uma atitude levemente mais positiva (Tabelas 8 e 9 ).

Tabela 8 - Distribuição dos escores de atitude e pontuação de conhecimento para o grupo controle

\begin{tabular}{cccccc} 
& Mínimo & Mediana & Máximo & Média & Desvio Padrão \\
\hline Conhecimento & 2,0 & 6,0 & 9,0 & 5,7 & 1,7 \\
Escore Fator 1 & 1,3 & 3,4 & 4,8 & 3,3 & 0,6 \\
Escore Fator 2 & 1,5 & 3,0 & 4,4 & 3,0 & 0,6 \\
Escore Fator 3 & 1,7 & 2,2 & 3,9 & 2,3 & 0,4 \\
Escore Fator 4 & 1,7 & 2,4 & 3,8 & 2,4 & 0,5 \\
Escore Fator 5 & 1,5 & 3,1 & 4,8 & 3,1 & 0,7 \\
\hline Atitude Geral & 10,7 & 14,1 & 18,3 & 14,2 & 1,6 \\
\hline
\end{tabular}

Tabela 9 - Distribuição dos escores de atitude e pontuação de conhecimento para o grupo experimental

\begin{tabular}{cccccc} 
& Mínimo & Mediana & Máximo & Média & Desvio Padrão \\
\hline Conhecimento & 0,0 & 6,0 & 9,0 & 5,6 & 2,0 \\
Escore Fator 1 & 2,7 & 3,9 & 4,9 & 3,9 & 0,5 \\
Escore Fator 2 & 1,2 & 2,9 & 4,3 & 2,9 & 0,7 \\
Escore Fator 3 & 1,7 & 2,1 & 3,3 & 2,2 & 0,3 \\
Escore Fator 4 & 1,5 & 2,3 & 3,5 & 2,4 & 0,5 \\
Escore Fator 5 & 1,2 & 3,0 & 4,7 & 3,1 & 0,7 \\
\hline Atitude Geral & 10,7 & 14,3 & 1,8 & 14,4 & 1,6 \\
\hline
\end{tabular}

Considerando as atitudes divididas por fatores - lembrando que o escore médio para cada fator varia de 1 a 5 , ambos os grupos apresentam como maior escore médio o relacionado ao Fator 1 , ou seja, o que se refere ao Alcoolista. Entretanto, o GE apresentou média 3,9 $(s=0,53)$ ligeiramente maior que o GC, que mostrou média $3,3(s=0,58)$. O segundo maior escore médio para ambos os grupos, foi o relacionado ao Fator 5 , ou seja, o relacionado à Bebida Alcoólica. O GC obteve média 3,1 $(s=0,67)$, e o GE 
$3,1(s=0,72)$. Ambos os grupos apresentaram o terceiro maior escore médio para o Fator 2, relacionado à Etiologia. O GC apresentou média maior que o GE. O primeiro obteve média 3,0 $(s=0,58)$, e o segundo $2,9(s=0,69)$. O quarto maior escore médio dos dois grupos relaciona-se ao Fator 4, referente às Repercussões Decorrentes do Uso/Abuso do Álcool. O GC obteve média $2,4(s=0,54)$, e o GE, média $2,4(s=0,48)$. O escore médio mais baixo apresentado pelos dois grupos foi referente ao Fator 3, relacionado à Doença. O GC apresentou média 2,3 $(s=0,37)$ e o GE, média $2,2(s=0,29)$.

Quando analisamos as atitudes dos grupos de enfermeiros por item da EAFAAA, verificou-se que, de acordo com as respostas, para mais de $50 \%$ de ambos os grupos de enfermeiros, o alcoolista é uma pessoa que não tem limites e são pacientes que não colaboram com o tratamento. O GC $53 \%$ revelaram acreditar que os alcoolistas não têm bom senso, que bebem sem ter a preocupação com o que vai acontecer depois (64\%), que o alcoolista sempre acaba voltando ao serviço de saúde com o mesmo problema (50\%), que é o paciente mais difícil de lidar $(43,4 \%)$, medo da agressividade do alcoolista $(58,4 \%)$, dão muito trabalho pra enfermagem $(62,4 \%)$, devo cuidar do alcoolista mesmo que ele não queira (58\%), não colaboram com o tratamento $(43,6 \%)$ e são difíceis de tratar $(66 \%)$.

Os enfermeiros do GE revelaram que concordam também que o paciente alcoolista é uma pessoa sem limites (50\%), que são pacientes violentos $(56,1 \%)$, que o paciente alcoolista depende da bebida para tudo $(58,3 \%)$, que é um caso perdido $(51,2 \%)$, que o alcoolismo é perda da identidade e da moral (82\%), que os alcoolistas têm sua situação de vida precária $(84,4 \%)$, que os fatores hereditários influenciam no abuso do alcool (59\%), que buscam nas bebidas soluções para seus problemas afetivos $(85,5 \%)$, que o desajuste familiar pode levar ao alcoolismo $(51,8 \%)$, que pessoas tímidas ou inibidas têm maior chance de desenvolver o alcoolismo $(65,1 \%)$, que todo alcoolista tem algo mal resolvido $(66,2 \%)$, ou que tem algo no passado que conduz a beber (59\%), que o alcoolismo está relacionado ao nível de instrução do indivíduo $(61,6 \%)$, que filhos de alcoolistas têm 
tendência a serem alcoolistas $(60,3 \%)$, que pessoas insatisfeitas abusam do álcool $(95,1 \%)$, que estão fugindo de algum problema $(91,5 \%)$, que têm problemas financeiros $(87,8 \%)$, que o alcoolista é um doente $(95,1 \%)$, que tem baixa autoestima $(97,5 \%)$, são psicologicamente abalados $(98,8 \%)$, não conseguem controlar sua ingestão alcoólica (97,6\%), que o alcoolismo é uma doença $(84,2 \%)$, que a equipe precisa de treinamento para trabalhar com alcoolista $(75,6 \%)$, que não adianta ser agressivo com o paciente alcoolista $(91,5 \%)$, que é preciso tomar cuidado ao trabalhar com paciente alcoolista $(93,9 \%)$, que o alcoolista deve ser encaminhado para a psiquiatria $(81,7 \%)$, bebe para fugir da realidade $(95 \%)$, que o alcoolista é uma doente $(93,8 \%)$ e que, para $91,3 \%$ desses enfermeiros, o álcool prejudica as funções mentais.

\subsection{RELAÇÃO ENTRE VARIÁVEIS SOCIODEMOGRÁFICAS, CONHECIMENTO E ATITUDES}

Não foram observadas diferenças nas atitudes entre os grupos, quando os agrupamos de acordo com a variável Sexo. Com relação ao conhecimento, os homens do GC obtiveram, em média, pontuação igual a 5,2 acertos $(s=1,48)$ contra 5,8 acertos $(s=1,65)$, em média das mulheres do mesmo grupo. Já para o GE, a situação inverte-se; as mulheres tiveram, em média, 5,5 acertos $(s=2,05)$ contra $5,8(s=1,81)$ dos homens (Tabela 10).

Tabela 10 - Distribuição dos escores e pontuação de conhecimento segundo a variável "Sexo" para os dois grupos

\begin{tabular}{|c|c|c|c|c|c|c|c|c|}
\hline \multicolumn{9}{|c|}{ Grupo controle } \\
\hline & Frequência & Conhecimento & $\begin{array}{c}\text { Fator } \\
1\end{array}$ & $\begin{array}{c}\text { Fator } \\
2\end{array}$ & $\begin{array}{c}\text { Fator } \\
3\end{array}$ & $\begin{array}{c}\text { Fator } \\
4\end{array}$ & $\begin{array}{c}\text { Fator } \\
5\end{array}$ & Geral \\
\hline Masculino & 10 & 5,2 & 3,5 & 3,1 & 2,2 & 2,2 & 2,8 & 13,8 \\
\hline Feminino & 90 & 5,8 & 3,3 & 3,0 & 2,3 & 2,4 & 3,1 & 14,2 \\
\hline Total & 100 & 5,7 & 3,3 & 3,0 & 2,3 & 2,4 & 3,1 & 14,2 \\
\hline \multicolumn{9}{|c|}{ Grupo experimental } \\
\hline & Frequência & Conhecimento & Fator & Fator & Fator & Fator & Fator & Geral \\
\hline
\end{tabular}




\begin{tabular}{ccccccccc} 
& & & $\mathbf{1}$ & $\mathbf{2}$ & $\mathbf{3}$ & $\mathbf{4}$ & $\mathbf{5}$ & \\
\hline Masculino & 10 & 5,8 & 4,0 & 3,0 & 2,2 & 2,2 & 2,8 & 14,2 \\
\cline { 5 - 9 } Feminino & 71 & 5,5 & 3,8 & 2,9 & 2,2 & 2,4 & 3,1 & 14,4 \\
\hline Total & 81 & 5,6 & 3,9 & 2,9 & 2,2 & 2,4 & 3,1 & 14,4 \\
\hline
\end{tabular}

De acordo com os dados da Tabela 11, para a variável Escola de formação, os profissionais do GC que se formaram em escola pública tiveram, em média, 6,1 ( $s=1,67)$ acertos nas questões de conhecimento contra $5,5(s=1,58)$ dos profissionais que se formaram em escola privada do mesmo grupo. Com relação ao GE, os profissionais que se formaram em escola pública tiveram, em média, $5,1(s=2,26)$ acertos contra $5,8(s=1,86)$ dos formados em escola privada. O maior escore de atitude foi observado pelo indivíduos formados em escola pública, pertencentes ao GE, e o menor escore foi observado pelos indivíduos do GC, formados em escola privada.

Tabela 11 - Distribuição dos escores de atitude e pontuação de conhecimento segundo a variável "Escola de Formação" para os dois grupos

\begin{tabular}{|c|c|c|c|c|c|c|c|c|}
\hline \multicolumn{9}{|c|}{ Grupo controle } \\
\hline & Frequência & Conhecimento & $\begin{array}{c}\text { Fator } \\
1\end{array}$ & $\begin{array}{c}\text { Fator } \\
2\end{array}$ & $\begin{array}{c}\text { Fator } \\
3\end{array}$ & $\begin{array}{c}\text { Fator } \\
4\end{array}$ & $\begin{array}{c}\text { Fator } \\
5\end{array}$ & Geral \\
\hline Pública & 40 & 6,1 & 3,4 & 3,0 & 2,3 & 2,4 & 3,1 & 14,3 \\
\hline Privada & 60 & 5,5 & 3,3 & 3,0 & 2,3 & 2,4 & 3,0 & 14,1 \\
\hline Total & 100 & 5,7 & 3,3 & 3,0 & 2,3 & 2,4 & 3,1 & 14,2 \\
\hline \multicolumn{9}{|c|}{ Grupo experimental } \\
\hline & Frequência & Conhecimento & $\begin{array}{c}\text { Fator } \\
1\end{array}$ & $\begin{array}{c}\text { Fator } \\
2\end{array}$ & $\begin{array}{c}\text { Fator } \\
3\end{array}$ & $\begin{array}{c}\text { Fator } \\
4\end{array}$ & $\begin{array}{c}\text { Fator } \\
5\end{array}$ & Geral \\
\hline Pública & 27 & 5,1 & 3,9 & 3,0 & 2,3 & 2,4 & 3,2 & 14,8 \\
\hline Privada & 54 & 5,8 & 3,8 & 2,9 & 2,1 & 2,3 & 3,0 & 14,2 \\
\hline Total & 81 & 5,6 & 3,9 & 2,9 & 2,2 & 2,4 & 3,1 & 14,4 \\
\hline
\end{tabular}

Pelos dados da Tabela 12, com relação à variável Possui experiência profissional com alcoolistas, não foram notadas grandes diferenças entre os grupos; no entanto, observou-se que: os enfermeiros com este tipo de experiência, tendem a ter, em média, 0,2 acertos a mais que os que não possuem esta experiência. Quanto à atitude, os indivíduos do GC tenderam a ter escores de atitude mais baixos que os indivíduos do GE. 
Tabela 12 - Distribuição dos escores de atitude e pontuação de conhecimento segundo a variável "Possui Experiência Profissional com Alcoolistas" para os dois grupos

\begin{tabular}{|c|c|c|c|c|c|c|c|c|}
\hline \multicolumn{9}{|c|}{ Grupo controle } \\
\hline & Frequência & Conhecimento & $\begin{array}{c}\text { Fator } \\
1\end{array}$ & $\begin{array}{c}\text { Fator } \\
2\end{array}$ & $\begin{array}{c}\text { Fator } \\
3\end{array}$ & $\begin{array}{c}\text { Fator } \\
4\end{array}$ & $\begin{array}{l}\text { Fator } \\
5\end{array}$ & Geral \\
\hline Sim & 46 & 5,8 & 3,3 & 3,0 & 2,3 & 2,3 & 3,1 & 14,0 \\
\hline Não & 52 & 5,6 & 3,4 & 3,0 & 2,4 & 2,5 & 3,1 & 14,3 \\
\hline Total & 98 & 5,7 & 3,3 & 3,0 & 2,3 & 2,4 & 3,1 & 14,2 \\
\hline \multicolumn{9}{|c|}{ Grupo experimental } \\
\hline & Frequência & Conhecimento & $\begin{array}{c}\text { Fator } \\
1\end{array}$ & $\begin{array}{c}\text { Fator } \\
2\end{array}$ & $\begin{array}{c}\text { Fator } \\
3\end{array}$ & $\begin{array}{c}\text { Fator } \\
4\end{array}$ & $\begin{array}{l}\text { Fator } \\
5\end{array}$ & Geral \\
\hline Sim & 38 & 5,6 & 3,9 & 2,9 & 2,2 & 2,2 & 3,1 & 14,3 \\
\hline Não & 42 & 5,4 & 3,9 & 3,0 & 2,1 & 2,5 & 3,0 & 14,5 \\
\hline Total & 80 & 5,6 & 3,9 & 2,9 & 2,2 & 2,4 & 3,1 & 14,4 \\
\hline
\end{tabular}

A respeito da variável Tempo de profissão, verificou-se que, para o GC, as notas mais altas de conhecimento são obtidas pelas pessoas com menor tempo de carreira e a atitude tende a se tornar menos positiva com o passar dos anos. No GE, nada pôde ser afirmado, já que as médias de questões corretas e os escores de atitude oscilaram, o que nos dá a ideia de que como todos passaram pelo mesmo treinamento, o conhecimento deste grupo foi homogeneizado.

Conforme os dados na Tabela 13, a respeito da variável Possui pósgraduação, as pontuações médias de conhecimento do GC são muito próximas, $5,7(s=1,70)$ e $5,6(s=1,08)$ para $\circ \operatorname{sim}$ e 0 não, respectivamente. Para o GE, a maior nota média de conhecimento é do grupo que não possui pós-graduação, com 6,1 acertos médios $(s=2,19$ ), contra 5,4 acertos médios $(s=1,93)$ dos que possuem pós-graduação. Referente à atitude, nota-se que nos dois grupos o escore de quem possui pós, é maior do que de quem não possui e que ainda se percebe um escore 
de atitude do grupo experimental levemente maior relacionado ao grupo controle.

Tabela 13 - Distribuição dos escores de atitude e pontuação de conhecimento segundo a variável "Possui Pós Graduação" para os dois grupos

\begin{tabular}{|c|c|c|c|c|c|c|c|c|}
\hline \multicolumn{9}{|c|}{ Grupo controle } \\
\hline & Frequência & Conhecimento & $\begin{array}{c}\text { Fator } \\
1\end{array}$ & $\begin{array}{c}\text { Fator } \\
2\end{array}$ & $\begin{array}{c}\text { Fator } \\
3\end{array}$ & $\begin{array}{c}\text { Fator } \\
4\end{array}$ & $\begin{array}{c}\text { Fator } \\
5\end{array}$ & Geral \\
\hline Sim & 87 & 5,7 & 3,4 & 3,0 & 2,3 & 2,4 & 3,1 & 14,2 \\
\hline Não & 12 & 5,6 & 3,2 & 2,9 & 2,4 & 2,3 & 3,1 & 13,8 \\
\hline Total & 99 & 5,7 & 3,3 & 3,0 & 2,3 & 2,4 & 3,1 & 14,2 \\
\hline \multicolumn{9}{|c|}{ Grupo experimental } \\
\hline & Frequência & Conhecimento & $\begin{array}{c}\text { Fator } \\
1\end{array}$ & $\begin{array}{c}\text { Fator } \\
2\end{array}$ & $\begin{array}{c}\text { Fator } \\
3\end{array}$ & $\begin{array}{c}\text { Fator } \\
4\end{array}$ & $\begin{array}{c}\text { Fator } \\
5\end{array}$ & Geral \\
\hline Sim & 60 & 5,4 & 3,9 & 3,0 & 2,2 & 2,4 & 3,1 & 14,5 \\
\hline Não & 21 & 6,1 & 3,9 & 2,8 & 2,1 & 2,3 & 3,1 & 14,1 \\
\hline Total & 81 & 5,6 & 3,9 & 2,9 & 2,2 & 2,4 & 3,1 & 14,4 \\
\hline
\end{tabular}

Como esperado, indivíduos do GE que possuem a pós-graduação, tendem a ter uma atitude levemente mais positiva que os indivíduos do GC, em oposição aos indivíduos que não possuem pós- graduação do grupo controle que tendem a ter uma atitude mais negativa que os indivíduos do grupo experimental que não possuem pós-graduação.

Conforme os dados da Tabela 14, quanto à variável Possui preparo para atuar com dependentes, observou-se que aqueles com algum tipo de preparo para lidar com dependentes obtiveram maiores pontuações médias; $6,0(s=1,59)$ para o $G C$, contra $5,6(s=1,67)$ dos que não possuíam preparo no mesmo grupo e $5,8(s=1,99)$ no GE, contra $5,3(s=1,94)$ dos que não possuíam preparo no mesmo grupo. Como esperado, indivíduos do GE que possuem este tipo de treinamento tendem a ter uma atitude mais positiva que os outros. 
Tabela 14 - Distribuição dos escores de atitude e pontuação de conhecimento segundo a variável "Possui Preparo para Lidar com Dependentes" para os dois grupos

Grupo controle

\begin{tabular}{|c|c|c|c|c|c|c|c|c|}
\hline & Frequência & Conhecimento & $\begin{array}{c}\text { Fator } \\
1\end{array}$ & $\begin{array}{c}\text { Fator } \\
2\end{array}$ & $\begin{array}{c}\text { Fator } \\
3\end{array}$ & $\begin{array}{c}\text { Fator } \\
4\end{array}$ & $\begin{array}{c}\text { Fator } \\
5\end{array}$ & Atitude \\
\hline Sim & 39 & 6,0 & 3,5 & 3,0 & 2,3 & 2,4 & 3,1 & 14,2 \\
\hline Não & 60 & 5,6 & 3,3 & 3,0 & 2,3 & 2,4 & 3,1 & 14,1 \\
\hline Geral & 99 & 5,7 & 3,3 & 3,0 & 2,3 & 2,4 & 3,1 & 14,2 \\
\hline \multicolumn{9}{|c|}{ Grupo experimental } \\
\hline & Frequência & Conhecimento & $\begin{array}{c}\text { Fator } \\
1\end{array}$ & $\begin{array}{c}\text { Fator } \\
2 \\
\end{array}$ & $\begin{array}{c}\text { Fator } \\
3\end{array}$ & $\begin{array}{c}\text { Fator } \\
4\end{array}$ & $\begin{array}{c}\text { Fator } \\
5\end{array}$ & Atitude \\
\hline Sim & 39 & 5,8 & 3,9 & 3,0 & 2,2 & 2,3 & 3,3 & 14,8 \\
\hline Não & 42 & 5,3 & 3,8 & 2,9 & 2,1 & 2,4 & 2,8 & 14,0 \\
\hline Geral & 81 & 5,6 & 3,9 & 2,9 & 2,2 & 2,4 & 3,1 & 14,4 \\
\hline
\end{tabular}

Segundo aos dados da Tabela 15, para a variável Idade, e o maior valor de conhecimento para o GC está entre os mais novos, de 20 a 26 anos, com média de acertos 6,6 ( $s=1,60$ ); para o $\mathrm{GE}$, isto ocorre com indivíduos de 40 a 45 anos, com 6,4 acertos médios $(s=1,12)$. Quanto à atitude, para os dois grupos, os mais novos apresentam atitudes mais positivas com relação aos mais velhos.

Tabela 15 - Distribuição dos escores de atitude e pontuação de conhecimento segundo a variável "Idade" para os dois grupos

\begin{tabular}{|c|c|c|c|c|c|c|c|c|}
\hline \multicolumn{9}{|c|}{ Grupo controle } \\
\hline & Frequência & Conhecimento & $\begin{array}{c}\text { Fator } \\
1\end{array}$ & $\begin{array}{c}\text { Fator } \\
2\end{array}$ & $\begin{array}{c}\text { Fator } \\
3\end{array}$ & $\begin{array}{c}\text { Fator } \\
4\end{array}$ & $\begin{array}{c}\text { Fator } \\
5\end{array}$ & Atitude \\
\hline 20 a 26 anos & 7 & 6,6 & 3,3 & 3,1 & 2,3 & 2,5 & 3,2 & 14,3 \\
\hline 27 a 31 anos & 29 & 6,1 & 3,5 & 3,0 & 2,3 & 2,6 & 3,0 & 14,5 \\
\hline 32 a 39 anos & 14 & 6,0 & 3,2 & 2,8 & 2,5 & 2,3 & 3,1 & 13,9 \\
\hline 40 a 45 anos & 23 & 4,9 & 3,3 & 3,1 & 2,3 & 2,3 & 3,1 & 14,1 \\
\hline $\begin{array}{c}\text { Acima de } 45 \\
\text { anos }\end{array}$ & 27 & 5,6 & 3,2 & 3,0 & 2,3 & 2,4 & 3,1 & 14,0 \\
\hline Geral & 100 & 5,7 & 3,3 & 3,0 & 2,3 & 2,4 & 3,1 & 14,2 \\
\hline \multicolumn{9}{|c|}{ Grupo experimental } \\
\hline & Frequência & Conhecimento & $\begin{array}{c}\text { Fator } \\
1 \\
\end{array}$ & $\begin{array}{c}\text { Fator } \\
2\end{array}$ & $\begin{array}{c}\text { Fator } \\
3\end{array}$ & $\begin{array}{c}\text { Fator } \\
4\end{array}$ & $\begin{array}{c}\text { Fator } \\
5\end{array}$ & Atitude \\
\hline 20 a 26 anos & 26 & 5,8 & 4,0 & 2,8 & 2,2 & 2,5 & 3,3 & 14,8 \\
\hline
\end{tabular}


Janaina Soares

\begin{tabular}{ccccccccc}
$\mathbf{2 7}$ a 31 anos & 16 & 5,8 & 4,0 & 3,0 & 2,0 & 2,3 & 3,0 & 14,4 \\
$\mathbf{3 2}$ a 39 anos & 23 & 4,7 & 3,7 & 3,0 & 2,2 & 2,3 & 2,8 & 14,1 \\
$\mathbf{4 0}$ a 45 anos & 9 & 6,4 & 3,7 & 3,4 & 2,1 & 2,1 & 2,9 & 14,3 \\
$\begin{array}{c}\text { Acima de 45 } \\
\text { anos }\end{array}$ & 6 & 6,0 & 3,6 & 2,6 & 1,9 & 2,5 & 3,2 & 13,7 \\
\hline Geral & 80 & 5,6 & 3,9 & 2,9 & 2,2 & 2,4 & 3,1 & 14,4 \\
\hline
\end{tabular}

\subsection{ASSOCIAÇÃO ENTRE AS VARIÁVEIS SOCIODEMOGRÁFICAS E AS ATITUDES DE ENFERMEIROS}

$\mathrm{Na}$ regressão logística múltipla, foram incluídas as variáveis que haviam apresentado significância estatística na análise univariada, observando-se que as variáveis "Carga-horária, ter cursado pósgraduação e possuir preparo para atuar com dependentes químicos" mantiveram-se positivamente associadas às atitudes positivas frente ao álcool, alcoolismo e alcoolista. Os maiores preditores dessa associação foram encontrados para possuir preparo para atuar com dependentes químicos $(z=2,895)$; Carga-horária $(z=2,202)$ e Ter cursado pósgraduação $(z=1,806)$ - (TABELA 16).

Tabela 16 - Regressão logística, análise de relação entre as atitudes frente o álcool, alcoolismo e alcoolista com as variáveis significantes no estudo.

\begin{tabular}{lcccc}
\hline & Estimativa & Erro padrão & z-valor & valor-p \\
\hline Intercepto & -1.213 & 2.200 & -0.551 & 0.581 \\
Estado Civil & -0.447 & 0.379 & -1.180 & 0.238 \\
Experiência & 0.087 & 0.431 & 0.202 & 0.840 \\
Carga-horária & -0.534 & 0.445 & 2.202 & 0.030 \\
Grupo & 0.131 & 0.467 & 0.281 & 0.778 \\
Idade & 0.068 & 0.288 & 0.238 & 0.811 \\
Possui Pós & -0.953 & 0.678 & 1.806 & 0.020 \\
Preparo & -0.781 & 0.412 & 2.895 & 0.050 \\
Tempo de Profissão & 0.056 & 0.322 & 0.176 & 0.860 \\
Sexo & 0.645 & 0.799 & 0.808 & 0.419 \\
Tipo Pós & 0.356 & 0.525 & 0.679 & 0.497 \\
\hline
\end{tabular}


Discussão 


\section{DISCUSSÃO}

Ao considerar a premissa de que o preparo e a capacitação podem exercer influência nos conhecimentos e atitudes dos enfermeiros frente ao álcool, alcoolismo e alcoolista, realizou-se uma pesquisa com objetivo de comparar as atitudes de dois grupos de profissionais enfermeiros frente à questão. A primeira etapa da pesquisa, consistiu na avaliação da semelhança entre os grupos de enfermeiros $e$ as informações sociodemográficas. No que se referiu à variável sexo, predominaram enfermeiros do gênero feminino em ambos os grupos. Quanto à idade, observou-se que o GE foi mais jovem que o GC, o que pode estar vinculado ao tempo de profissão, pois, notou-se que o GC possuía também maior tempo de exercício profissional na enfermagem comparado ao GE, indicando que o GE era predominantemente mais jovem em idade e tempo de profissão.

Quanto à experiência profissional com alcoolistas, em geral, cerca da metade dos profissionais enfermeiros pesquisados já teve experiência profissional com alcoolistas. Os enfermeiros da atenção hospitalar podem ter maior facilidade para identificar os usuários de álcool pelo estado debilitado, que, geralmente, o paciente chega ao hospital, mas, apesar do crescente fluxo de atendimento de pacientes com problemas relacionados ao uso e abuso de álcool, este cliente passa despercebido pelos enfermeiros quando o paciente não chega a esse serviço em estado de intoxicação ou alcoolizado, sobretudo, quando o mesmo paciente alcoolista chega a este serviço em estado "normal". Nem sempre os enfermeiros identificam problemas relacionados ao uso de álcool ou quando identificam não se sentem preparados para cuidar desse paciente. Embora os enfermeiros mantenham contato direto com essa clientela, sentem dificuldade para identificar e orientar os usuários sobre o consumo e abuso de álcool (Deehan et al., 2002). 
O GC revelou maior tempo no exercício da profissão, mas observouse que mostrou pouca experiência profissional com alcoolistas. De acordo com literatura, os enfermeiros de instituições hospitalares, indicam não ter habilidades suficientes para identificar e tratar o paciente alcoolista, apesar da crescente demanda em instituições hospitalares de pacientes com problemas devido o uso/abuso de álcool (Noto et al., 2002).

De modo geral, a maioria dos enfermeiros de ambos os grupos foi formado em instituições privadas e relatou ter algum tipo de pós-graduação, além de possuir alguma especialização.

Neste estudo, a maioria dos enfermeiros pesquisados realizou pósgraduação em saúde da família, saúde pública ou específicas dos setores hospitalares.

Os estudos realizados por Heinemann e Rhodes (1967) e Silva (2005) evidenciaram que enfermeiros com maior nível formação independente a área de atuação tendem a ter atitudes mais positivas quanto aos problemas relacionados ao uso do álcool, sugerindo que, quanto maior o conhecimento do enfermeiro melhores serão as atitudes frente o paciente alcoolista ou, ainda, os enfermeiros que trabalham diretamente com essa população de pacientes ou que trabalham em locais de tratamento específicos têm um cuidado mais humanista com tais pacientes (Van, Gabrynowicz, 1977; Gross, Lismam, 1979; Pinikahana et al., 2002).

No que se refere ao preparo, mais da metade dos grupos informou não ter recebido nenhum tipo de preparo para atuar com dependentes químicos durante sua formação em enfermagem, e os que receberam algum preparo, a maioria respondeu ter tido carga-horária de 5 horas, mais de $30 \%$ do GC e $50 \%$ do GE apontaram a alternativa "outras", dentre as cargashorárias questionadas (5h,10h,15h,20,h e 30h), sugerindo que esses enfermeiros, em sua maioria, podem ter tido carga-horária incipiente ou menor que $5 \mathrm{~h}$ na área de dependência química durante sua graduação. Corroborando esse resultado, estudo recente realizado com estudantes de enfermagem de escolas privadas evidenciou que, em média, esses 
estudantes têm recebido $3 \mathrm{~h}$ de conteúdos relacionados à temática durante a graduação (Vargas, 2010b).

Além disso, verificou-se que cerca de $60 \%$ dos enfermeiros em dos dois grupos não apontaram nenhuma carga-horária, podendo indicar que a maioria não tenha recebido preparo na área de álcool e outras drogas durante sua formação em enfermagem.

Diante deste dado, é imprescindível que sejam operadas mudanças, como a inclusão de disciplinas especificamente voltadas à área de álcool e outras drogas ou a remodelação das já existentes, para garantir a cargahorária teórico-prática suficiente, apesar do consenso entre os pesquisadores (Lopes, Luís 2005; Vargas, Luís, 2008a; Lopes, Pessanha 2008) e das recomendações do MS para melhorar as estratégias de formação e capacitação dos profissionais de saúde para o atendimento de pacientes com problemas relacionados ao álcool e outras drogas (Brasil, 2004). Atualmente, o ensino formal na área da enfermagem sobre o uso e abuso de drogas parece não corresponder às reais necessidades que a temática vem impondo à sociedade nos últimos anos (Lopes, Luís, 2005).

No que se refere à experiência prática, apenas enfermeiros do GE indicaram ter tido tal vivência antes e durante a graduação. A maioria dos enfermeiros do GE teve essa vivência durante a graduação, evidenciando que nos dois grupos foram significativos os profissionais que relataram ter tido alguma experiência com pacientes com problemas relacionados às substâncias psicoativas, quer durante a graduação, quer no exercício profissional.

Para Lopes e Luís, (2005), a graduação constitui-se em um momento fundamental para desfazer a visão do senso-comum e construir ou ampliar a visão do profissional ou futuro profissional sobre a realidade dessa problemática. Ainda para os autores citados, o enfermeiro que nunca teve experiência com usuários de álcool e outras drogas, nem teve nenhum tipo de preparo na área durante a graduação provavelmente terá atitudes moralistas ou de sensocomum frente a esses pacientes. 
Mais de $30 \%$ dos enfermeiros de ambos os grupos não responderam à questão sobre ter tido ou não experiência clínica com alcoolistas, confirmando mais uma vez que podem não ter tido formação suficiente em álcool e drogas durante a graduação para identificar esses pacientes nos atendimentos cotidiano (Bartek, Lindeman, Newton, 1988).

Ainda sobre esse assunto, Lucca e Vargas (2006), evidenciam um baixo percentual de enfermeiros que revelou contato frequente com pacientes alcoolistas. Para esses autores, o fato pode estar relacionado à falta de preparo do enfermeiro ao reconhecer o alcoolismo e sua relação com as patologias clínicas, uma vez que não reconheçam o alcoolismo como associado a outras patologias, é compreensível que revele pouco contato com alcoolistas em seu cotidiano de trabalho.

Com relação ao conhecimento e às atitudes dos participantes frente ao álcool, alcoolismo e alcoolista, embora tenha encontrado resultados semelhantes quanto às notas obtidas no questionário de conhecimento entre os grupos de enfermeiros, quando foram analisadas as perguntas individualmente, notou-se quanto ao padrão de uso de álcool (Questão 1), o GC apresentou maior dificuldade para diferenciar os dois padrões de uso, e consequentemente, mostrou maior número de respostas erradas $(79,2 \%)$.

Já na questão $5 G$ referente ao estágio motivacional do paciente e a questão $5 \mathrm{H}$ sobre a dependência do álcool, o GC obteve maior conhecimento, tendo uma porcentagem de acertos de $82,2 \%$ e $98 \%$, respectivamente. Quanto ao GE, 41,7\% souberam diferenciar os padrões de consumo de álcool e as questões sobre intoxicação 63,1\% (Questão 3) e tolerância, 64,3\% (Questão 4).

Esta análise mostra que o GE, de modo mais amplo, apresentou ter maior conhecimento sobre os padrões de consumo de álcool, intoxicação e tolerância ao álcool e outras drogas do que o GC. No entanto, quando se trata de uma análise geral, comparando os dois grupos não foram observadas grandes diferenças nos níveis de conhecimento, um exemplo do fato pode ser representado pelos resultados obtidos na Questão 2 que tratava de diferenciar alucinose alcoólica. Nesse item, ambos os grupos 
Janaina Soares

responderam em sua maioria incorretamente, mostrando falta de conhecimento do assunto. O resultado foi consistente com aquele encontrado por Silva (2005) que evidenciou que enfermeiros submetidos a treinamento em álcool e outras drogas não conseguiram diferenciar o mesmo conteúdo. Isso sugere que o conteúdo seja ensinado de forma diferenciada, ou que talvez as capacitações não se mostraram eficazes no sentido de esclarecer melhor tal assunto, havendo necessidade do mesmo ser ensinado de forma mais adequada.

No quesito atitudes, avaliando os fatores da EAFAAA separadamente observou-se que o GE tendeu a ter atitudes levemente mais positivas do que o GC. Consistente com esse resultado, Munro et al. (2007) avaliando o impacto de um treinamento sobre álcool e outras drogas, evidenciaram que os enfermeiros pesquisados logo após treinamento revelaram ter atitudes mais positivas, assim como aumento de conhecimento.

Conforme o resultado das respostas correspondentes ao fator $1 \mathrm{da}$ escala EAFAAA, observou-se que o maior escore médio em ambos os grupos foi relacionado às atitudes dos enfermeiros frente ao alcoolista. $O$ menor escore médio foi percebido nas atitudes frente ao alcoolismo e nas repercussões decorrentes do uso/abuso de álcool.

De acordo com os participantes do estudo, independente do grupo, ao mesmo tempo em que o alcoolismo é concebido como a perda da identidade e da moral, também é visto como uma doença. A esse respeito Howard e Chung (2000), identificam por meio do levantamento de outras pesquisas relacionadas às atitudes de enfermeiros frente ao alcoolismo que os enfermeiros tendem a ter atitudes moralmente mais condenatórias ao dependente químico que outros profissionais de saúde, ainda sobre a questão Vargas (1983) afirma que vários grupos de profissionais reconhecem o alcoolismo como doença, sendo mais fácil aceitar isso do lado intelectual do que emocional. Reforçando o resultado das pesquisas sobre essa temática (Vargas, Labate, 2003; Vargas, 2005; Vargas, Labate, 2006), tem evidenciado que há um consenso entre os profissionais a respeito do alcoolismo caracterizar-se como doença, porém, quando se trata de assistir 
esse paciente, aparecem sentimentos de desconforto e embaraçosos, sendo o consumo de álcool visto como "moralmente" errado.

Para os dois grupos (GC e GE), o alcoolista é uma pessoa sem limites, sendo um paciente que não colaboram com o tratamento. Para esses enfermeiros, conforme o verificado no estudo de Vargas e Luís (2008a), o alcoolista tem poucas chances de recuperação, podendo levar o profissional a valorizar pouco o atendimento a esse paciente, pois pelo ao contrario de outros pacientes, ele não terá seu problema resolvido e sempre retornará ao serviço, alcoolizado para um novo atendimento.

Vargas e Labate (2005) evidenciam que há uma insatisfação do enfermeiro para trabalhar com tais pacientes, mostrando ainda que os profissionais preferem trabalhar com outros pacientes do que com alcoolistas, sugerindo que ideias preconceituosas permanecem em relação ao alcoolista, gerando sentimentos negativos na relação de ajuda. Revelando a influência do esteriótipo atribuído ao alcoolismo e ao alcoolista nas atitudes de enfermeiros (Wallston, Wallston, De Velli, 1976; Cornish, Miller, 1976).

Observou-se que os enfermeiros consideram que o alcoolista não colabora com o tratamento, pois este é desesperançoso, o que é consistente com Blane e Hill, (1964), que apontam que essa atitude pode estar relacionada ao desconforto do enfermeiro. A esse respeito, foi apontado que essa atitude pode estar relacionada às próprias características do paciente alcoolista, pois é próprio do alcoolista o mecanismo de negação para entender e reconhecer-se como uma pessoa doente que precisa de ajuda e se o enfermeiro não perceber esse mecanismo poderá entender essa atitude como recusa de ajuda (Vargas, Labate, 2005).

Neste estudo, foi possível observar que a maioria dos profissionais $(87,3 \%)$ tende a julgar o alcoolista, como responsável pela sua doença, visto que a pessoa procura pela bebida; os enfermeiros acreditam que o álcool também prejudica as funções mentais (91,3\%). Biener (1983) também encontrou dados semelhantes a estes, mostrando que os enfermeiros 
acreditavam que o paciente alcoolista é mais responsável pela sua doença do que aqueles não alcoolistas.

Embora tenham apresentado uma tendência a atitudes positivas, a análise das respostas individuais aos itens revelou que, tanto o GE como o GC tenderam a ter atitudes mais negativas, embora em porcentagens reduzidas o GE procurou concordar com mais frequência com os itens positivos 24- "O alcoolismo causa dependência física e psíquica", 28- "A equipe de enfermagem precisa de treinamento para trabalhar com alcoolista", 33- "Não adianta ser agressivo com o paciente alcoolista" e 43"O alcoolista deve ser encaminhado ao psiquiatra", do que o grupo controle, sugerindo que esse resultado pode estar vinculado ao impacto do treinamento dado pelo curso SUPERA $3^{a}$ Edição nas atitudes positivas frente ao álcool, alcoolismo e alcoolista.

Quanto ao escore médio de atitudes por fatores da EAFAAA, os resultados de ambos os grupos têm maior probabilidade de atitudes positivas frente ao alcoolista (Fator 1) e menores chances de terem atitudes positivas frente ao alcoolismo (Fator 3), ou seja, o indivíduo que faz uso, é melhor aceito pelos enfermeiros, mas ainda se observam atitudes mais moralistas frente à doença.

A esse respeito, estudos mostram que os enfermeiros são favoráveis ao tratamento para o alcoolismo (Pillon, 2003; Vargas et al., 2003), e o alcoolista é percebido como um doente, mas apresenta atitudes negativas frente à satisfação em trabalhar com essa clientela (Vargas, Labate, 2005).

Avaliando a relação entre as atitudes e os conhecimentos, observouse que quanto maior a média de acertos no questionário de conhecimentos maior a média geral na escala de atitudes, evidenciando que o conhecimento e as atitudes estão diretamente relacionados, ou seja, quanto maior o conhecimento, a atitude tende a ser mais positiva. A esse respeito, pesquisadores como Willaing e Ladelund (2005) evidenciam que o preparo e o conhecimento relacionam-se diretamente às atitudes positivas frente ao paciente alcoolista. 
Quando a relação entre as variáveis sociodemográficas e os conhecimento e as atitudes foi analisada, verificou-se a atitude geral mostrou que os dois grupos de enfermeiros apresentaram atitudes levemente positivas frente à problemática em estudo. Apesar dos grupos mostrarem-se bastante homogêneos quanto às atitudes frente ao álcool, alcoolismo e alcoolista, a frequência de respostas corretas relacionadas ao questionário de conhecimento foi maior no GE, o que já era esperado, uma vez que os enfermeiros tiveram capacitação em álcool e outras drogas.

Além disso, independente do grupo, os enfermeiros com algum conhecimento na área adquirido por meio de cursos, capacitações, pósgraduação ou experiência profissional pelo contato com essa clientela, tenderam a apresentar atitudes mais positivas. Quanto a isso, estudo semelhante encontrou que os enfermeiros com maior nível educacional apresentavam atitudes mais positivas frente à problemática estudada (Heinemann, Rhodes, 1967).

Embora os enfermeiros tenham revelado algum contato com o paciente alcoolista existe uma resistência em prestar cuidados ao mesmo pela falta de conhecimento ao abordá-lo, pois cerca de $50 \%$ dos participantes revelaram não terem recebido preparo para tratar de tal paciente durante a graduação. Além disso, o fenômeno do uso das substâncias psicoativas ainda é visto por alguns profissionais como um problema moral, o fato pode estar relacionado a esse profissional considerar que não tem função no tratamento desses indivíduos, levando ao número elevado de encaminhamentos a outros serviços (Vargas, Luís, 2008a), como os serviços de tratamento especializado. Entretanto, como qualquer outro problema de saúde, o uso e abuso do álcool também deve ser tratado pelos profissionais de unidades básicas de saúde e de hospitais gerais e não apenas pelos profissionais especializados na área de álcool e outras drogas, pois é um problema de saúde que deve ser avaliado individualmente. $\mathrm{Na}$ maioria das vezes, não precisa necessariamente do tratamento especializado a não ser nos quadros em que se detecte a dependência. 
Considerando que o enfermeiro tenha habilidades para identificar tal paciente, logo terá mais segurança e tranquilidade para tratá-lo, assim como se conhecer seu papel e função, proporcionando uma mudança de atitude e redução das taxas de desistência para a continuidade e chances desse paciente precisar de um tratamento mais especializado, ou seja, com maiores custos.

Além de ter sido identificado que o enfermeiro que recebeu preparo durante a formação para atuar com dependentes químicos, tende a ter a atitudes positivas, observou-se também que aquele com pós-graduação tende a ter atitudes mais positivas frente ao álcool, alcoolismo e alcoolista, podendo pressupor-se que o enfermeiro com maior nível de formação ou com algum tipo de capacitação na área, tende a ter atitudes positivas. O que é corroborado pela literatura que vem identificando o impacto positivo da formação e educação sobre as questões relativas ao uso de álcool e outras drogas (Gorman et al., 1990; Ford, Ryrie, 2000; Bland et al., 2001). Pillon et al. (2006) evidenciam que o preparo e o conhecimento estão diretamente relacionados às atitudes positivas.

Apesar da constatação de que o nível de formação do indivíduo influencia nas atitudes frente à problemática relacionada ao álcool, conforme já foi mencionado neste estudo, a formação acadêmica não tem oferecido conhecimento nem habilidades suficientes para enfrentar situações, como o uso de drogas (Lopes, Luís, 2005; Lopes, Pessanha, 2008), cuja abrangência ultrapassa fronteiras, abarca dimensões internacionais e nacionais, políticas, econômicas, sociais, éticas, culturais e outras. Não respeita crenças, credos, famílias e sociedades, sendo compreensível de maneira geral, que os professores apresentem dificuldades para abordar o assunto, uma vez que não detêm conteúdos suficientes para levar uma discussão mais aprofundada em sala de aula, pois ainda existe fragilidade no conhecimento do assunto em três níveis: docente, discente e enfermeiro já formado, que está atuando no campo (Lopes, Pessanha, 2008).

Visando a sanar essa lacuna deixada durante a formação dos profissionais de saúde em álcool e outras drogas, algumas estratégias vêm 
Janaina Soares

sendo propostas, como o surgimento de programas de treinamento e capacitação de profissionais da área de saúde para atuar na atenção a usuários de álcool e outras drogas. Neste estudo, objetivou-se avaliar o impacto do curso SUPERA $3^{a}$ Edição nas atitudes dos profissionais enfermeiros, sobretudo pelo fato de que, segundo a literatura, a educação continuada vem mostrando resultados na melhora da atitude dos enfermeiros (Ford, Bammer, Becker, 2009).

Em relação à associação entre a aquisição de conhecimento e a mudança de atitudes é unânime ainda entre os pesquisadores sobre o tema (Rosebaun, 1977; Hegemaster et al., 1993; Gerace, Hughes, Spunt, 1995; Bendtsen, Akerlind,1999; Silva, 2005; Ford, Bammer, Becker,2009), a necessidade de aprimorar os conhecimentos desses profissionais, para que haja uma mudança de atitude, desde a formação até a educação continuada ou capacitação (Vargas, 2010b). Essa necessidade é inclusive reconhecida pelo próprio Ministério da Saúde que, por meio da Política Nacional de Atenção Integral ao Usuário de Álcool e Outras Drogas, preconiza a promoção e o oferecimento de programas de formação específica aos trabalhadores de saúde que atuam na rede de atenção aos usuários de álcool no Sistema Único de Saúde. No âmbito educacional, a mesma política aponta, que deve ser desenvolvido trabalho intersetorial voltado à revisão e reformulação dos parâmetros curriculares vigentes, garantindo a inclusão consistente de álcool e drogas nas grades curriculares escolares (Brasil, 2004).

Entretando, ainda que as atitudes profissionais de saúde relacionadas às pessoas com problemas de uso e abuso de álcool tendam a refletir na sociedade, pois inquéritos realizados nos EUA, Austrália e Reino Unido têm encontrado que as atitudes dos profissionais de saúde são geralmente negativas (Eliason, Gerken, 1999; El-Guebaly et al., 2000; Happell, Taylor, 2001). Assim, é importante ressaltar que, para a mudança de atitude de um individuo, não basta apenas o conhecimento, mas também que haja uma adequação de papel, um papel de legitimidade e suporte (Shaw et al., 1978). 
Janaina Soares

A adequação do papel profissional ou a função refere-se ao fato de que os profissionais que se sentem suficientemente preparados para a atuação vêem-se, como tendo um conhecimento adequado. O papel de legitimidade é um termo utilizado para descrever, conforme as pessoas consideram os aspectos específicos de seu trabalho, como sendo de sua responsabilidade e o papel suporte refere-se ao apoio que os profissionais reconhecem ter recebido de colegas para ajudá-los a atuar de forma eficaz. O que sugere que a presença desses fatores aumenta a motivação para o trabalho com os usuários de álcool, as expectativas de satisfação e autoestima profissional, ao contratar com eles atividade terapêutica (Shaw et al.,1978). Portanto, para uma mudança de atitude de um profissional é preciso conhecimento e preparo para atuar com esses pacientes, mas também uma organização com serviço eficaz (Silva, 2005).

Se houver algum profissional com carga-horária, com algum tipo de pós- graduação e preparo para atuar com dependentes químicos, poderá influenciar nas atitudes frente ao álcool, alcoolismo e alcoolista. Assim, o individuo com alguma carga-horária na formação em álcool e outras drogas ou com maior nível de conhecimento tenderá a ter atitudes mais positivas.

Mesmo que os grupos de enfermeiros pesquisados apresentem-se muito semelhantes quanto ao nível de conhecimento, pois o GC usado para comparar os enfermeiros que participaram do curso SUPERA $3^{\circ}$ Edição, foi constituído de profissionais de um hospital universitário o qual exige um nível de formação do GC, pode ter influenciado, ou seja, aqueles com pouca formação, poderíamos visualizar melhor o impacto desse treinamento na mudança de atitudes. O treinamento obtido propicia a formação de um conhecimento que pode levar os respectivos enfermeiros capacitados a procurarem a dar continuidade a essa formação e ajudar na assistência da clientela citada.

Este estudo apresentou limitações, dentre elas, ter envolvido populações semelhantes, no que se refere ao preparo, além disso, o instrumento pode não ter sido capaz de discriminar a diferença entre as atitudes dos dois grupos, e outro fator que pode ter sido limitante, foi o fato 
dos enfermeiros capacitados não terem sido investigados, antes de receberem a intervenção. Assim, seria importante que novas pesquisas fossem realizadas com o objetivo de pesquisar os enfermeiros antes de um treinamento e mesmo após, para identificar se realmente o treinamento poderá influenciar na mudança de atitudes desses profissionais. 


\section{Conclusões}




\section{CONCLUSÕES}

O nível de conhecimento influencia diretamente nas atitudes dos enfermeiros. Possuir preparo para atuar com dependentes químicos, ter recebido maior carga-horária durante a graduação sobre a temática álcool e outras drogas e possuir pós-graduação independente da área foram os maiores preditores para atitudes positivas.

A relação entre as atitudes e conhecimentos é proporcional, ou seja, quanto maior o conhecimento maior a tendência de apresentar atitudes mais positivas.

A hipótese inicial de que os enfermeiros que foram capacitados por meio do curso SUPERA $3^{a}$ Edição apresentariam atitudes mais positivas e melhor conhecimento frente ao álcool, alcoolismo e alcoolista do que os enfermeiros que não foram capacitados foi negada, o que se pode justificar pelas próprias características do grupo controle, que é oriundo de uma instituição de referência, ou seja, de um hospital universitário onde supostamente os profissionais têm maior facilidade de acesso ao conhecimento, independente de serem especializados na área ou não.

A segunda hipótese do estudo foi validada, enfermeiros que receberam maior carga horária de conteúdos relacionada ao tema durante a formação profissional, apresentaram atitudes mais positivas e melhor conhecimento frente ao álcool, alcoolismo e alcoolista do que os que não receberam nenhuma formação ou receberam-na em menor carga horária.

Portanto, considerando a necessidade da identificação e avaliação de novos métodos que favoreçam a aquisição de conhecimentos e a mudança de atitudes dos enfermeiros frente às questões relacionadas ao álcool e outras drogas, é importante que estratégias de formação sejam investigadas com o intuito de comparar se enfermeiro que já teve treinamento com outro grupo desprovido de formação. Assim como, realizar pesquisas desse tipo com outros profissionais de saúde, além de que é necessário que sejam 
investidos a inclusão de disciplinas especificamente voltadas a esta área de álcool e outras drogas ou na remodelação das já existentes, garantindo carga-horária teórico-prática suficiente para a formação do profissional de saúde, uma vez que isto influencia em suas atitudes. 


\section{Referências}

bibliográficas 


\section{REFERÊNCIAS BIBLIOGRÁFICAS}

Aalto M, Pekuri P, Seppä K. Primary health care nurses' and physicians' attitudes, knowledge and beliefs regarding brief intervention for heavy drinkers. Addiction. 2001;96(2):305-11.

Allen K. Attitudes of registered nurses toward alcoholic patients in a general hospital population. Int J Addict. 1993;28(9):923-30.

Bartek JK, Lindeman M, Newton M, Fitzgerald AP, Hawks JH. Nurseidentified problems in the management of alcoholic patients. J Stud Alcohol.1988,49(1): 62-70.

Bendtsen P, Holmqvist M, Johansson K. Implementation of computerized alcohol screening and advice in an emergency department--a nursing staff perspective. Accid Emerg Nurs. 2007;15(1):3-9.

Biener L. Perceptions of patients by emergency room staff: substance abusers versus non-substance abusers. J Health Soc Behav. 1983; 24(3): 264-75.

Blane HT, Hill MJ.Public health nurses speak up about alcoholism. Nurs Outlook. 1964;12:34-7.

Bland E, Oppenheimer L, Brisson-Carroll G, Morel C, Holmes P, Gruslin A. Influence of an educational program on medical students' attitudes to substance use disorders in pregnancy. American Journal of Drug and Alcohol Abuse. 2001; 27 (3): 483-490.

Brasil. Ministério da Saúde. Secretaria de Atenção à Saúde. SVS/CNDST/AIDS. A Política do Ministério da Saúde para Atenção Integral a Usuários de Álcool e outras Drogas/Ministério da Saúde. Brasília; 2004

Brasil. Ministério da Saúde. Secretaria Nacional Antidrogas. Glossário de álcool e drogas. Brasília; 2006.

Brasil. Ministério da Saúde. Secretaria Nacional Antidrogas. Serviço Social da Indústria. Prevenção ao uso de álcool e outras drogas no ambiente de trabalho: conhecer para ajudar. Brasília; 2008.

Campbell DT, Stanley JC. Delineamentos de experimentais e quaseexperimentais de pesquisa. São Paulo: EPU; 1979.

Carlini EA, Galduróz JCF, Noto AR, Nappo AS. I Levantamento domiciliar sobre o uso de drogas psicotrópicas no Brasil. Parte A: estudo envolvendo as 107 maiores cidades do país,1999. Centro Brasileiro de Informações 
Janaina Soares

Sobre Drogas Psicotrópicas, Departamento de psicobiologia da Escola Paulista de medicina. São Paulo; 2001.

Chung JYM, Chan JTS, Yeung RSD, Wan RCH, Ho ST. Nurses' attitude toward alcoholic patients in accident and emergency department in Hong Kong. Journal of Emergency Medicine.2003;10(2): 104-112.

Cook SW, Selltiz CA. A multiple-indicator approach to attitude measurement. Psychol. Bull. 1964; 62(1): 36-55.

Cornish RD, Miller MV. Attitudes of registered nurses toward the alcoholic. $J$ Psychiatr Ment Health Serv. 1976;14(12): 19- 22.

Deehan A, McCambridge J, Ball DM, Strang J. Increasing practice nurse access to alcohol training. Drug Alcohol Rev. 2002;21(3):281-6.

El-Guebaly N, Toews J, Lockyer J, Armstrong S, Hodgins D. Medical education in substance-related disorders: components and outcome. Addiction. 2000; 95 (6), 949-957.

Eliason MJ, Gerken KC. Attitudes shown by nursing college students, staff, and faculty towards substance abuse. Journal of Substance Use. 1999; 4: 155-163.

Fishbein EW, Ajzen I. Belief, attitude, intention and behavior: Introdution to theory and research. Massachusets: Addison-Wesley Publishing;1975.

Ford R, Bammer G, Becker N. Improving nurses' therapeutic attitude to patients who use illicit drugs: workplace drug and alcohol education is not enough. Int J Nurs Pract. 2009;15(2):112-8.

Ford C, Ryrie I. A comprehensive package of support to facilitate the treatment of problems drug users in primary care: an evaluation of the training component. International Journal of Drug Policy. 2000; 11: 387-392.

Galduróz JCF, Noto AR, Nappo AS, Carlini EA. II Levantamento domiciliar sobre uso de drogas psicotrópicas no Brasil. Parte A: estudo envolvendo as 108 maiores cidades do país, 2005. Brasília: Centro Brasileiro de Informações Sobre Drogas Psicotrópicas, Departamento de Psicobiologia da Escola Paulista de Medicina e SENAD - Secretaria Nacional Antidrogas, Presidência da República, Gabinete de Segurança Nacional; 2006.

Gallassi AD, Alvarenga PG, Andrade AG, Couttolenc BF. Custos dos problemas causados pelo abuso do álcool. Rev. Psiq. Clín. 2008; 35(01): 2530.

Gazal-Carvalho C, Carlini-Cotrim B, Silva OA, Sauaia N. Prevalência de alcoolemia em vítimas de causas externas admitidas em centro urbano de atenção ao trauma. Revista de Saúde Pública. 2002; 36(1): 47-54. 
Janaina Soares

Gerace LM, Hughes TL, Spunt J. Improving nurses' responses toward substance-misusing patients: a clinical evaluation project. Arch Psychiatr Nurs. 1995;9(5):286-94.

Gonçalves JA, Nunes MT. Metodologia da Investigação I. DEFCUL; 2005.

Gorman, D.M., Werner, J.M., Jacobs, L.M., Duffy, S.W. Evaluation of an alcohol package for non-specialist health care and social workers. British Journal of Addiction. 1990; 85: 223-233.

Grief CL, Elliott R. Emergency nurses' moral evaluation of patients. J Emerg Nurs. 1994;20(4):275-9.

Gross BV, Lismam S. Attitudes of paraprofessionals toward alcoholism; setting effects. J Studies Alcohol. 1979; 40(5):65-72.

Hagemaster J, Handley S, Plumlee A, Sullivan E, Stanley S. Developing educational programmes for nurses that meet today's addiction challenges. Nurse Educ Today. 1993;13(6):421-5.

Happell B, Taylor C. Negative attitudes towards clients with drug and alcohol related problems: finding the elusive solution. Aust $\mathrm{N} Z \mathrm{~J}$ Ment Health Nurs. 2001;10(2):87-96.

Harrison AA. A psicologia como ciência social. São Paulo: Cultrix; 1975.

Heinemann E, Rhodes RJ. How nurses view the tuberculosis alcoholic patient. Nurs Res. 1967;16(4):361-5.

Hisatomi N, Ito K, Nagashima Y, Fujiwara K, Yasuda K, Ashizawa et al. Nurses' knowledge of alcohol-related problems and their treatment: a comparison of nurses in general hospital and alcoholism treatment units. Nihon Arukoru Yakubutsu Igakkai Zasshi. 1998;33(6):671-82.

Howard MO, Chung SS. Nurses' attitudes toward substance minusers.I. Surveys. Substance use minuse. 2000; 35(3): 347-365.

Johnson MW. Nurses speak out on alcoholism. Nurs Forum. 1965;4(4):1622.

Krech D et al. O indivíduo na Sociedade - um manual de Psicologia social. São Paulo: Editora da Universidade de São Paulo; 1969. p.311.

Krueger J. Perceptions of sexual assault victim responsibility by emergency nurses whem there was chemical use by victim. J Emergency Nurs. 1995;21:174-175.

Lock CA, Kaner E, Lamont S, Bond S. A qualitative study of nurses' attitudes and practices regarding bri ef alcohol intervention in primary health care. $J$ Adv Nurs. 2002;39(4):333-42. 
Janaina Soares

Lopes GT, Luis MAV. A formação do enfermeiro e o fenômeno das drogas no estado do Rio de Janeiro - Brasil: atitudes e crenças. Rev. Latino-am Enferm. 2005;13(n. esp): 1-14.

Lopes GT, Pessanha HL. Concepções de professores de enfermagem sobre drogas. Esc. Anna Nery Rev Enferm, 2008;12(3): 465-472.

Lucca DM, Vargas D, Vargas D. As concepções de enfermeiros de hospital geral frente as questões relacionadas ao álcool e ao alcoolismo. Rev. Enferm. Bras.2006; 5(5): 260-266.

Magnabosco MB, Formigoni MLOS, Ronzani TM. Avaliação dos padrões de uso de álcool em usuários de serviços de atenção primária à saúde de Juiz de Fora e Rio Pomba (MG). Rev. Bras. Epidemiol. 2007; 10(4): 637-647.

Meloni JN, Laranjeira R. Custo social e de saúde do consumo do álcool. Rev. Bras. Psiquiatr. 2004; 26(Suppl 1): 7-10.

Munro A, Watson HE, McFadyen A. Assessing the impact of training on mental health nurses' therapeutic attitudes and knowledge about comorbidity: a randomized controlled trial. Int. J Nurs Stud. 2007, 44(8): 1430-8.

Navarrete PR, Luís MAV. Atitude da enfermeira de um complexo hospitalar em relação ao paciente alcoólico. Rev. Latino-am. Enfermagem. 2004;12: 420-426.

Newton SE. Alcohol relapse and its relationship to the lived experience of adult liver transplant recipients. Gastroenterol Nurs. 2007;30(1):37-42.

Nida. National Institute on Drug Abuse. Drugs of abuse/Related topics: Alcohol. [periódico na internet]. 2009 dez. 07 [citado 2010 jul. 17] . Disponível em: http://www.nida.nih.gov/drugpages/alcohol.html.

Noto AR, Moura YG, Nappo AS, Galduróz JCF, Carlini EA . Internações por transtornos mentais e de comportamento decorrentes de substâncias psicoativas: um estudo epidemiológico nacional do período de 1988 a 1999. Jornal Bras Psiquiat. 2002; 51(2):113-121.

Organização Mundial de Saúde. CID-10 - Critérios diagnósticos para pesquisa. Porto-Alegre: Artes Médicas; 1998.

Pillon CS. Atitudes dos enfermeiros com relação ao alcoolismo [Dissertação]. São Paulo: Escola Paulista de Medicina, Universidade Federal de São Paulo; 1998.

Pillon CS. O uso do álcool e a educação formal dos enfermeiros [Tese]. São Paulo: Escola Paulista de Medicina, Universidade Federal de São Paulo, 2003. 
Janaina Soares

Pillon CS, Laranjeira R. Formal education and nurses' attitudes towards alcohol and alcoholism in a Brazilian sample. São Paulo Med J. 2005; 123(4): 175-180.

Pillon CS, Luís MAV, Laranjeira R. Atitudes dos enfermeiros relacionadas ao alcoolismo. Revista Nursing. 2006; 96(9).

Pinikahana J, Happell B, Carta B. Mental health professionals' attitudes to drugs and substance abuse. Nurs Health Sci. 2002;4(3):57-62.

Polit DF, Beck CT, Hungler BP. Fundamentos de Pesquisa em enfermagem: Médos, avaliação e utilização. $5^{\circ}$ ed. Porto Alegre: Artmed; 2004.

Potamianos G; Winter D; Duffy SW; Gorman DM; Peters TJ. The perception of problem drinkers by general hospital staff, general practitioners and alcoholic patients. Alcohol. 1985, 2(4): 563-6.

Reismam BL, Shrader RW. Effect of nurses' attitudes toward alcoholism on their referral rate for treatment. Occup Health Nurs.1984; 32(5):273-5.

Rodrigues A. Psicologia social. $12^{\circ}$ ed. Petrópolis: Vozes; 1978.

Rosebaun PD. Public health nurses in the treatment of alcohol abusers. Can. J. Public Health. 1977; 68(6): 503-508.

Shaw S, Cartwright A, Spratley T. Harwin, J. Responding to Drink Problems. London: Croom Helm; 1978.

Silva CJ. Impacto de um curso em diagnóstico e tratamento do uso nocivo e dependência do álcool sobre a atitude e conhecimento de profissionais da rede de atenção primária à saúde [Tese]. São Paulo: Escola Paulista de Medicina, Universidade Federal de São Paulo, 2005.

Silveira DX, Moreira FG. Panorama atual de drogas e dependencias. $1^{\circ} \mathrm{ed}$. São Paulo: Atheneu; 2006.

Spricigo JS, Alencastre MB. O enfermeiro de unidade básica de saúde e o usuário de drogas - um estudo em Biguaçu-SC. Rev. Latino-am Enfermagem.2004; 12: 427-432.

Supera. Guia do estudante. $3^{a}$ ed. Brasília: Secretaria Nacional de Políticas sobre Drogas; 2009.

Triads HC. Attitude and attitude change. New York: John Wiley; 1971.

Van B, Gabrynowicz JW. Doctors' and nurses' views on alcohol dependency. Aust Nurses J. 1977; 7(4): 42-5.

Vargas D, Labate RC, Costa Junior ML. Alcoolistas tratar ou punir: disposição de enfermeiros de Hospital Geral. Revista Enfermagem (UERJ).2003; 11(2): 188-192. 
Vargas D. A construção de uma escala de atitudes frente ao álcool, ao alcoolismo e ao alcoolista: um estudo psicométrico [Tese].Ribeirão Preto: Escola de Enfermagem de Ribeirão Preto, Universidade de São Paulo, 2005.

Vargas D. Atitudes de enfermeiros frente as habilidades de identificação para ajudar o paciente alcoolista. Revista Brasileira de Enfermagem. 2010a; 63:190-195.

Vargas D. Nursing students' attitudes towards alcohol, alcoholism and alcoholics: A study of a Brasilian sample. Addiction Nursing. 2010b. No prelo.

Vargas D, Araújo E. Prevalência de dependência alcoólica em serviços de atenção primária a saúde de Bebedouro (SP) - Brasil. Cadernos de Saúde Pública. 2009; 25(8): 1711-1720.

Vargas HS. Repercussões do álcool e do alcoolismo. São Paulo: Fundo Ed. Byk-procienx; 1983.

Vargas D, Labate RC. Trabalhar com pacientes alcoolistas: satisfação de enfermeiros de hospital geral. Revista Gaúcha de Enfermagem. 2005; 26(2): 252-260.

Vargas D, Labate RC. Atitudes de enfermeiros de hospital geral frente ao uso do álcool e alcoolismo. Rev. Bras. Enferm.2006; 59(1): 47-51.

Vargas D, Luís MAV. Álcool, alcoolismo e alcoolista: concepções e atitudes de enfermeiros de unidades básicas distritais de saúde. Rev. Latino-am. Enfermagem, 2008a; 16.

Vargas D, Luís MA. Construção e validação de uma escala de atitudes frente ao álcool, ao alcoolismo e ao alcoolista. Rev Lat Am Enfermagem. 2008b;16(5):895-902.

Vargas D, Soares J. Atitudes de enfermeiros frente ao álcool, ao alcoolismo e ao alcoolista: Revisão da literatura. Cogitare. 2010. No prelo

Velho G. A dimensão cultural e política dos mundos das drogas.In: Zaluar A, organizadora. Drogas e cidadania: Repressão ou redução de riscos. São Paulo: Brasiliense; 1999.p.23-9.

Wallston KA, Wallston BS, DeVellis BM. Effect of a negative stereotype on nurses' attitudes toward an alcoholic patient. J Stud Alcohol. 1976;37(5):65965.

Waring, ML. The impact of specialized training in alcoholism on management-level professional. J. Stud. Alcohol. 1975; 36(3):406-415.

Whedall K. Comportamento social: problemas fundamentais e importância social. Rio de Janeiro: ZAHAR; 1976. 
Janaina Soares

Willaing I, Ladelund S. Nurse counseling of patients with an overconsumption of alcohol. J Nurs Scholarsh. 2005;37(1):30-5. 
Anexos 


\section{ANEXO 1}

\section{Escala de Atitudes frente ao Álcool, ao Alcoolismo e ao Alcoolista}

No instrumento que segue, Indique o quanto você concorda ou discorda com cada uma das declarações marcando um número na linha da direita de cada declaração.

\section{1-Concordo totalmente \\ 2-Concordo em parte \\ 3-Estou em dúvida \\ 4-Discordo em parte \\ 5-Discordo totalmente}

\begin{tabular}{|c|c|c|c|c|c|c|}
\hline 1 & O alcoolista é uma pessoa que não tem limite. & 1 & 2 & 3 & 4 & \\
\hline 6 & Alcoolistas não têm bom senso. & 1 & 2 & 3 & 4 & 5 \\
\hline 16 & O alcoolista é um irresponsável. & 1 & 2 & 3 & 4 & 5 \\
\hline 26 & Os Alcoolistas são pacientes violentos. & 1 & 2 & 3 & 4 & 5 \\
\hline 31 & O alcoolista bebe sem a preocupação do que vai acontecer depois. & 1 & 2 & 3 & 4 & 5 \\
\hline 36 & Penso que pessoas que desenvolvem o alcoolismo são fracas. & 1 & 2 & 3 & 4 & \\
\hline 41 & O alcoolista não quer se cuidar. & 1 & 2 & 3 & 4 & 5 \\
\hline 46 & Não se deve confiar em pessoas alcoolistas. & 1 & 2 & 3 & 4 & 5 \\
\hline 50 & 0 alcoolista é um imoral. & 1 & 2 & 3 & 4 & 5 \\
\hline 58 & Penso que o alcoolista é culpado por seus problemas de saúde. & 1 & 2 & 3 & 4 & 5 \\
\hline 63 & O alcoolismo é um vício irreparável. & 1 & 2 & 3 & 4 & 5 \\
\hline 65 & $\begin{array}{l}0 \text { paciente alcoolista acaba sempre voltando ao serviço com o mesmo } \\
\text { problema. }\end{array}$ & 1 & 2 & 3 & 4 & 5 \\
\hline 67 & Considero paciente alcoolista o mais difícil de lidar. & 1 & 2 & 3 & 4 & 5 \\
\hline 69 & O alcoolista é um paciente que nunca dá retorno do cuidado. & 1 & 2 & 3 & 4 & 5 \\
\hline 71 & O alcoolista é uma pessoa de difícil contato. & 1 & 2 & 3 & 4 & 5 \\
\hline 73 & Eu tenho medo de abordar o problema do alcoolismo com o paciente. & 1 & 2 & 3 & 4 & 5 \\
\hline 75 & Eu tenho medo da agressividade do alcoolista. & 1 & 2 & 3 & 4 & 5 \\
\hline 76 & Sinto-me frustrado quando trabalho com alcoolistas. & 1 & 2 & 3 & 4 & 5 \\
\hline 77 & Quando o paciente não quer colaborar, o melhor é desistir de ajudar. & 1 & 2 & 3 & 4 & 5 \\
\hline 78 & Quando trabalho com o alcoolista, não sei como conduzir a situação. & 1 & 2 & 3 & 4 & 5 \\
\hline 79 & Para atender o alcoolista, é preciso contê-lo. & 1 & 2 & 3 & 4 & 5 \\
\hline 80 & Penso que alcoolistas dão muito trabalho para a enfermagem. & 1 & 2 & 3 & 4 & 5 \\
\hline 81 & Devo cuidar do alcoolista, mesmo que ele não queira. & 1 & 2 & 3 & 4 & 5 \\
\hline 84 & Sinto raiva ao trabalhar com alcoolistas. & 1 & 2 & 3 & 4 & 5 \\
\hline 85 & O paciente alcoolista não aceita o que eu falo. & 1 & 2 & 3 & 4 & 5 \\
\hline 86 & Percebo o alcoolista como um caso perdido. & 1 & 2 & 3 & 4 & 5 \\
\hline 87 & Alcoolistas são pacientes que não colaboram com o tratamento. & 1 & 2 & 3 & 4 & 5 \\
\hline 88 & Alcoolistas são pessoas difíceis de tratar. & 1 & 2 & 3 & 4 & 5 \\
\hline 89 & $\begin{array}{l}\text { Pacientes alcoolistas só são encontrados para atendimento em unidades } \\
\text { básicas de periferia. }\end{array}$ & 1 & 2 & 3 & 4 & 5 \\
\hline 90 & O alcoolista não leva o tratamento a sério. & 1 & 2 & 3 & 4 & 5 \\
\hline 91 & Eu prefiro trabalhar com pacientes alcoolistas a trabalhar com outros pacientes. & 1 & 2 & 3 & 4 & 5 \\
\hline 94 & 0 alcoolismo é a perda da identidade e da moral. & 1 & 2 & 3 & 4 & 5 \\
\hline 95 & Os alcoolistas têm uma situação de vida precária. & 1 & 2 & 3 & 4 & \\
\hline 07 & Penso que fatores hereditários influenciam no abuso do álcool. & 1 & 2 & 3 & 4 & 5 \\
\hline 12 & $\begin{array}{l}\text { Alcoolistas são pessoas que buscam na bebida soluções para problemas } \\
\text { afetivos. }\end{array}$ & 1 & 2 & 3 & 4 & 5 \\
\hline 17 & Penso que passar por um desajuste familiar leva ao alcoolismo. & 1 & 2 & 3 & 4 & 5 \\
\hline
\end{tabular}




\begin{tabular}{|c|c|c|c|c|c|c|}
\hline 22 & O álcool é usado como fuga. & 1 & 2 & 3 & 4 & 5 \\
\hline 27 & Pessoas tímidas ou inibidas têm maior chance de desenvolver o alcoolismo. & 1 & 2 & 3 & 4 & 5 \\
\hline 37 & O alcoolista tem algo no passado que o conduz a beber. & 1 & 2 & 3 & 4 & 5 \\
\hline 42 & A falta de autocontrole leva ao alcoolismo & 1 & 2 & 3 & 4 & 5 \\
\hline 47 & Problemas sociais e econômicos desencadeiam o beber excessivo & 1 & 2 & 3 & 4 & 5 \\
\hline 51 & Penso que a depressão leva ao alcoolismo. & 1 & 2 & 3 & 4 & 5 \\
\hline 55 & O alcoolismo está relacionado ao nível de instrução do indivíduo. & 1 & 2 & 3 & 4 & 5 \\
\hline 59 & O que falta no alcoolista é força de vontade. & 1 & 2 & 3 & 4 & 5 \\
\hline 64 & Pessoas sem emprego fixo desenvolvem o alcoolismo. & 1 & 2 & 3 & 4 & 5 \\
\hline 66 & Filhos de alcoolistas têm tendência a serem alcoolistas. & 1 & 2 & 3 & 4 & 5 \\
\hline 68 & Pessoas mal resolvidas se tornam alcoolistas. & 1 & 2 & 3 & 4 & 5 \\
\hline 70 & Pessoas insatisfeitas abusam do álcool. & 1 & 2 & 3 & 4 & 5 \\
\hline 72 & Penso que pessoas que consomem álcool estão fugindo de algum problema. & 1 & 2 & 3 & 4 & 5 \\
\hline 74 & Penso que alcoolistas têm problemas financeiros. & 1 & 2 & 3 & 4 & 5 \\
\hline 03 & O alcoolista é um doente. & 1 & 2 & 3 & 4 & 5 \\
\hline 08 & Percebo que o alcoolista tem baixa auto-estima. & 1 & 2 & 3 & 4 & 5 \\
\hline 13 & Os alcoolistas são pessoas psicologicamente abaladas. & 1 & 2 & 3 & 4 & 5 \\
\hline 18 & O alcoolista é um indivíduo que não consegue controlar sua ingestão alcoólica & 1 & 2 & 3 & 4 & 5 \\
\hline 23 & O alcoolismo é uma doença. & 1 & 2 & 3 & 4 & 5 \\
\hline 28 & A equipe precisa de treinamento para trabalhar com o alcoolista. & 1 & 2 & 3 & 4 & 5 \\
\hline 33 & Não adianta ser agressivo com o paciente alcoolista. & 1 & 2 & 3 & 4 & 5 \\
\hline 38 & Ë preciso tomar cuidado ao trabalhar com o paciente alcoolista. & 1 & 2 & 3 & 4 & 5 \\
\hline 43 & $\mathrm{O}$ alcoolista deve ser encaminhado ao psiquiatra. & 1 & 2 & 3 & 4 & 5 \\
\hline 48 & As pessoas bebem para se sentirem mais alegres e mais soltas. & 1 & 2 & 3 & 4 & 5 \\
\hline 52 & O álcool é usado como uma válvula de escape. & 1 & 2 & 3 & 4 & 5 \\
\hline 56 & O alcoolista bebe para fugir da realidade. & 1 & 2 & 3 & 4 & 5 \\
\hline 60 & O alcoolista é um doente & 1 & 2 & 3 & 4 & 5 \\
\hline 09 & Percebo o alcoolista como alguém marginalizado. & 1 & 2 & 3 & 4 & 5 \\
\hline 19 & Penso que o álcool prejudica as funções mentais. & 1 & 2 & 3 & 4 & 5 \\
\hline 24 & $\mathrm{O}$ alcoolismo causa dependência física e psíquica. & 1 & 2 & 3 & 4 & 5 \\
\hline 29 & A maioria dos alcoolistas acaba só. & 1 & 2 & 3 & 4 & 5 \\
\hline 34 & O álcool leva à loucura e à morte. & 1 & 2 & 3 & 4 & 5 \\
\hline 39 & A bebida alcoólica altera o estado emocional. & 1 & 2 & 3 & 4 & 5 \\
\hline 5 & Penso que as pessoas têm o direito de beber se elas quiserem. & 1 & 2 & 3 & 4 & 5 \\
\hline 10 & A bebida alcoólica é agradável e traz bem-estar. & 1 & 2 & 3 & 4 & 5 \\
\hline 15 & O uso de bebida alcoólica é algo normal. & 1 & 2 & 3 & 4 & 5 \\
\hline 20 & Penso que beber uma dose de uísque é considerado beber social. & 1 & 2 & 3 & 4 & 5 \\
\hline 25 & A bebida em qualquer quantidade vai deixar o indivíduo dependente. & 1 & 2 & 3 & 4 & 5 \\
\hline 30 & Beber com moderação não é prejudicial. & 1 & 2 & 3 & 4 & 5 \\
\hline 35 & Eu sou contra o uso do álcool em qualquer momento. & 1 & 2 & 3 & 4 & 5 \\
\hline 40 & O álcool em quantidades reduzidas é benéfico. & 1 & 2 & 3 & 4 & 5 \\
\hline 45 & O álcool relaxa as tensões do dia-a-dia & 1 & 2 & 3 & 4 & 5 \\
\hline 49 & Eu sou a favor do beber moderado. & 1 & 2 & 3 & 4 & 5 \\
\hline 53 & Doses pequenas de álcool são capazes de causar dependência. & 1 & 2 & 3 & 4 & 5 \\
\hline
\end{tabular}




\section{ANEXO 2}

\section{QUESTIONÁRIO SOBRE ÁLCOOL E ALCOOLISMO}

1- Paciente de 50 anos de idade faz uso de bebida alcoólica desde os 20 anos. Usa bebida destilada (uísque) todos os dias: uma dose $(50 \mathrm{ml})$ no almoço e outra $(50 \mathrm{ml})$ no jantar. É casado e a sua esposa se irrita freqüentemente com a quantidade que bebe. Nos últimos 5 meses vem apresentando sintomas depressivos, como desânimo perda de apetite e insônia.

(_) Paciente é dependente porque faz uso de bebida alcoólica a longo tempo e apresenta problemas conjugais devido a isso.

(_) Paciente preenche critérios para diagnóstico de uso nocivo.

(_) O Diagnóstico é Dependência porque o paciente já apresenta problemas relacionados ao uso do álcool. Não sei.

2- Paciente com diagnóstico de dependência do álcool, diminuiu a ingestão há 3 dias e apresenta alucinações auditivas (vozes de homens que chamam pelo seu nome). Não apresenta alterações no nível de consciência. (_) O diagnóstico é SAA (Síndrome de Abstinência do Álcool) e o tratamento é internação com benzodiazepínicos e hidratação.

(_) O diagnóstico é Alucinose Alcoólica.

_) O diagnóstico é Delirium Tremens.

) Não sei.

3- Paciente com diagnóstico de dependência do álcool, deu entrada no pronto socorro com quadro de agitação intensa após ter usado grande quantidade de bebida alcoólica.

(_) Trata-se de intoxicação patológica.

(_) Trata-se de intoxicação aguda

(_) Trata-se de intoxicação crônica

) Não sei.

4- Quando a pessoa diz que precisa de mais e mais álcool ou outra droga para "ficar alto" isso pode demonstrar:

(_) Tolerância.

(_) Intoxicação.

(_) Dependência.

(_) Uso nocivo e ou prejudicial.

\section{Assinale V ( Verdadeiro) ou $\mathrm{F}$ ( Falso):}

A-(__ Um homem adulto pode beber até no máximo 2 doses de uísque (total de $100 \mathrm{ml}$ ) por dia.

B-(__ A mulher pode beber menos do que o homem, porque possui proporcionalmente, maior quantidade de gordura corporal, o que aumenta a biodisponibilidade do álcool.

C-(__ A Intervenção Breve (IB) é um tipo de tratamento não farmacológico que é eficaz para dependências leves e usuários nocivos.

D-(_) A IB pode ser aplicada em consultas de 10 a 15 minutos por médicos, enfermeiros, psicólogos, e outros profissionais treinados.

E-(__ A meta do beber seguro (socialmente) deve ser evitada para pacientes que fazem uso nocivo de bebidas alcoólicas.

F-(__) Para pacientes não motivados ao tratamento, o médico deve respeitar a sua opinião e aguardar até que ele se sinta motivado para iniciar o tratamento.

G-(_) Pacientes em pré-contemplação consideram a hipótese de parar de beber, mas não conseguem mudar de comportamento em relação a bebida.

$\mathrm{H}-(\ldots)$ Uma vez identificada a dependência do álcool deve-se fazer as primeiras orientações e encaminhar 0 paciente ao especialista. 


\section{ANEXO 3}

\section{Dados Pessoais - Grupo Controle}

1) Sexo $\square M \square F$

2) Idade

3) Estado civil $\quad \square$ casado $\quad \square$ solteiro $\square$ Viúvo $\square$ separado $\square$ outros

4) Profissão: $\square$ Enfermeiro

5) Experiência profissional com alcoolistas $\square$ sim $\quad \square$ não

6) Se a resposta a questão anterior foi SIM, com que freqüência você se depara com pacientes com problema s relacionados ao uso de álcool e outras drogas no trabalho?

$\square$ semanalmente

$\square$ mensalmente

nunca

7)clínica

trabalho:

8) Tempo de profissão anos.

9) Possui curso de Pós graduação? $\square \operatorname{Sim} \square$ Não
Especialização
mestrado
doutorado

Em que área

10) Formação: Você estudou em: Faculdade Pública $\square$ Faculdade privada

11) Durante seu curso de formação em enfermagem você recebeu preparo para atuar com dependentes químicos?

$\square \operatorname{Sim} \square$ Não

12) Se a resposta da pergunta acima for SIM, qual foi a carga-horária dedicada ao curso?

$\square 5$ horas $\square 10$ horas $\square 15$ horas $\square 20$ horas $\square 30$ horas $\square$ Outras

13) Essa formação foi dada através de:

$\square$ Aulas $\square$ palestras $\square$ seminários $\square$ Comentários do professor outros:

14) Experiência prática:

$\square$ antes da graduação $\square$ durante a graduação $\square$ após a graduação

15) Quando e como foi esta experiência prática? 


\section{ANEXO 4}

\section{Dados Pessoais - Grupo Experimental}

1) Sexo $\square M \square F$

2) Idade

3) Estado civil $\square$ casado $\square$ solteiro $\quad \square$ Viúvo $\square$ separado $\square$ outros

4) Profissão: $\square$ Enfermeiro

5) Experiência profissional com alcoolistas $\square$ sim $\quad \square$ não

6) Se a resposta a questão anterior foi SIM, com que freqüência você se depara com pacientes com problema s relacionados ao uso de álcool e outras drogas no trabalho?

$\square$ diariamente $\square$ semanalmente $\quad \square$ mensalmente $\square$ nunca

7)clínica de de trabalho:

8) Tempo de profissão anos.

9) Possui curso de Pós graduação? $\square \operatorname{Sim} \square$ Não

Especialização $\square$ mestrado $\square$ doutorado

Em que área

10) Formação: Você estudou em: Faculdade Pública $\square$ Faculdade privada

11) Durante seu curso de formação em enfermagem você recebeu preparo para atuar com dependentes químicos?

$\neg$ Sim $\square$ Não

12) Se a resposta da pergunta acima for SIM, qual foi a carga-horária dedicada ao curso?

$\square 5$ horas $\square 10$ horas $\square 15$ horas $\square 20$ horas $\square 30$ horas $\square$ Outras

13) Essa formação foi dada através de:

$\square$ Aulas $\square$ palestras $\square$ seminários $\square$ Comentários do professor outros:

14) Experiência prática:

$\square$ antes da graduação $\square$ durante a graduação $\square$ após a graduação

15) Quando e como foi esta experiência prática?

16) Você participou do curso SUPERA $3^{\text {a }}$ Edição?

$\square \operatorname{sim} \square$ não 


\section{ANEXO 5 \\ INSTRUÇÕES - Grupo Controle}

Estamos realizando um estudo para conhecer e comparar as atitudes e os conhecimentos de dois grupos de enfermeiros frente ao álcool, ao alcoolismo e ao alcoolista, nosso intuito é obter o maior numero possível de respostas diferentes sobre questões pessoais e sociais do paciente alcoolista. Bem como verificar seus conhecimentos frente às questões relacionadas ao álcool e ao alcoolismo.Como as pessoas percebem de modo diferente 0 que acontece com o outro, a opinião pessoal de cada enfermeiro será, para nós, a resposta mais adequada.

Evidentemente, a aplicação deste instrumento não fornecerá respostas certas ou erradas, o que conta é a opinião do profissional.

Para cada questão você deverá escolher a resposta que considera mais verdadeira, marcando com um $X$ no espaço indicado.

Responda as perguntas ABERTAMENTE e HONESTAMENTE. Este é um importante estudo científico e é necessário que suas respostas sejam muito sinceras.

Asseguramos que suas respostas serão ABSOLUTAMENTE CONFIDENCIAIS sendo analisadas somente fazendo como parte do total dos dados colhidos, o questionário não deverá conter identificação, portanto não 0 assine.

Lembre-se de que sua participação é extremamente importante para nós.

Obrigada. 


\section{ANEXO 6}

\section{INSTRUÇÕES - Grupo Experimental}

Estamos realizando um estudo para conhecer e comparar as atitudes e os conhecimentos de dois grupos de enfermeiros frente ao álcool, ao alcoolismo e ao alcoolista, nosso intuito é obter o maior numero possível de respostas diferentes sobre questões pessoais e sociais do paciente alcoolista. Bem como verificar seus conhecimentos frente às questões relacionadas ao álcool e ao alcoolismo.Como as pessoas percebem de modo diferente o que acontece com o outro, a opinião pessoal de cada enfermeiro será, para nós, a resposta mais adequada.

Evidentemente, a aplicação deste instrumento não fornecerá respostas certas ou erradas, o que conta é a opinião do profissional.

Para cada questão você deverá escolher a resposta que considera mais verdadeira, marcando com um X no espaço indicado.

Responda as perguntas ABERTAMENTE e HONESTAMENTE. Este é um importante estudo científico e é necessário que suas respostas sejam muito sinceras.

Asseguramos que suas respostas serão ABSOLUTAMENTE CONFIDENCIAIS sendo analisadas somente fazendo como parte do total dos dados colhidos, o questionário não deverá conter identificação, portanto não o assine.

Após o Preenchimento dos questionários, deverão enviar os mesmos a autora do projeto através do e-mail: janainasoares@usp.br.

Passos para enviar as respostas:

1- Salve o documento da pesquisa com suas respostas numa pasta no seu computador;

2- Abra seu e-mail, clique em anexo, procure o documento da pesquisa salvo no seu computador;

3- Clique no documento e anexe.

4- Envie para janainasoares@usp.br.

Lembre-se de que sua participação é extremamente importante para nós.

Obrigada. 


\section{ANEXO 7 \\ Termo de Consentimento Livre e Esclarecido}

Prezado Colega

Tenho a honra de convidá-lo a participar do estudo ATITUDES E CONHECIMENTOS DE ENFERMEIROS FRENTE AO ÁLCOOL, AO ALCOOLISMO E AO ALCOOLISTA: ESTUDO COMPARATIVO ENTRE DOIS GRUPOS. Se for de seu interesse participar desse estudo, responderá algumas questões sobre sua opinião a respeito da problemática do álcool, do alcoolismo e do alcoolista. Você terá liberdade de tirar dúvidas se surgirem, bem como desistir de participar a qualquer momento.

A sua opinião será de grande valor para nosso estudo, pois terei a oportunidade de verificar quais as atitudes e os conhecimentos dos enfermeiros em relação ao álcool, ao alcoolismo e ao alcoolista, o que possibilitara pensar na assistência a esses indivíduos.

Como responsável por este estudo, tenho o compromisso de manter em segredo todos os dados confidenciais.

Qualquer questão, dúvida, esclarecimento ou reclamação sobre os aspectos éticos desta pesquisa, favor entrar em contato com: Comitê de Ética em Pesquisas do Hospital Universitário da USP em São Paulo-SP, Av. Dr. Lineu Pestes, 2565 - CEP: 05508-000 - Cidade Universitária - São Paulo/SP - Telefone: 3091-9457 - Fax: 3091-9452 - e-mail: cep@hu.usp.br.

Você está recebendo duas vias desse termo, assim, se estiver clara para você a finalidade desse estudo e concorda em participar, por favor, assine abaixo, devolvendo essa via juntamente com os questionários respondidos e permaneça com a segunda via. Lembrando que você terá liberdade de retirar o consentimento a qualquer momento e, portanto, deixar de participar do estudo.

Declaro que, após convenientemente esclarecido pelo pesquisador e ter entendido 0 que me foi explicado, consinto em participar do presente Projeto de Pesquisa.

Desde já meus sinceros agradecimentos por sua colaboração.

Divane de Vargas COREn/SP 80884

Fone: (11) 3061-7615
Janaina Soares COREn/SP 004926

Fone: (11) 6677-8129

Nome:

Data de Nascimento:

Sexo: ( )F

( )M

ASS:

RG:

São Paulo de de 20 